\title{
Increased police patrols for preventing alcohol-impaired driving (Review)
}

\author{
Goss CW, Van Bramer LD, Gliner JA, Porter TR, Roberts IG, DiGuiseppi C
}

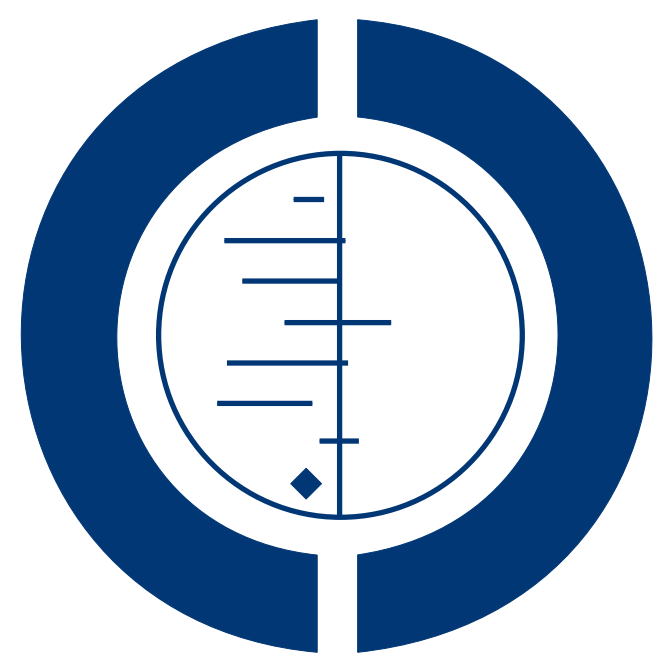

\section{THE COCHRANE COLLABORATION $^{\circledR}$}

This is a reprint of a Cochrane review, prepared and maintained by The Cochrane Collaboration and published in The Cochrane Library 2008, Issue 4

http://www.thecochranelibrary.com

\section{WILEY}


TABLE OF CONTENTS

HEADER . . . . . . . . . . . . . . . . . . . . . . . . . . . . . . 1

ABSTRACT . . . . . . . . . . . . . . . . . . . . . . . . . . . . . . . . . . . . . . . 1

PLAIN LANGUAGE SUMMARY . . . . . . . . . . . . . . . . . . . . . . . . . . . . . . . . . . . 2

BACKGROUND . . . . . . . . . . . . . . . . . . . . . . . . . . . . . . . . . . . . . .

OBJECTIVES . . . . . . . . . . . . . . . . . . . . . . . . . . . . . . . . . . . . . .

METHODS . . . . . . . . . . . . . . . . . . . . . . . . . . . . . . . . . . . . . .

RESULTS . . . . . . . . . . . . . . . . . . . . . . . . . . . . . . . . . . . . . . . 7

Figure 1. . . . . . . . . . . . . . . . . . . . . . . . . . . . . 10

Figure 2. . . . . . . . . . . . . . . . . . . . . . . . . . . . . . . . . . . . . .

Figure 3. . . . . . . . . . . . . . . . . . . . . . . . . . . . . . . . . . . . . . 12

Figure 4. . . . . . . . . . . . . . . . . . . . . . . . . . . . . . . . . . . . . . 12

Figure 5. . . . . . . . . . . . . . . . . . . . . . . . . . . . . . . . . . . 13

Figure 6. . . . . . . . . . . . . . . . . . . . . . . . . . . . . . . . . . . . . . 14

Figure $7 . \quad$. . . . . . . . . . . . . . . . . . . . . . . . . . . . . . . . . . . . 15

Figure 8. . . . . . . . . . . . . . . . . . . . . . . . . . . . . . . . . . . 16

Figure 9. . . . . . . . . . . . . . . . . . . . . . . . . . . . . . . . . . 18

Figure 10. . . . . . . . . . . . . . . . . . . . . . . . . . . . . . . . . . . . . . . . .

DISCUSSION . . . . . . . . . . . . . . . . . . . . . . . . . . . . . . . . . . . . . .

AUTHORS' CONCLUSIONS . . . . . . . . . . . . . . . . . . . . . . . . . . . . . . . . . . . . . . .

ACKNOWLEDGEMENTS . . . . . . . . . . . . . . . . . . . . . . . . . . . . . . . . . . . . . . . .

REFERENCES . . . . . . . . . . . . . . . . . . . . . . . . . . . . . . . . . . . . . . . . 25

CHARACTERISTICS OF STUDIES . . . . . . . . . . . . . . . . . . . . . . . . . . . . . . . . . . . . . 33

DATA AND ANALYSES . . . . . . . . . . . . . . . . . . . . . . . . . . . . . . . . . . . 61

ADDITIONAL TABLES . . . . . . . . . . . . . . . . . . . . . . . . . . . . . . . . . . . . . . . . . .

APPENDICES . . . . . . . . . . . . . . . . . . . . . . . . . . . . . . . . . . . . . . 78

WHAT'S NEW . . . . . . . . . . . . . . . . . . . . . . . . . . . . . . . . . . . . . . . . . . . . .

HISTORY . . . . . . . . . . . . . . . . . . . . . . . . . . . . . . . . . . . . . . . . . . . . . . . . 8

CONTRIBUTIONS OF AUTHORS . . . . . . . . . . . . . . . . . . . . . . . . . . . . . . . . . . . . . . 87

DECLARATIONS OF INTEREST . . . . . . . . . . . . . . . . . . . . . . . . . . . . . . . . . . . . . . . . . . . .

SOURCES OF SUPPORT . . . . . . . . . . . . . . . . . . . . . . . . . . . . . . . . . . 88

NOTES . . . . . . . . . . . . . . . . . . . . . . . . . . . . . . . . . . . . . . . . 88

INDEX TERMS . . . . . . . . . . . . . . . . . . . . . . . . . . . . . . . . . . . .

Increased police patrols for preventing alcohol-impaired driving (Review)

Copyright $\odot 2008$ The Cochrane Collaboration. Published by John Wiley \& Sons, Ltd. 


\title{
[Intervention Review] \\ Increased police patrols for preventing alcohol-impaired driving
}

\author{
Cynthia W Goss ${ }^{1}$, Lisa D Van Bramer ${ }^{2}$, Jeffrey A Gliner ${ }^{3}$, Todd R Porter ${ }^{4}$, Ian G Roberts ${ }^{5}$, Carolyn DiGuiseppi ${ }^{1}$ \\ ${ }^{1}$ Colorado Injury Control Research Center, Colorado School of Public Health, University of Colorado Denver, Denver, CO, USA. \\ ${ }^{2}$ Rocky Mountain Research \& Prevention Institute, Aurora, Colorado, USA. ${ }^{3}$ Colorado Injury Control Research Center, Colorado \\ School of Public Health, Colorado State University, Fort Collins, Colorado, USA. ${ }^{4}$ Department of Pediatrics, School of Medicine, \\ University of Colorado Denver, Denver, Colorado, USA. ${ }^{5}$ Cochrane Injuries Group, London School of Hygiene \& Tropical Medicine, \\ London, UK
}

Contact address: Cynthia W Goss, Colorado Injury Control Research Center, Colorado School of Public Health, University of Colorado Denver, 4200 E 9th Avenue, Box C245, Denver, CO, 80262, USA. cynthia.goss@uchsc.edu.

Editorial group: Cochrane Injuries Group.

Publication status and date: New, published in Issue 4, 2008.

Review content assessed as up-to-date: 31 May 2006.

Citation: Goss CW, Van Bramer LD, Gliner JA, Porter TR, Roberts IG, DiGuiseppi C. Increased police patrols for preventing alcohol-impaired driving. Cochrane Database of Systematic Reviews 2008, Issue 4. Art. No.: CD005242. DOI: 10.1002/14651858.CD005242.pub2.

Copyright (C) 2008 The Cochrane Collaboration. Published by John Wiley \& Sons, Ltd.

\begin{abstract}
A B S T R A C T
Background

Road traffic injuries cause 1.2 million deaths worldwide each year. Alcohol consumption increases the risk of traffic crashes, especially fatal crashes. Increased police patrols aim to increase both the perceived and actual likelihood of being caught driving while alcoholimpaired, potentially reducing alcohol-related driving, crashes and injuries.
\end{abstract}

\section{Objectives}

To assess the effects on injuries and crashes of increased police patrols that target alcohol-impaired driving.

\section{Search methods}

We searched the Cochrane Injuries Group Specialised Register (5/2006), CENTRAL (The Cochrane Library 2006, Issue 2), MEDLINE (1966 to 5/2006), TRANSPORT (1968 to 5/2006), C2-SPECTR (2/2005), NCJRS (1/1951 to 5/2006), PsycINFO (1872 to 5/ 2006), Social Science Citation Index (1974 to 5/2006), SIGLE (1980 to 2/2006), Science Citation Index Expanded (1970 to 5/2006), Dissertation Abstracts (1870 to 5/2006), NTIS (1964 to 12/2004), conference proceedings, and reference lists. We contacted authors of eligible studies.

\section{Selection criteria}

Randomized controlled trials, controlled trials, controlled before and after studies, interrupted time series (ITS) studies, and controlled ITS studies evaluating increased police patrols, either alone or combined with other interventions, targeting alcohol-impaired motor vehicle drivers.

\section{Data collection and analysis}

Two investigators independently screened citations, extracted data, and assessed quality criteria. We compared intervention and nointervention geographical areas or time periods. We re-analyzed study data as required. Results are presented narratively. 


\section{Main results}

The 32 eligible studies included one randomized controlled trial, eight controlled before-after studies, 14 controlled ITS studies, six ITS studies, and three studies with both ITS and controlled before-after analyses. Most interventions targeted only alcohol-impaired driving (69\%) and included additional interventions such as media campaigns or special training for police officers (91\%). Only two studies reported sufficient information to assess study quality completely. Two-thirds of studies were scored 'not adequate' on at least one feature. Five of six studies evaluating traffic fatalities reported reductions with the intervention, but differences were statistically significant in only one study. Effects of intervention on traffic injuries were inconsistent in the six studies evaluating this outcome, and no results were statistically significant. All four controlled studies evaluating fatal crashes reported reductions with the intervention, which were statistically significant in one study. All 12 controlled studies assessing injury crashes reported greater reductions with the intervention, though effects were minimal or not significant in several studies. ITS studies showed less consistent effects on fatal crashes (three studies) and injury crashes (four studies), and effect estimates were typically imprecise. Thirteen of 20 studies showed reductions in total crashes and about two-thirds of these were statistically significant.

\section{Authors' conclusions}

Studies examining increased police patrol programs were generally consistent in reporting beneficial effects on traffic crashes and fatalities, but study quality and reporting were often poor. Methodological limitations included inadequate sample size, dissimilar baseline measures, contamination, and inadequate data analysis. Thus existing evidence, although supportive, does not firmly establish whether increased police patrols, implemented with or without other intervention elements, reduce the adverse consequences of alcoholimpaired driving.

\section{PLAIN LANGUAGESUMMARY}

\section{Increased police patrols for preventing alcohol-impaired driving}

More than one million people are killed worldwide each year in traffic crashes. Driving after drinking alcohol increases the chance of a traffic crash. To reduce alcohol-impaired driving, some police agencies have increased the number of police patrols or the time the police spend patrolling. The aim of these increased patrols is to raise the perceived and actual likelihood that impaired drivers will be identified and stopped. Identification is based on observable behavioral cues, which include moving violations, erratic driving, and crash involvement. In response to these cues, police officers stop the driver and administer tests for alcohol impairment. We found 32 studies that tested the effects of increased police patrols on traffic deaths, injuries, and crashes. There was one randomized controlled trial and no quasi-randomized controlled trials. Almost all of the programs included additional interventions like community information programs, media campaigns, and special training for police officers. Most studies found that increased police patrols reduced traffic crashes and fatalities. Evidence for the effect on traffic injuries was less consistent. The detail provided on the methodology of included studies was almost uniformly poor. When this information was reported, the methodological quality was often weak. Therefore, the available evidence does not firmly establish that increased police patrols reduce the adverse consequences of alcohol-impaired driving. Good quality controlled studies with adequate sample size are needed to evaluate increased patrols. Also needed are studies assessing the cost-effectiveness of this intervention.

\section{B A C K G R O U N D}

An estimated 1.2 million deaths due to road traffic crashes occurred worldwide in 2002 (Peden 2004). In high-income countries, motor vehicle-related injuries kill more children and young adults than any other single cause of death (Peden 2002). At the same time, the highest rates of road-traffic fatalities are reported in the low- and middle-income regions of the eastern Mediterranean and in Africa (Peden 2004).

According to the World Health Organization's World Report on Road Traffic Injury Prevention (Peden 2004), alcohol impairment increases the risk of both motor vehicle crash involvement and resulting death or serious injury. After adjusting for demographic 
covariates and potential sources of bias, Blomberg 2005 found a positive relationship between alcohol consumption and traffic crashes. An increase in traffic crash involvement was observed at blood alcohol concentrations (BAC) as low as $0.01 \mathrm{~g} / \mathrm{dl}$. At a BAC of $0.08 \mathrm{~g} / \mathrm{dl}$, the risk of any type of crash was 2.7 times greater than with a BAC of $0.00 \mathrm{~g} / \mathrm{dl}$.

Alcohol contributes to traffic-related injuries and deaths throughout the world. In 2005, 23\% of US drivers aged 15 to 20 years who were killed in crashes had a BAC level of $0.08 \mathrm{~g} / \mathrm{dl}$ or higher (NHTSA 2005). Of all drivers killed in Great Britain in 2004, $25 \%$ had a BAC level of $0.08 \mathrm{~g} / \mathrm{dl}$ or higher (TRL 2006). In African countries, an estimated $31 \%$ to $56 \%$ of non-fatally injured drivers were either alcohol-impaired or over the legal BAC limit, while in the southeast Asian region, $11 \%$ to $44 \%$ of patients hospitalized after traffic crashes had consumed alcohol (Davis 2003). In Bangalore, India (Gururaj 2004), 22\% of people who experienced brain injuries in a road traffic incident were under the influence of alcohol.

Alcohol-impaired driving is common, worldwide. In one US survey, $4.5 \%$ of adults reported having driven while impaired at least once in the preceding 12 months (Chou 2006). Over $4 \%$ of drivers participating in roadside BAC surveys in Croatia were found to be alcohol-impaired (Gledec 2004). In roadside BAC surveys in European Union countries (ETSC 1995), 1\% to 3\% of drivers reported driving while impaired. In Ghana (Mock 2001), more than $7 \%$ of drivers had BAC levels above $0.08 \mathrm{~g} / \mathrm{dl}$ in a random, roadside survey.

Both the perceived and actual likelihood of arrest for alcohol-impaired driving are low in most countries and various interventions designed to increase perceived or actual risk have been tested. Increasing the perceived risk of arrest appears to deter alcoholimpaired driving more effectively than increasing the severity of the penalty after arrest (Ross 1984; Homel 1988; Sweedler 1995). Enforcement measures, such as increased breath testing, sobriety checkpoints, and increased police patrols, can increase both perceived and actual arrest risk.

Both selective and random breath testing at sobriety checkpoints, where law enforcement officers systematically stop drivers to assess impairment objectively, reduce alcohol-impaired driving, alcoholrelated crashes, and associated injuries (Shults 2001). However, many US states are reluctant to conduct sobriety checkpoints because they are believed to be costly or ineffective, or because of legal or policy reasons (Fell 2004). In 2000, sobriety checkpoints were illegal in 12 states in the US. In several states that did allow checkpoints, prosecutors and elected officials objected to their use.

Increased police patrols are another intervention designed to increase the perceived and actual likelihood of being caught driving while alcohol-impaired. Increased (sometimes described as saturation, selective, or roving) patrols augment the number of officers or the time they spend on patrol to increase the likelihood that impaired drivers will be identified. Identification is based on observable behavioral cues, which include moving violations, erratic driving, and crash involvement (Voas 1990). In response to these cues, police officers stop the driver and administer tests for alcohol impairment. Because an increase in police patrols does not require the purchase of costly equipment, such as roadside breath-alcohol testing devices (Stuster 1995), it may be more readily implemented than sobriety checkpoints in low- and middle-income countries, although cost comparisons have not accounted for high costs of fuel and vehicle maintenance.

The effects of increased patrols may be enhanced by mass media campaigns, including public service announcements and paid media (for example, advertisements), as well as by 'earned' (unpaid) media coverage generated by the activities of an intervention (for example, news stories) or fostered by the campaign (for example, through letters to the editor, grass roots advocacy) ( www.nhtsa.dot.gov/people/outreach/SafeSobr/). Media-based intervention components seek to increase motorists' perception of the risk of being caught. Media efforts are also used to increase public acceptance of enforcement of laws against driving under the influence of alcohol (DUI) while decreasing public tolerance for alcohol-impaired driving (Elder 2004). In some cases, increased patrols are also combined with sobriety checkpoints or other interventions, such as community or school education programs, anti-DUI laws, and facilitation of DUI prosecution. Whether the addition of a media campaign is necessary for increased patrols to be effective has not been established, nor has the added value of these other components.

\section{Why it is important to do this review}

An earlier meta-analysis (Zobeck 1994; Wagenaar 1995) examined the effects of increased police patrols on alcohol-related injuries and crashes. Although on average such patrols were associated with reductions in crashes and casualties, the review authors noted that many studies had weak designs. A review that updates the literature on increased police patrols is needed. In addition, this review explored the contributions of media campaigns and other components when added to increased patrols.

\section{O B J E C T I V E S}

The objective of this review was to examine the effect of increased police patrols, implemented alone or combined with other strategies such as public education campaigns, on alcohol-impaired driving and its consequences.

\section{METHOD S}




\section{Criteria for considering studies for this review}

\section{Types of studies}

Randomized controlled trials, controlled trials, controlled beforeafter studies, and interrupted time series were included. The units of study were individual participants, groups, intervention sites, or geographical areas.

Political or economic grounds that are beyond the investigator's control are often the basis for the implementation of laws, policies, and community-based programs, and for the selection of geographic areas to receive these interventions. Therefore, we did not restrict types of studies to randomized and other controlled trials. Inclusion criteria for controlled before and after (before-after) studies and interrupted time series studies were adapted from the data collection checklist of the Cochrane Effective Practice and Organisation of Care Review Group (EPOC 2002).

The included study designs with their eligibility criteria are listed in Appendix 1.

\section{Types of participants}

The target population of interest was drivers of any type of motor vehicle on public roads.

\section{Types of interventions}

Studies were considered for inclusion if they evaluated increased police patrols that aimed to reduce alcohol-impaired driving or its consequences. Increased patrols were defined as an increase in the number of officers or in the frequency or duration of patrols with the purpose of identifying impaired drivers through behavioral cues (Voas 1990). Increased patrols with or without concurrent public information and education campaigns, sobriety checkpoint programs, or other intervention elements were included.

Interventions based solely on the identification of impaired drivers using chemical indicators, for example, random breath testing or sobriety checkpoints (with either mobile or stationary patrols), were excluded. These interventions have been reviewed elsewhere (Peek-Asa 1999; Shults 2001).

\section{Types of outcome measures}

Eligible studies measured at least one quantifiable outcome relevant to alcohol-impaired driving.

\section{Primary outcomes}

- Alcohol-related traffic crashes and resulting injuries and fatalities

\section{Secondary outcomes}

- Blood alcohol content (BAC) among drivers

- Self-reported impaired driving

- Alcohol test refusal with resultant on-the-spot license revocation rates

We extracted data on alcohol consumption, where reported. We also examined violations, for example, arrests for driving while intoxicated or under the influence. However, these are thought to be ambiguous outcome measures for special enforcement programs (Voas 1990) because an increase in arrests could indicate an increase in DUI enforcement activity, an increase in persons driving while alcohol-impaired, or both. Therefore, we excluded studies which examined only enforcement outcomes.

\section{Search methods for identification of studies}

We selected commonly occurring keywords and text words from known relevant papers and initial searches, as well as exploded $\mathrm{MeSH}$ terms related to alcohol, driving, and law enforcement that we retrieved from the MeSH database. The Elsevier Life Science (EMTREE), PsycINFO, and Alcohol and Other Drug (NIAAA 2000) thesauri were consulted for additional text terms. Other search terms were identified from related reviews, the Cochrane Injuries Review Group search strategies, and consultation with a research librarian. Because of the broad range of types of study designs to be included, we did not include methodological terms. The Trials Search Coordinator for the Cochrane Injuries Group reviewed the search strategy. Search terms encompassed terms related to driving, crashes, drinking, and enforcement (see Appendix 2).

\section{Electronic searches}

We searched 12 databases in four general categories.

Health

- Cochrane Injuries Group Specialised Register (5/2006)

- CENTRAL (The Cochrane Library 2006, Issue 2)

- MEDLINE (1966 to May week 4 2006)

\section{Transportation}

- International Transport Research Documentation in TRANSPORT (1968 to 5/2006)

- Transportation Research Information Services in TRANSPORT (1968 to 5/2006)

\section{Social Sciences}

- C2-SPECTR (Campbell Collaboration Social, Psychological, Educational and Criminological Trials Register, version Feb-17-2005) (searched May 2006)

- NCJRS (National Criminal Justice Reference System) (1/ 1951 to $5 / 2006)$

- PsycINFO (1872 to May week 4 2006) 
- Social Science Citation Index (1974 to 5/2006)

\author{
General \\ - SIGLE (System for Information on Grey Literature in \\ Europe (1980 to 2/2006) \\ - Science Citation Index Expanded (1970 to 5/2006) \\ - Dissertation Abstracts (1870 to 5/2006) \\ - National Technical Information Service (NTIS) \\ Bibliographic Database (1964 to 12/2004)
}

The search strategy was modified to meet the requirements of each database. There were no language or date restrictions.

Eligible studies identified prior to 1 June 2006 were included in this review. Studies identified subsequently are listed under 'Studies awaiting assessment'. The most up-to-date search strategies can be found in Appendix 2. NTIS was searched to 12/2004.

\section{Searching other resources}

We handsearched the proceedings of the 6th to 10th and 12th to 16th International Conferences on Alcohol Drugs and Traffic Safety (we were unable to obtain proceedings from the 11th Conference). Reference lists of eligible studies and relevant systematic reviews (Zobeck 1994; Peek-Asa 1999; Shults 2001; Elder 2004) were examined. Investigators of eligible studies were asked to identify any additional relevant published and unpublished reports.

\section{Data collection and analysis}

\section{Selection of studies}

Eligible studies reported at least one quantifiable outcome relevant to alcohol-impaired driving. We extracted data on alcohol consumption, where reported. We also examined violations, for example, arrests for driving while intoxicated or under the influence. However, these are thought to be ambiguous outcome measures for special enforcement programs (Voas 1990) because an increase in arrests could indicate an increase in DUI enforcement activity, an increase in persons driving while alcohol-impaired, or both. Therefore, we excluded studies which examined only enforcement outcomes.

Electronic search results were downloaded into ProCite and deduplicated. One trained screener excluded titles that were clearly irrelevant to both alcohol and driving. Two authors independently reviewed titles and abstracts of all remaining citations to identify potentially relevant studies, using the specified selection criteria. Citations judged by both authors as ineligible were excluded. Citations identified by at least one author as definitely or possibly eligible were obtained in full text. Full texts were screened independently for eligibility by two authors. Differences were resolved through discussion; a third author was consulted when necessary. When eligibility could not be determined from available text, we attempted to request further details from the study investigators. If otherwise eligible studies did not report relevant outcome measures, we asked the investigators to provide any unpublished data on such outcomes. Studies were excluded (see Characteristics of excluded studies) if relevant outcome data were not collected or could not be provided.

\section{Data extraction and management}

Two authors independently extracted data. Authors were not blinded to study investigators' names as the benefit of such masking is unclear (Berlin 1997). Data were extracted on study design, participants, and quality measures. In cases of discrepancy, key information was confirmed by discussion. Persistent discrepancies were referred to a third author.

The intervention information extracted included type of special patrols (for example, drunk driving only, speeding and drunk driving, general traffic); method of increasing patrols (for example, overtime, new hires); frequency of patrolling (for example, weekly, holidays only); and presence of adjunct interventions such as sobriety checkpoints, special equipment (for example, passive alcohol sensors, video cameras), or mass media campaigns (for example, public service announcements, paid advertising, news stories).

We extracted outcome measurements for fatal, injury (all or nonfatal only), and total crashes (for which the crash was the unit of measurement); fatal and total injuries (for which the individual was the unit of measurement); drunk driving; and alcohol consumption. Enforcement of alcohol-impaired driving (for example, arrests, citations) was extracted as a measure of police activity. Only those outcomes that met minimum design criteria (see 'Types of studies' above) were extracted. For each selected outcome measure, data on blinding, reliability, and for ITS designs appropriate statistical analysis, were extracted.

In most studies crash data were collected from traffic crash reports routinely completed at the scene by police officers. As a result, the definition of alcohol-involved crashes varied substantially between studies. Alcohol involvement may have been assessed through BAC, by the police officer at the crash scene, or not at all. In the latter cases one or more proxy measures for alcohol-involved crashes were typically collected and reported. We reported direct measures of 'alcohol-involved crashes' (whether from BAC or police report) when these were provided and a proxy measure when direct measures were not provided. Where more than one proxy measure for alcohol-related crashes was collected we selected one measure for this review using a predefined hierarchy. This hierarchy was based on the likelihood that the specified type of crash was alcohol-related (NHTSA 2005). Specifically, within each crash type (that is, total, injury, fatal) outcome measures were chosen in the following order:

1. Alcohol-involved crashes

2. Single vehicle, night-time crashes

3. All night-time crashes 
4. All single vehicle crashes

5. All crashes

Measuring alcohol involvement through police reports has the potential to be biased due to police officers' knowledge of the intervention, as was suggested by some investigators (for example, Wolfe 1984; Lacey 1986; Lacey 1988). Therefore, we compared within-study results for police-reported alcohol-related crashes and selected proxy measures in order to identify any systematic bias in magnitude or direction of effect, or statistical significance of results. We identified all eight studies that collected both police-reported alcohol involvement and either of two proxy measures highly associated with alcohol-involvement -- single vehicle night-time crashes, if available, otherwise all night-time crashes -for the same outcome type (Brackett 1983; Mallory 1984; Lacey 1986; Lacey 1987; Lacey 1988; Jones 1995a; Jones 1995b; Voas 1997). Results for the two measures are presented side-by-side in Additional Table 1. For seven of eight studies and 10 of 11 comparisons, the direction of effect and statistical significance (or lack of) were the same with comparable effect magnitude. These data do not suggest a systematic bias toward greater effects of intervention when results from police-reported alcohol-involved crashes are selected over other proxy measures.

For RCTs and CTs, we extracted post-test rates or proportions for intervention and comparison areas. For controlled before-after studies, we extracted pre-test and post-test rates or proportions for intervention and comparison areas. For ITS designs and controlled ITS designs, we extracted results of autoregressive integrated moving average (ARIMA) analyses or time series regressions with adjustments or tests for serial correlation, when available. When these analyses were not performed, we extracted individual data points if they were provided in a graph or a table. To obtain data points from graphs, figures were scanned to computer and digitized. Then CurveUnscan 1.4 software (www.curveunscan.com) was used to calibrate the axes and read $\mathrm{x}$ and $\mathrm{y}$ coordinates from each point on the figure. Similar approaches have previously been described (for example, Grilli 1993; Grilli 2002). When neither ARIMA analyses nor data points were provided, we provided the investigator-reported results.

\section{Assessment of risk of bias in included studies}

The methodological quality of the included studies was assessed by the reporting of design and conduct features that are likely to prevent systematic errors or bias. To assess study quality of RCTs, CTs, and CBAs we used the guidelines provided by the Cochrane Effective Practice and Organisation of Care (EPOC) checklist (EPOC 2002). We applied the quality criteria used by Aaserud 2006 to ITS studies. A few of these quality criteria were revised to be appropriate to the intervention and population for this particular review. The detailed quality criteria are listed in Appendix 3. The quality assessment for each study is described in the method section of Characteristics of included studies. For all assessments, we assigned 'not clear' when sufficient information to make an adequate determination could not be obtained from the full text or from the investigators, and 'not adequate' if it was clear that the study did not satisfy the conditions for scoring 'adequate' (see below). When a study included more than one comparison group, quality criteria were applied to the group most similar to the intervention group, unless both comparison groups were equally similar to the intervention group in which case both groups were included in the quality assessment. When multiple outcome measures were extracted, each outcome measure underwent quality assessment for blinding, reliability, and for ITS designs appropriate statistical analysis.

\section{Data synthesis}

The primary comparison was between intervention and no-intervention (control) geographical areas or time periods. For all included studies we stated the results for each relevant outcome. We also compared intervention programs with and without adjuncts. Statistical significance was reported, when possible.

For RCTs and CTs, we calculated relative risk and $95 \%$ confidence intervals (CI) between groups.

For CBAs, we calculated rate ratios, that is, the ratio of post-test to pre-test event rates in the intervention group (for example, area) divided by the corresponding ratio in the comparison group. The rate ratio can be used to determine the percent change in the intervention group relative to the comparison group. For example, a rate ratio of 0.75 can be interpreted as a $25 \%$ reduction from the pre-test phase to the post-test phase in the intervention group relative to the comparison group; $95 \% \mathrm{CIs}$ were calculated when possible. When rate ratios could not be calculated from the reported data, we provided the results as reported by the study investigator.

For ITS and CITS studies that reported ARIMA or time series regression analyses with adjustments or tests for serial correlation, we reported the mean change from pre-test to post-test, corresponding standard error, the $\mathrm{t}$-value from the test of the transfer function (for ARIMA analyses), the corresponding statistical significance, and the percentage change from pre-test to post-test, when provided. For all other ITS and CITS studies, and if adequate data were provided, we calculated and reported the pre-test and post-test means and standard deviations. To test intervention effects we employed a time series regression analysis with maximum likelihood estimation, adjusting for first-order autocorrelation as described by Ramsay 2003 and Aaserud 2006 (SPSS 13.0). Model parameters included pre-test slope, post-test slope, change in level, an intercept, and an error term, which were used to predict the outcome at any given time point. Parameter estimates from this model were used to determine the change in slope, which is defined as the difference between the pre-test and post-test slopes; and the change in level, which is defined as the difference between the first post-test time point estimated from the post-intervention 
regression line and the same post-test time point extrapolated from the pre-intervention regression line (Grilli 2002). The change in level reflects the immediate change at the start of the intervention, while the change in slope reflects the overall changes. Change in slope, change in level, corresponding standard error, and statistical significance were reported. An alpha level of 0.05 was selected. Time series that were missing data for large numbers of time points (for example, a series of weekly data points separated by several months with no data) could not be analyzed. When neither a data table nor graph was provided, or data could not be analyzed, we showed results as reported by the study investigator.

Because fewer than half of the study analyses provided sufficient data to allow for meta-analysis, we felt that combining data quantitatively could be misleading. Therefore, the results are summarized narratively. In addition, to aid interpretation we created figures showing the results for each outcome. For total, fatal and injury crashes, and fatal and total injuries, we plotted the point estimates and error measurements, when available, in the figures. For CBA designs, the rate ratios and $95 \%$ CIs were plotted. For ITS designs, the change in slope (or mean change when available) and 95\% CIs were plotted. For CITS designs, we plotted the difference in mean change between the intervention and comparison groups, when available; CIs for this difference could not be calculated. In order to display figures with different units on one graph, estimates of change in slope or mean change and standard error were standardized to the change in outcome per year. We reported the change in slope versus change in level, because it detects gradual change, including changes that occur as an intervention is disseminated over time; and because it is more similar to investigatorcalculated ARIMA results. Although statistical significance can be inferred from CIs, when available, we have also noted each statistically significant effect with an asterisk. To differentiate between effects that were not statistically significant and those that were not tested for statistical significance, the latter are noted with a dagger. Results that could not be depicted are reported in the text and figures. Where no data were provided, results are listed in the figures as 'reduced crashes,' 'increased crashes,' or 'no effect.'

Throughout this review we have used 'reduction' or 'beneficial' whenever the reported result was less than 0.00 (for change) or $<1.0$ (for rate ratio, relative risk (RR), or odds ratio (OR)). We have used 'harmful' whenever the reported result was greater than 0.00 (for change) or $>1.0$ (for rate ratio, RR, or OR). When a 'harmful' or 'beneficial' effect was minimal (for example, $\mathrm{RR}=$ 1.01) we indicated this in the text.

\section{RES U L T S}

\section{Description of studies}

See: Characteristics of included studies; Characteristics of excluded studies.

\section{Included studies}

Thirty-two eligible studies were identified (Characteristics of included studies). Investigators of 27 studies were traced. Additional data or methodological information were provided by investigators for 11 studies (Aden 1981; Hurst 1981; Sali 1983; Amick 1984; Voas 1987; Hingson 1996; Voas 1997 ;Fuller 2001; Harrison 2001; Stuster 2001; Voas 2002). One investigator provided an additional study (NMDOH 2000).

One project was published as three separate studies, each of which reported a unique pair of sites (Lacey 1986; Lacey 1987; Lacey 1988). These were included as separate studies. Another project was published as three separate studies (Jones 1995a; Jones 1995b; Jones 1995 under Jones 1995a) and used a single site as the control for two of the intervention sites (Jones 1995a). We grouped the results of both of those comparisons together. Hence, this project was included as two rather than three studies.

A program established by the US Department of Transportation in the early 1970s, the Alcohol Safety Action Projects (ASAP), was tested in 35 communities across the US, each was reported separately as well as together (USDOT 1979 under Zador 1976). This program was conceptualized as a community-based intervention program involving four specified countermeasures that were implemented and evaluated at multiple sites using the same outcomes. The ASAP program was not applied identically in the different communities and differences in other factors (for example, population, geography) may have influenced results. It is, nevertheless, appropriate to evaluate the program as a whole, given the apparent intention to do so in the initial program development and evaluation (USDOT 1972 under Zador 1976). The ASAPs have been reviewed and meta-analyzed previously (Zador 1976). This meta-analysis is included in the Tables and the descriptions of studies below as a single, controlled before-after study.

Of the 32 studies included, most $(91 \%)$ were conducted in the United States. Australia, Ireland, and New Zealand also served as study sites. The most common study design was a controlled ITS (44\%). There were eight controlled before-after studies, six ITS studies, and three studies that included both controlled beforeafter and ITS analyses. There was one randomized controlled trial and no quasi-randomized controlled trials.

The majority (69\%) of interventions were targeted specifically and solely to reduction of DUI. Four interventions targeted DUI and other traffic violations (speeding, failure to wear a seat belt, or both) and two targeted all traffic or moving violations, including DUI. One program had different targets (that is, DUI, speeding, all moving violations, or high accident areas) at different intervention sites; one intervention targeted both DUI and underage drinking; one targeted high accident areas; and one did not specify the primary target. 
The method by which patrols were increased varied. The most commonly used were: reassigning regular officers to DUI enforcement (25\%), having regular officers work extra hours (overtime) $(19 \%)$, or a combination of these two methods (13\%). A few programs hired new officers $(6 \%)$, 'borrowed' officers from nearby communities $(3 \%)$, or combined new hires and reassignment $(6 \%)$. In three studies (9\%) involving multiple intervention sites (Zador 1976; Campbell 1981; Voas 1997), different methods or combinations of methods, including overtime, reassignment, and in some programs new hires, were used at different sites. Six studies (19\%) did not specify how patrols were increased.

Three studies indicated that increased patrols occurred regularly but did not specify the timing, and five failed to specify the frequency of patrols. Among the 24 remaining studies, extra patrols occurred daily in seven studies $(29 \%)$, four to six days per week in four $(17 \%)$, every weekend in six $(25 \%)$, and less frequently (for example, weekly, on holidays, or sporadically) in seven studies (29\%).

The duration and timing of the interventions varied substantially, from 1 to 60 months, with a median duration of 15 months. Thirteen interventions lasted two or more years. For two studies with multiple intervention groups, intervention periods ranged from 12 to 48 months (Campbell 1981) and from 24 to 60 months (Zador 1976), respectively.

Three studies (9\%) evaluated increased patrols alone, 28 (88\%) included other additional interventions, and one $(3 \%)$ evaluated increased patrols both alone and in combination with other interventions by including comparison groups with and without other interventions. Of 29 studies that evaluated additional interventions, $86 \%$ included more than one additional intervention. Almost all (90\%) incorporated public awareness or education components, including community or school-based public information and awareness programs, media campaigns, media coverage, or public advocacy and grassroots campaigns. Other commonly added interventions included special DUI training and equipment for officers $(55 \%)$, sobriety checkpoints or random breath testing $(31 \%)$, and coordination of sentencing or parole processes $(21 \%)$. Only one study (Stuster 1995) compared increased patrols to an alternative intervention that was not also present in the intervention area. All other comparisons were included in the primary analysis.

Most studies (84\%) measured and reported multiple, relevant outcomes. More than half $(56 \%)$ reported at least one outcome directly related to motor vehicle crashes resulting from alcohol-impaired driving. These included alcohol-related total crashes (78\%), fatal crashes $(22 \%)$, and injury crashes $(22 \%)$. The remaining studies used various proxy measures including: injuries or fatalities occurring either in any traffic crashes or in night-time traffic crashes; or injury, fatal or total crashes (single vehicle, night time, weekend, or all types combined). Nine studies (28\%) measured alcohol-impaired driving.

Nearly half of the studies (47\%) reported outcomes documenting police enforcement of drinking and driving laws. These measures included DUI warnings, citations or arrests, blood alcohol levels of arrested drivers, and total warnings or citations.

Some studies also measured outcomes not directly related to alcohol-impaired driving, such as other types of crashes (for example, property damage only, daytime crashes); injuries (for example, pedestrian fatalities); or traffic citations (for example, for speeding). These outcomes were not reported on.

\section{Risk of bias in included studies}

The detail provided on the methodology of included studies was almost uniformly poor and, when adequately reported, the methodology was often judged to be of poor quality. Of 32 identified studies only two reported sufficient information on all design and conduct features to enable a complete assessment of study quality; and just one (3\%) of those (Marchetti 1995) was adequate on all features assessed. Twenty-one studies (69\%) were rated as 'not adequate' on at least one key design or conduct feature. The rest (28\%) did not report sufficient information to assess study quality fully, although reported items were deemed adequate.

\section{Study design and analysis}

RCTs: The one RCT, which allocated groups by coin toss, showed data for baseline measures from which relative risks for the selected outcomes could be calculated. There were no significant differences between study groups in baseline measures for outcomes or other characteristics. This trial had less than $80 \%$ follow up, however.

CBAs: Among 11 studies that included controlled before-after analyses, eight provided enough information to assess at least one quality criterion. Of these, three reported that baseline measures were similar, four that other baseline characteristics were similar, and one that contamination between intervention and control groups was unlikely.

ITS: All nine studies that included uncontrolled ITS analyses provided sufficient information to assess at least two quality criteria, although none could be completely assessed. All studies pre-specified the shape of the intervention effect. Four provided sufficient numbers of pre-test and post-test data points, but two of these provided sufficient data points for only some outcome measures. All nine failed to provide information on whether the intervention was likely to affect data collection.

CITS: The 14 CITS studies tended to include more methodological details, with $13(93 \%)$ reporting on at least three design or conduct criteria. Eight reported sufficient information to assess baseline measures for outcomes, of which five demonstrated similar measures in intervention and control areas. All studies reported on other baseline characteristics, and 11 showed that they were similar between groups. Seven of eight studies evaluating possible effects 
of contamination indicated that it was unlikely. One study indicated that the intervention was not independent of other changes over time. Nine studies used sufficient numbers and intervals of pre-test and post-test data points in their analysis, while 12 studies met the criterion 'rational explanation for effect shape'. No studies noted that the intervention was unlikely to affect data collection, although one (Lacey 1986) performed a sensitivity analysis to examine an outcome measurement change that occurred near the start of the intervention.

\section{Outcomes assessment}

Data on selected primary outcomes were gathered mostly from police records and accident records systems. Two studies used government registries of motor vehicles (Campbell 1981; Hingson 1996). One study (Hurst 1981) specified its source of injury crashes as Ministry of Transport accident reports but did not report the data source for road fatalities. Data sources for five studies were not specified (Aden 1981; Pigman 1984; Maynard-Moody 1986; Lacey 1991; Stuster 2001). We assessed the reliability of all data sources as 'not clear'.

None of the studies commented specifically on blinding of primary outcome measurements. Fatal, injury and crash outcomes are typically collected routinely by traffic safety or public safety agencies (including police departments and state patrols). When a research study uses such data as outcome measures, there is a risk of bias when the agency collecting and reporting the data is aware of the intervention. However, we were not able to ascertain with certainty, for any study, that those individuals or agencies collecting the data definitely had knowledge of the intervention.
Therefore, all such outcomes were rated as 'not clear' in terms of blinding of outcomes assessment.

All CITS studies except Campbell 1981 employed ARIMA analyses, time series regressions, or other analyses that included adjustments or tests for serial correlation. Only one ITS study did so (Pigman 1984), but it did not describe adjusting or testing for serial correlation, hence it was scored as 'not clear'. Another ITS study (Hurst 1981) reported fatality data only in a graph but performed a time series analysis of injury crash data, without adjusting or testing for serial correlation. These outcomes were assessed separately and were scored as 'not adequate' and 'not clear', respectively. All other ITS studies provided sufficient data for reanalysis using time series regression and hence were scored as 'adequate'.

\section{Effects of interventions}

Results are presented in Additional Table 2 and are summarized narratively below.

\section{Fatalities in traffic crashes}

Figure 1 and Figure 2 show results for ITS and CBA designs, respectively. Six studies, including the Alcohol Safety Action Project (ASAP), reported effects of increased patrols on fatalities from traffic crashes (Zador 1976; Hurst 1981; St Louis Police 1981; Mallory 1984; Lacey 1991; Fuller 2001). In five of six studies, fatalities were reduced in the intervention group compared with pre-test or comparison groups; differences were statistically significant in one study. 
Figure I. Fatalities in traffic crashes (ITS)

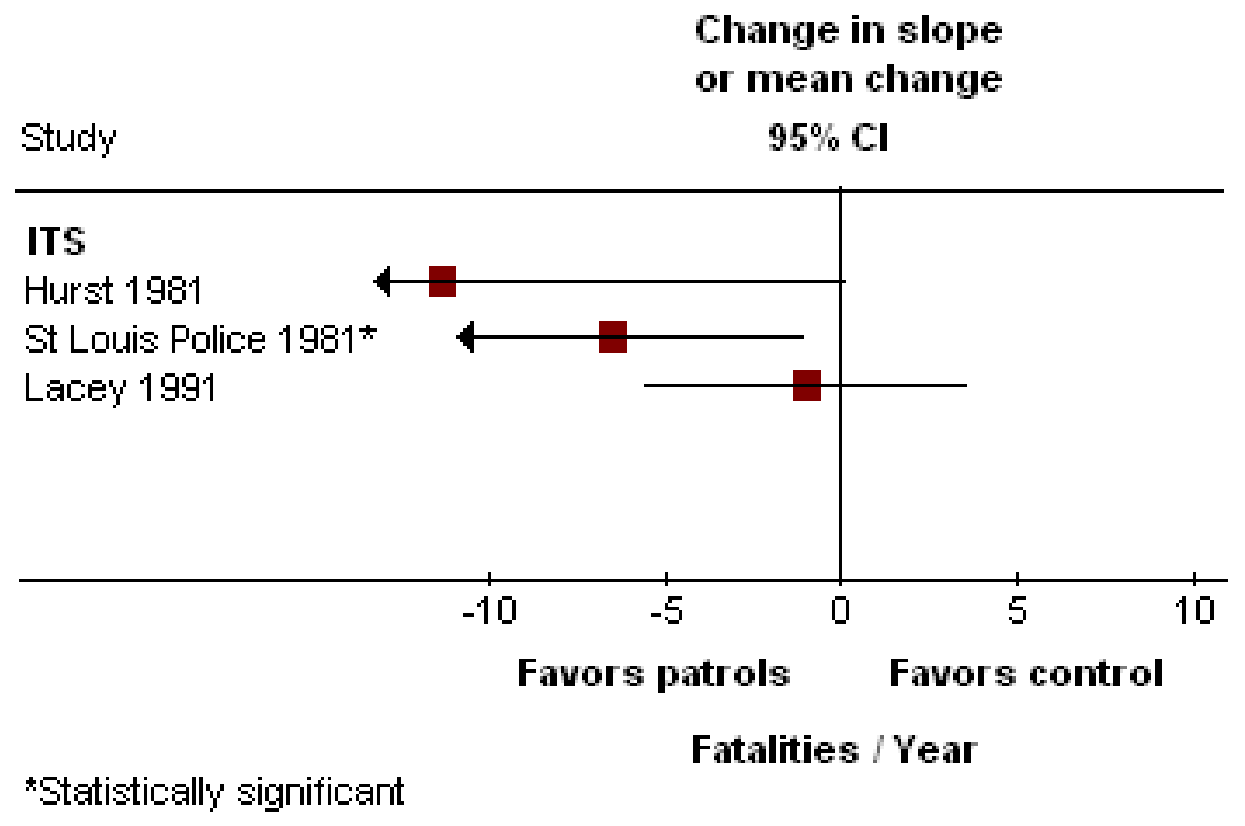

Figure 2. Fatalities in traffic crashes (CBAs)

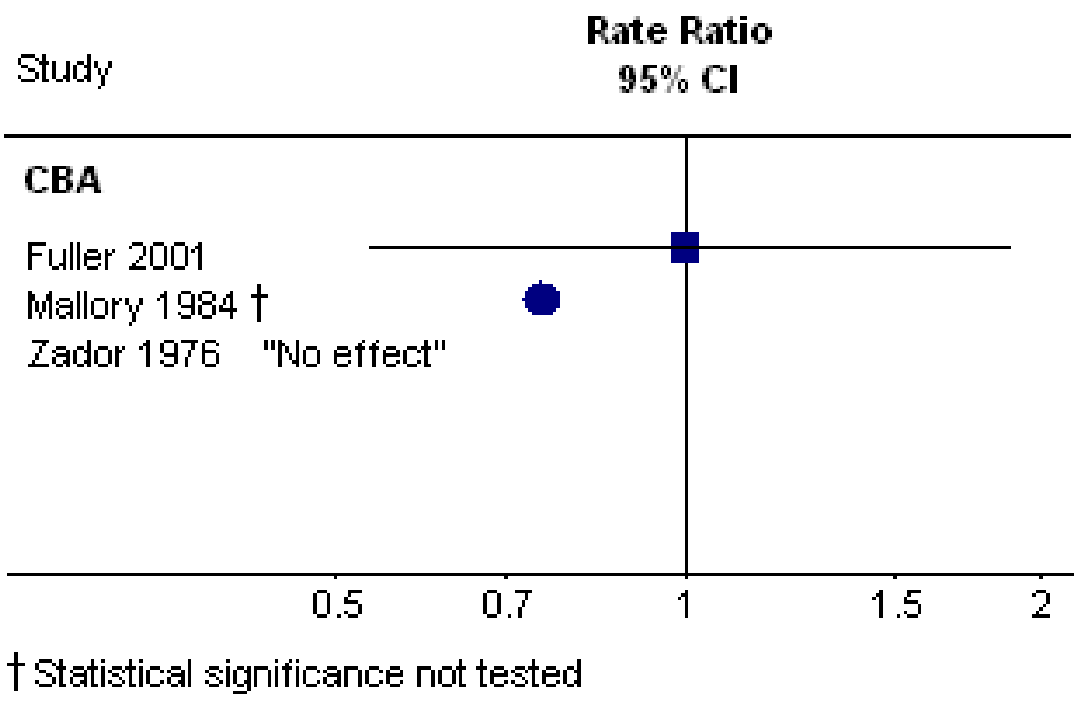


Mallory 1984 reported a reduction in the intervention relative to comparison areas (rate ratio $=0.78$ ); however, insufficient data were provided for calculation of CIs. All three ITS studies (Hurst 1981; St Louis Police 1981; Lacey 1991) showed small to moderate post-test decreases in both level (range: $<-1$ to -8 fatalities) and slope (range: -1 to -12 fatalities per year) that were statistically significant in one study (St Louis Police 1981); change in slope was of borderline significance in another (Hurst 1981). The CBA by Fuller 2001 showed a minimal relative reduction after intervention (rate ratio $0.99,95 \%$ CI 0.52 to 1.89 ).

The ASAPs were initially evaluated with a one-way ANOVA test and investigators reported a small but statistically significant reduction in the ratio of night-time to daytime fatal crashes (NHTSA 1975 under Zador 1976). The authors justified using a one-way ANOVA based on their finding that a test for autocorrelation of the time series was not statistically significant. However, the lack of a control group is problematic in this study because of the simultaneous occurrence of two events that led to reductions in both vehicle miles traveled and traffic crashes during the study period: a national oil and gasoline shortage that occurred between 1973 and 1974 , and a reduction in the national highway speed limit to 55 miles per hour in January 1974. Since the effects of these two events would have been universal throughout the United States, Zador 1976 addressed this problem by using comparison communities that were matched on population size, population growth, geographic location, and urbanization in his analysis. Using analysis of variance techniques, with the ratio of ASAP fatalities divided by ASAP plus comparison fatalities as the dependent variable, he found no statistically significant differences between ASAP and comparison areas in year-to-year fluctuations in fatalities. We reanalyzed his raw data using mixed (between and within) ANOVAs and found similar results.

Zador 1976 also analyzed day and night fatalities from both ASAP and comparison groups, concluding that a decrease in the proportion of night-time fatal crashes was equally present in both ASAP and comparison areas. The actual night-time data he used were not tabled in his article and thus could not be re-analyzed. Zador concluded that there was no evidence of program effectiveness. The report by Zador 1976 has been criticized for the use of total fatalities in major analyses: given that night-time fatal crashes were the focus of NHTSA's evaluation, the lack of power to detect a statistically significant difference, discrepancies in the data used between the 1974 DOT study and the Zador study, and the comparison areas chosen by Zador (Johnson 1976 under Zador 1976). These authors argued for the strength of the ITS design of the 1974 DOT report. Zador 1977 (under Zador 1976) responded that the use of comparison groups most often provides the stronger quasi-experimental design, especially if the comparison group is a good match as in his study. Levy 1978 (under Zador 1976) subsequently evaluated data from all 35 ASAPs. The authors compared daytime to night-time traffic fatalities within ASAPs, and compared night-time traffic fatalities between ASAPs and 11 comparison sites. Each site was analyzed individually against one of the 11 comparison sites using Box-Tiao time series analysis and controlling for effects of the national fuel shortage and speed limit reduction. Using a one-tailed t-test, the analysis showed that 12 of the 35 sites had a statistically significant decrease in night-time traffic fatalities compared to comparison sites. The other 23 sites presumably had no statistically significant change, or an increase, but results were not reported. The directional t-test did not allow for the identification of significant increases in traffic fatalities at any of these sites because, according to the authors, "only a reduction in crashes would logically be considered an indication of project impact". This analysis can also be criticized for using the same control group for multiple comparisons without adjusting for the family-wise error rate, thus increasing the probability of incorrectly rejecting the null hypothesis. Based on all the available reports it is clear that a beneficial effect of the ASAPs on traffic fatalities was not demonstrated.

\section{Injuries in traffic crashes}

Figure 3 displays results for ITS and CITS studies. Figure 4 shows results for CBA studies. Six studies reported effects of increased patrols on injuries from traffic crashes (Hurst 1981; St Louis Police 1981; Mallory 1984; Jones 1995a; Hingson 1996; Fuller 2001). One additional study collected these data but did not report them (Jones 1995b) and we were unable to obtain these results. Of these six studies, three reported minor injuries separately from serious and fatal injuries (Jones 1995a; Jones 1995b) or serious injuries (Fuller 2001). The other four studies examined total injuries. Of the six studies that provided results two reported reduced injuries, two reported mixed effects (both positive and negative), and two reported that there was no intervention effect but gave no numerical results; none of the differences were statistically significant. 
Figure 3. Injuries in traffic crashes (ITS and CITS)

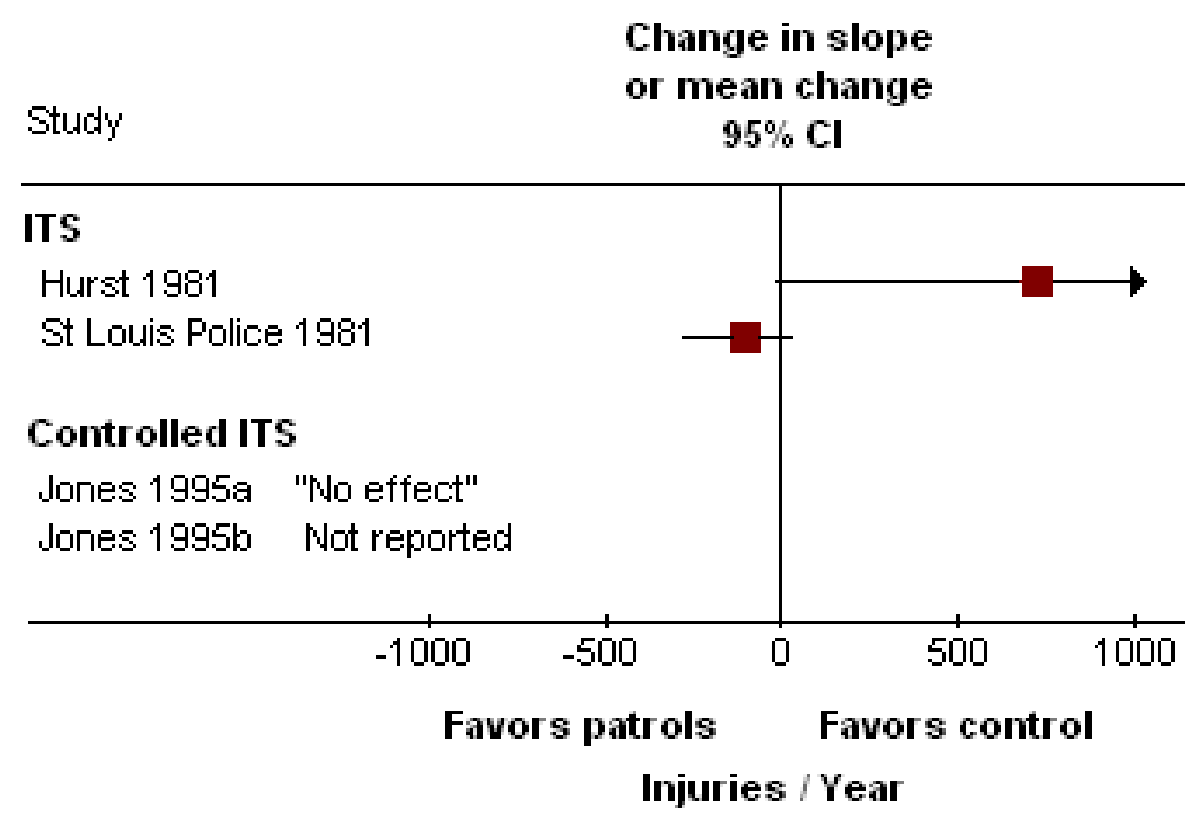

Figure 4. Injuries in traffic crashes (CBAs)

Study

\section{Rate Ratio}

$95 \% \mathrm{Cl}$

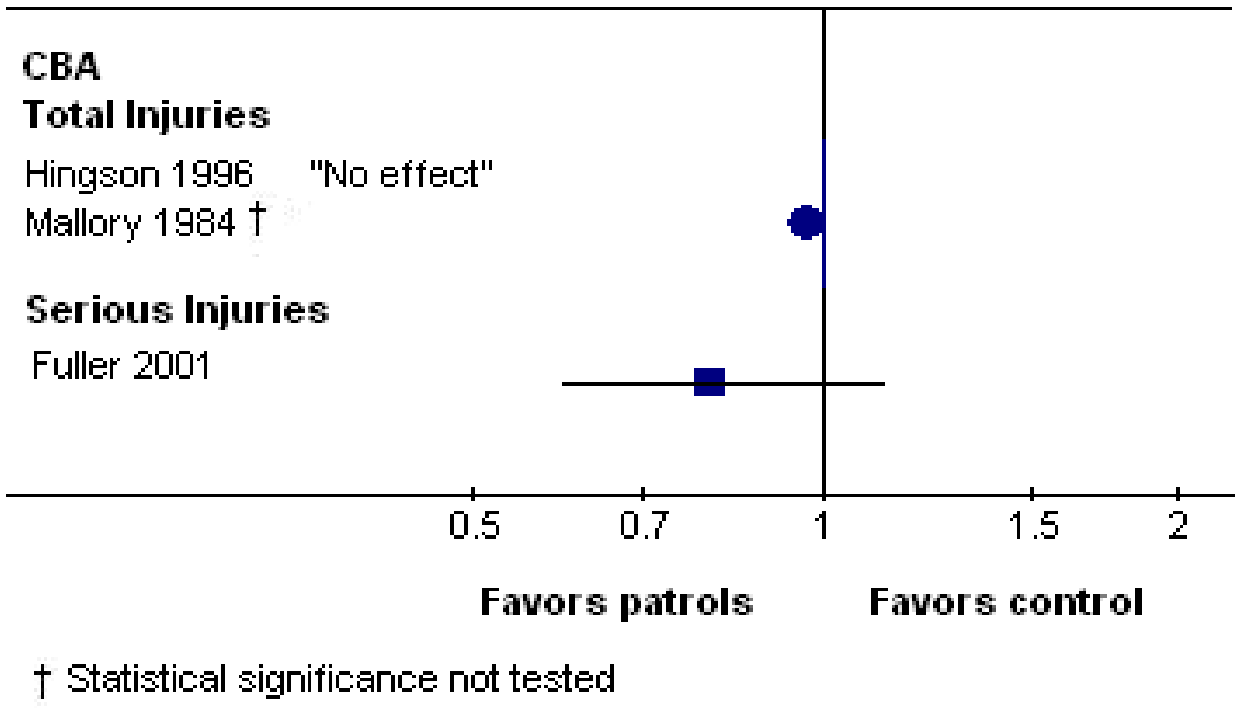


Fuller 2001 found a relative decrease in serious injuries (rate ratio 0.82; $95 \%$ CI 0.59 to 1.13 ) with increased patrols. There was also a reduction in minor injuries (rate ratio $0.91,95 \%$ CI 0.78 to 1.07$)$. Mallory 1984 reported a minimal relative decrease with the intervention (rate ratio $=0.98$ ) without statistical testing.

The ITS by the St Louis Police 1981 revealed an increase in level $(+9.8$ injuries, $\mathrm{P}=0.83)$ and a decrease in slope $(-10.1$ injuries per month, $\mathrm{P}=0.06$ ), suggesting an unfavorable effect at the start of the intervention but a favorable effect overall during the posttest period. In another ITS, the findings were reversed, that is, a decrease in level $(-17.2$ hospitalizations, $\mathrm{P}=0.43)$ and an increase in slope $(+14.4$ hospitalizations per week, $\mathrm{P}=0.07$ ) (Hurst 1981); however, a steep decrease in hospitalizations during the pre-test period complicated interpretation of the increase observed during the post-test period.

Jones 1995a and Hingson 1996, using appropriate analytic methods, reported no significant intervention effects although data were not reported numerically.

\section{Fatal crashes}

Figure 5 displays results for ITS and CITS studies. Figure 6 shows results for CBA studies. Eight studies collected data on fatal crashes, which were reported in seven (Aden 1981; St Louis Police 1981; Brackett 1983; Mallory 1984; Wolfe 1984; Maynard-Moody 1986; Hingson 1996) but not in one ITS (Hurst 1981). Three reported alcohol-related fatal crashes (Brackett 1983; Wolfe 1984; Hingson 1996), one reported fatal single-vehicle night-time crashes (Maynard-Moody 1986), and three reported all types of fatal crashes (Aden 1981; St Louis Police 1981; Mallory 1984). Six of seven studies reporting results found reductions in fatal crashes; the reduction was statistically significant in one study. The remaining study reported mixed results.

Figure 5. Fatal crashes (ITS and CITS)

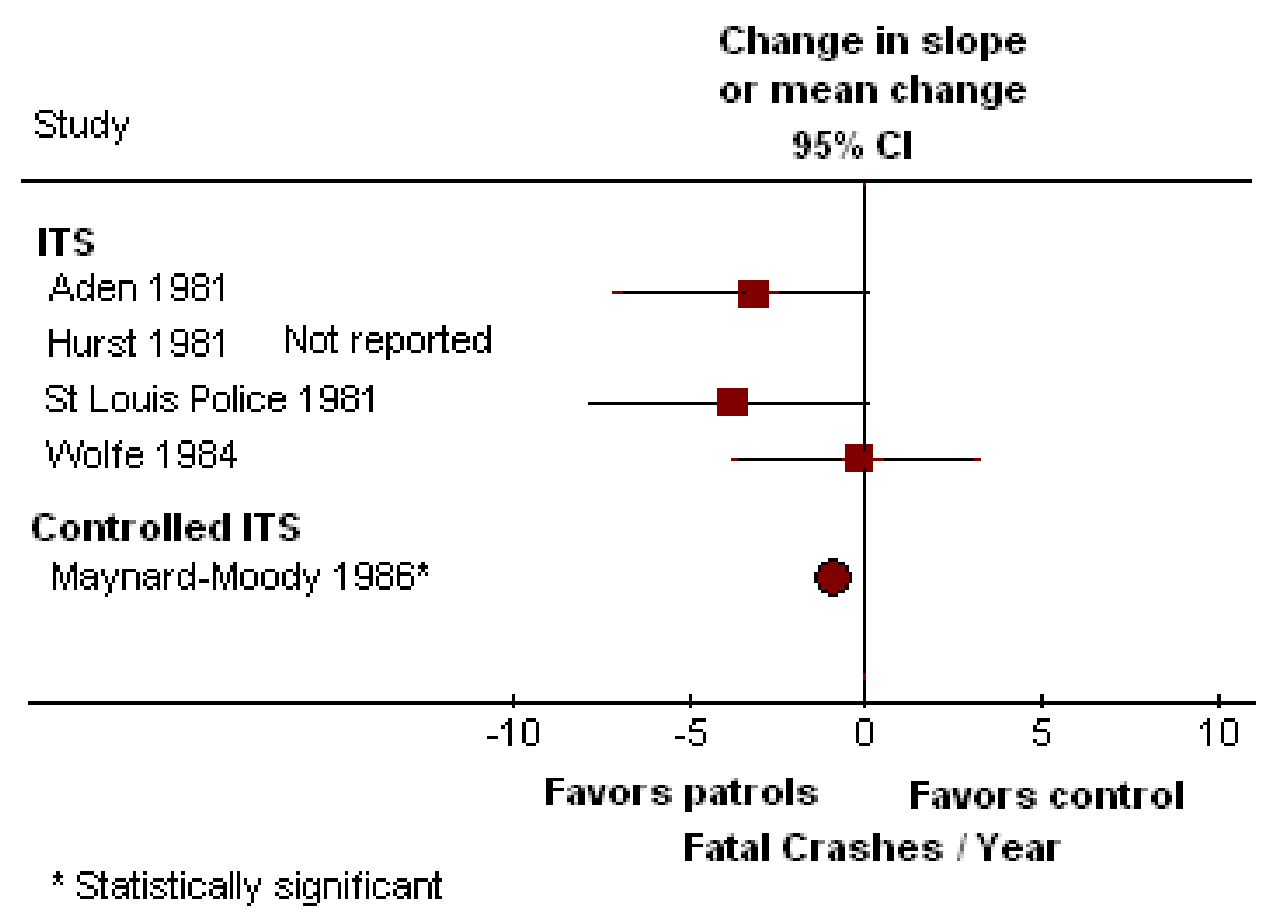

Increased police patrols for preventing alcohol-impaired driving (Review) 
Figure 6. Fatal crashes (CBAs)

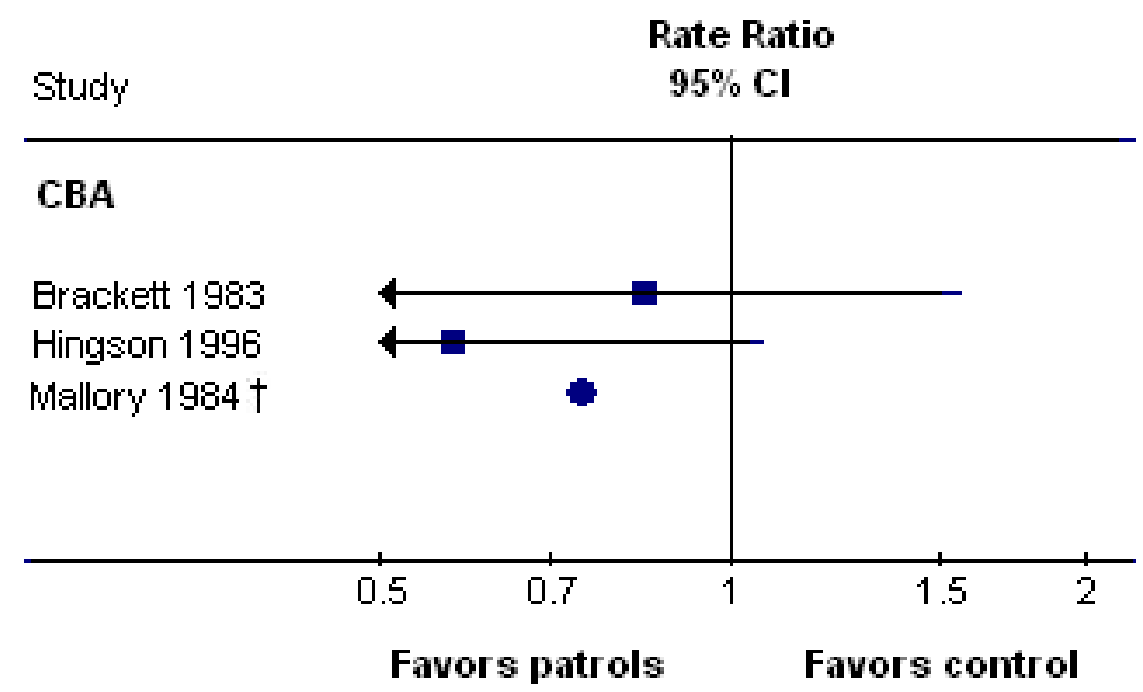

† Statistical significance not tested

Maynard-Moody 1986 reported a 37\% pre-post reduction in the intervention area $(-0.11$ crashes/month per 100,000 population, $\mathrm{P}<0.05)$, compared to an $8 \%$ reduction in the comparison area $(-0.04$ crashes/month per 100,000 population, $P \geq 0.05)$. In the CBA by Brackett 1983 there was a pre-post reduction in the intervention area relative to the comparison area (rate ratio $0.84,95 \%$ CI 0.45 to 1.57 ). Mallory 1984 found a relative reduction in fatal crashes with the intervention (rate ratio 0.77); statistical tests were not performed and data were not provided. Hingson 1996 also reported a pre-post reduction in the intervention areas relative to the comparison areas (RR $0.58,95 \%$ CI 0.32 to 1.08 ).

In the three ITS studies, relative changes in fatal crashes after intervention ranged from $-9.7 \%$ to $+5.2 \%$ (Aden 1981; St Louis Police 1981; Wolfe 1984). Time series regressions showed decreases in slope for all three studies, which approached statistical significance in the cases of Aden 1981 ( -0.88 crashes per quarter, $\mathrm{P}=0.06)$ and St Louis Police 1981 ( -0.32 crashes per month, $\mathrm{P}=0.07)$. Decreases in level were found in Wolfe 1984 and St Louis Police 1981 ( -1.3 and -2.4 fatal crashes, respectively), while an increase was found in Aden 1981 (+0.1 fatal crashes) although none of these changes were statistically significant.

One additional CITS examined the number of drivers with BAC $\geq 0.01$ who were in fatal crashes (Wiliszowski 2003), reporting a $25 \%$ pre-post reduction in the intervention area relative to the control area. An author-calculated ARIMA was statistically significant for the intervention area $(P=0.04)$, with no significant change for the comparison area $(\mathrm{P}=0.81)$.

\section{Injury crashes}

Figure 7 displays results for ITS and CITS studies. Figure 8 shows results for CBA studies. Sixteen studies reported the effects of increased patrols on injury crashes (Aden 1981; Hurst 1981; St Louis Police 1981; Brackett 1983; Sali 1983; Amick 1984; Mallory 1984; Wolfe 1984; McEwen 1985; Maynard-Moody 1986; Jones 1995a; Jones 1995b; Stuster 1995; Voas 1997; Stuster 2001; Voas 2002). Four reported alcohol-related injury crashes (Brackett 1983; Wolfe 1984; Stuster 1995; Voas 2002); seven reported proxies, that is, night-time (Hurst 1981; Amick 1984; McEwen 1985; Maynard-Moody 1986; Voas 1997) or single-vehicle night-time (Jones 1995a; Jones 1995b) crashes; and five reported all types of injury crashes (Aden 1981; St Louis Police 1981; Sali 1983; Mallory 1984; Stuster 2001). All 12 controlled studies reported greater reductions in injury crashes in the intervention areas compared to control areas; intervention effects were statistically significant in most of the studies. Results were somewhat less consistent for the four ITS studies, although effect estimates were generally imprecise. 
Figure 7. Injury crashes (ITS and CITS)

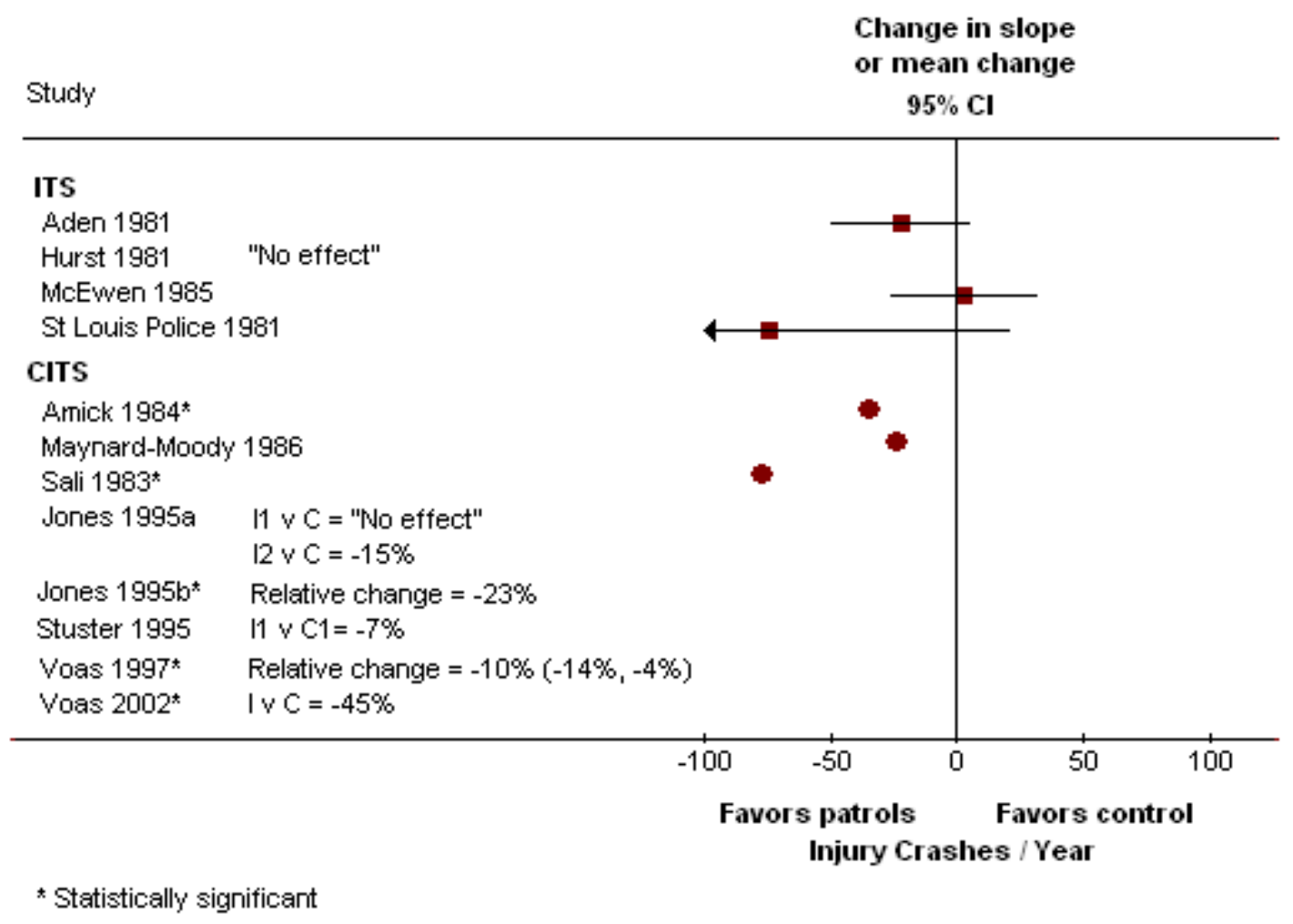


Figure 8. Injury crashes (CBAs)

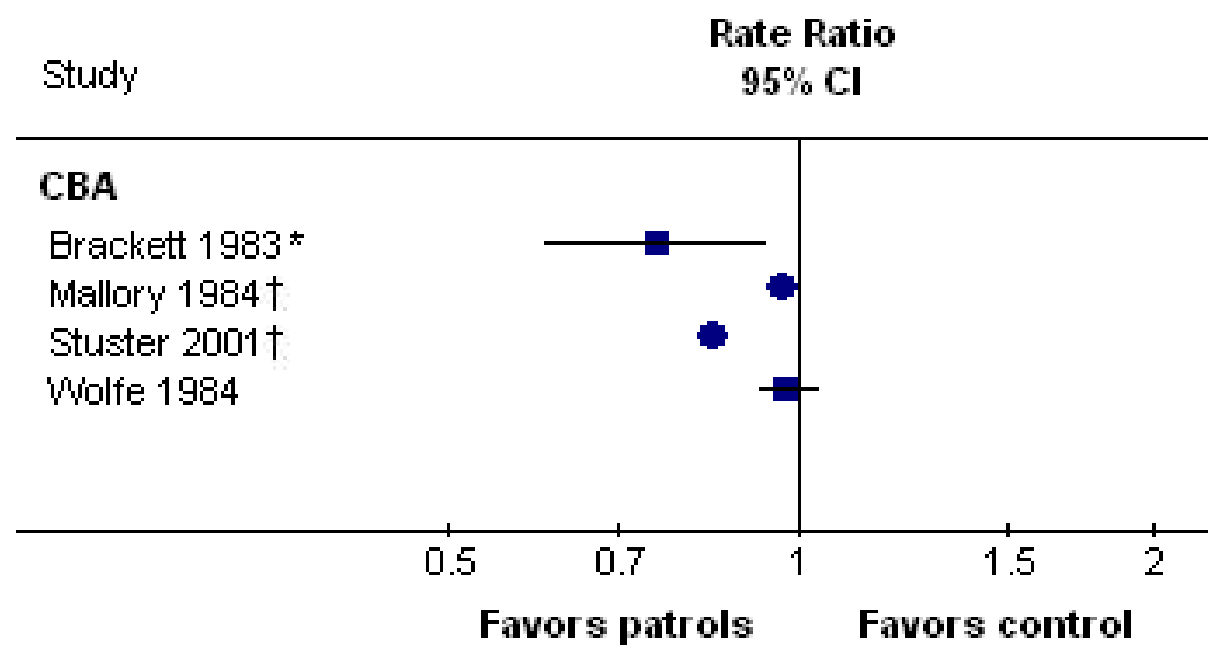

\section{* Statistically significant \\ † Statistical significance not tested}

\section{CITS}

Author-calculated results were reported for the eight CITS studies (Sali 1983; Amick 1984; Maynard-Moody 1986; Jones 1995a; Jones 1995b; Stuster 1995; Voas 1997; Voas 2002), all of which showed larger reductions in intervention versus control areas; only two actually tested the differential reduction between groups. The six other CITS studies analyzed and reported intervention and comparison series separately without directly comparing results between groups.

Two studies performed time series analyses on the ratio of injury crashes in the intervention relative to the comparison area. Voas 1997 reported a relative decrease of $10 \%(\mathrm{P}=0.009)$ and Jones $1995 \mathrm{~b}$ a relative decrease of $23 \%(\mathrm{P}<0.005)$.

Three studies showed significantly decreased injury crashes in the intervention areas versus nonsignificant decreases, no change, or increases in the control areas. Sali 1983 found a statistically significant average decrease of 14 crashes per month $(P<0.01)$ in the intervention area versus a decrease of 8 crashes per month ( $P$ $>0.05$ ) in the comparison area. Amick 1984 found a significant decrease of 4.6 crashes per month in the intervention area versus increases of 0.6 and 4.5 crashes per month in the two comparison areas, the latter increase being statistically significant. Voas 2002 reported a $-45.3 \%$ reduction in the ratio of alcohol-related to non-alcohol related crashes among ages 16 to 20 years in the intervention area $(\mathrm{P}=0.032)$ and no change (data not reported) in the comparison area $(\mathrm{P}>0.40)$.
Two studies reported significant reductions in both groups, with greater reductions in the intervention group. Maynard-Moody 1986 found mean reductions in injury crashes of -2.38 crashes/ month per 100,000 population in the intervention group and 0.57 in the control, both of which were statistically significant. Stuster 1995 reported decreases of $18 \%$ in the intervention area and $11 \%$ in the no-treatment control area, and corresponding statistically significant decreases in both groups with ARIMA analyses.

The eighth study (Jones 1995a) reported a decrease of 15\% (mean change not reported, $\mathrm{P}<0.20$ ) in one intervention area and no change in the other intervention area nor in the comparison area (data not reported).

\section{CBAs}

All four CBA studies indicated a pre-test to post-test reduction in the intervention area relative to the control area, although these reductions were minimal in Wolfe 1984 (rate ratio 0.99, 95\% CI 0.96 to 1.03 ) and Mallory 1984 (rate ratio 0.96, confidence interval could not be calculated). In contrast, Brackett 1983 revealed a significant differential reduction (rate ratio $0.75,95 \%$ CI 0.60 to 0.94 ) while Stuster 2001 calculated a reduction of $18 \%$ in the intervention area compared to a $3 \%$ reduction in the comparison areas $(\mathrm{P}<0.002)$. 
ITS

Results were mixed for the four ITS studies that examined injury crashes (Aden 1981; Hurst 1981; St Louis Police 1981; McEwen 1985) and all but one of the differences reported may have been due to chance alone. Hurst 1981 reported a $44 \%$ reduction in number of night-time injury crashes (change factor 0.61, 95\% CI 0.51 to 0.72 ) after taking into account accident year, month, time of day, and accident type using Poisson error ANOVA. To enable comparisons with other results in this review, we re-analyzed Hurst's data for the proportion of night-time injury crashes and found no change in slope $(0.000, \mathrm{P}=0.922)$. McEwen 1985 revealed a modest decline in level (-1.86 injury crashes) but the change in slope was positive ( 0.3 injury crashes per month), indicating an increasing trend in injury crashes after intervention. On the other hand, in two studies (Aden 1981; St Louis Police 1981) there were relative increases of $24 \%$ and $17 \%$, respectively, in the mean number of injury crashes from baseline to post-test. However, both studies exhibited nonsignificant decreases in slope from baseline to post-test (-22.1 and -75.1 injury crashes per year, respectively) suggesting decreasing trends in injury crashes after intervention.

\section{Total crashes}

Figure 9 displays results for ITS and CITS studies. Figure 10 shows results for CBA studies. Twenty studies (63\% of all included studies) reported effects of the intervention on total (that is, fatal, non-fatal injury, and other) crashes (Jansma 1978; Aden 1981; Campbell 1981; St Louis Police 1981; Brackett 1983; Mallory 1984; Pigman 1984; Sykes 1984; Wolfe 1984; Lacey 1986; Lacey 1987; Voas 1987; Lacey 1988; Pigman 1988; Jones 1995a; Jones 1995b; Stuster 1995; Voas 1997; Fuller 2001; Stuster 2001). Thirteen reported alcohol-related crashes (Jansma 1978; Campbell 1981; Brackett 1983; Mallory 1984; Pigman 1984; Wolfe 1984; Lacey 1986; Lacey 1987; Lacey 1988; Pigman 1988; Jones 1995a; Jones 1995b; Voas 1997); two reported proxies, that is, single vehicle (Stuster 1995) and night-time (Voas 1987) crashes; four reported all types of crashes (Aden 1981; St Louis Police 1981; Fuller 2001; Stuster 2001); and one reported total crashes during patrol hours (Sykes 1984). 
Figure 9. Total crashes (ITS and CITS)

Study

Change in slope

or mean change

$95 \% \mathrm{Cl}$

\section{ITS}

Aden 1981

Pigman 1984 *

Pigman 1988* Pre-post change $=-26 \%$

St Louis Police 1981

Stuster 2001*

Wolfe 1984 *

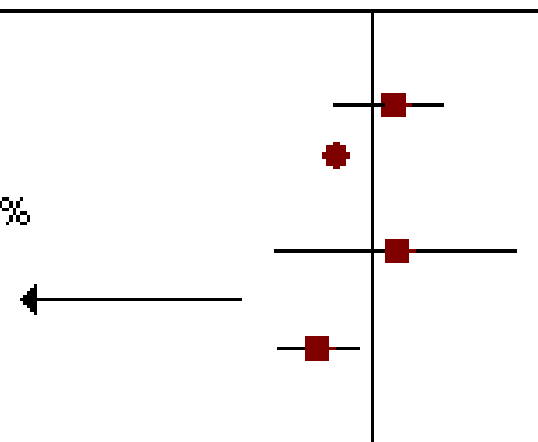

\section{CITS}

Campbell 1981

Jones 1995a

"No effect"

Jones $1995 b$

"No effect"

"Increased crashes"

Lacey $1986^{*}$

I $\vee \mathrm{C}=-20 \%$

Lacey 1987

"Increased crashes"

Lacey 1988

"No effect"

Voas $1987 *$

Voas $1997^{*}$

$I \vee C=-6 \%(-8 \%,-3 \%)$

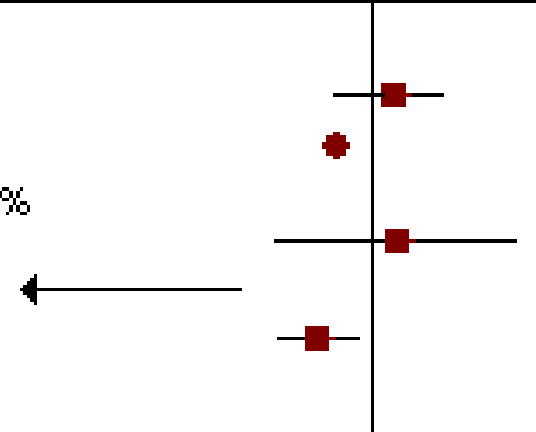

$-1000-500$

\section{Favors patrols}

Total Crashes / Year 
Figure 10. Total crashes (CBAs)

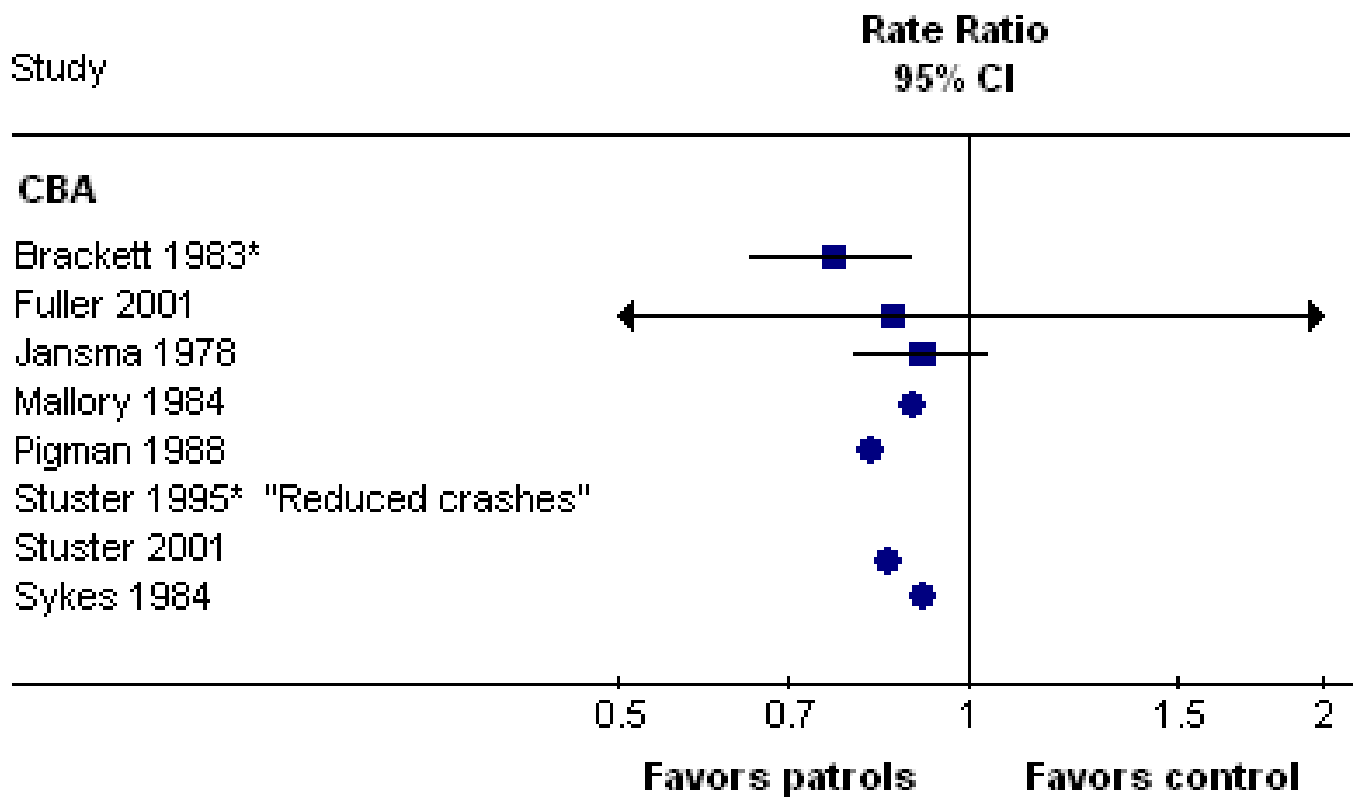

\section{* Statistically significant}

Eight of these studies used a CITS design (Campbell 1981; Lacey 1986; Lacey 1987; Voas 1987; Lacey 1988; Jones 1995a; Jones 1995b; Voas 1997); six used a CBA design (Jansma 1978; Brackett 1983; Mallory 1984; Sykes 1984; Stuster 1995; Fuller 2001); four implemented ITS designs (Aden 1981; St Louis Police 1981; Pigman 1984; Wolfe 1984); and two used both ITS and CBA designs (Pigman 1988; Stuster 2001).

Overall, 13 of 20 studies (65\%) showed reductions in total crashes (69\% of the reductions being statistically significant in at least one analysis). Four studies reported increased crashes with intervention, none of which were shown to be statistically significant. In three studies the authors reported 'no effect' but only one author provided numerical results.

CITS

Author-calculated results were reported for the eight CITS studies, which revealed inconsistent effects of intervention. Five studies found no effect (Campbell 1981; Lacey 1988; Jones 1995a) or a relative increase (Lacey 1987; Jones 1995b) in total crashes in the intervention versus control areas, although only Campbell 1981 reported the actual data this study did not use ARIMA analysis. Lacey 1988 reported no change in the ratio of alcohol-related crashes in the intervention area relative to the comparison area (shift parameter $-0.001, \mathrm{P}>0.10$ ). The other three CITS studies reported statistically significant reductions in total crashes in the intervention area relative to the comparison area. Lacey 1986 reported a reduction of $20.3 \%$ in the shift parameter $(\mathrm{P}<$ $0.0005)$ with the intervention. Voas 1987 reported a $15 \%$ prepost reduction of alcohol-related crashes in the intervention areas (mean change -5.3 crashes per month, $\mathrm{P}<0.01$ ), while pre-post changes in the comparison areas ranged from $-8 \%$ to $+24 \%$ (mean change +2.7 crashes per month, $\mathrm{P}>0.01$ ). Voas 1997 calculated a $6 \%$ reduction $(95 \% \mathrm{CI}-8 \%$ to $-3 \%)$ in the log of the relative ratio of total alcohol-related crashes in the intervention areas relative to the comparison areas.

\section{CBAs}

All CBA analyses showed beneficial effects of the intervention. Five CBA studies for which rate ratios or RRs could be calculated (Jansma 1978; Brackett 1983; Mallory 1984; Sykes 1984; Fuller 2001) showed decreases in total crashes in the intervention relative to the comparison area, ranging from $-8 \%$ to $-24 \%$. Precision could be calculated for only three of these studies (Jansma 1978: rate ratio $0.91,95 \%$ CI 0.80 to 1.04 ; Brackett 1983: rate ratio 0.76, $95 \%$ CI 0.65 to 0.90 ; Fuller 2001: rate ratio $0.87,95 \%$ CI 0.18 to 4.27 ; ). Of note, when Fuller 2001 analyzed total crashes using vehicle kilometers traveled rather than population as the denominator, they reported a non-significant increase with the in- 
tervention (rate ratio $1.06,95 \%$ CI 0.21 to 5.29). Mallory 1984 and Sykes 1984 reported relative reductions in total crashes (rate ratios 0.89 and 0.92 , respectively) but no statistical tests were performed. Stuster 1995 reported a statistically significant reduction in the intervention area $(\mathrm{P}<0.05)$ but not in the comparison area $(\mathrm{P} \geq 0.05)$; data were not provided. In a before-after comparison Stuster 2001 reported a $12 \%$ decrease in the intervention area and a $4 \%$ increase in the comparison area $(\mathrm{P}<0.002)$. Pigman 1988 found decreases in both intervention $(-30.4 \%)$ and control $(-14.2 \%)$ areas (rate ratio 0.81 ) but only the former was statistically significant.

\section{ITS}

The majority of ITS analyses showed beneficial effects of the intervention. Pigman 1984 reported a statistically significant mean reduction of 2.23 crashes per week (a $21 \%$ decrease). A time series regression of data from Wolfe 1984 revealed substantial decreases in both level $(-227.5$ crashes, $\mathrm{P}=0.04)$ and slope $(-38.2$ crashes per quarter, $\mathrm{P}=0.02)$. Two studies performed ITS analyses in addition to CBA analyses (Pigman 1988; Stuster 2001). Time series regression of data from Stuster 2001 revealed a statistically significant reduction in crashes during the post-test period (-95.2 crashes per month, $\mathrm{P}=0.002$ ) and a similarly large, statistically significant decline in level. ARIMA results from Pigman 1988 revealed a 26.1\% reduction in alcohol-related crashes during the post-test period ( $\mathrm{P}$ $<0.05$; mean change not reported). The other two studies showed nonsignificant increases in both slope and level (St Louis Police 1981: change in slope +5.2 crashes per month, $\mathrm{P}=0.72$, change in level +109.4 crashes, $\mathrm{P}=0.38$; Aden 1981: change in slope +10.8 crashes per quarter, $\mathrm{P}=0.61$, change in level +52.4 crashes, $\mathrm{P}=$ 0.42). St Louis Police 1981 showed a small relative reduction in total alcohol-related crashes of $-6.5 \%$, while Aden 1981 showed a substantial relative increase of $+54.8 \%$ in total alcohol-related crashes with the intervention.

\section{Alcohol-impaired driving}

Prevention of alcohol-impaired driving is a likely mechanism for reduction in alcohol-related traffic injuries. Nine studies reported effects of increased patrols on alcohol-impaired driving (Lacey 1986; Maynard-Moody 1986; Lacey 1987; Lacey 1988; Jones 1995a; Jones 1995b; Marchetti 1995; Voas 1997; Harrison 2001). Four studies found beneficial effects on alcohol-impaired driving (Lacey 1986; Lacey 1988; Marchetti 1995; Voas 1997), which were statistically significant in three cases (Lacey 1988; Marchetti 1995; Voas 1997). Four studies found a harmful effect (MaynardMoody 1986; Lacey 1987; Jones 1995a; Harrison 2001), which was statistically significant in one case (Maynard-Moody 1986); and one study reported 'no effect' without providing data (Jones 1995b).

Seven of these studies examined both alcohol-impaired driving and at least one selected outcome measure. Results for the two measures were consistent in three of the studies and inconsistent in terms of direction of effect in four cases.

Of the five studies where any beneficial effects on injuries or crashes were found, only two reported beneficial effects on alcohol-impaired driving. Voas 1997 measured drunk driving using roadside breath tests in one intervention area, and reported a statistically significant decline in alcohol-impaired driving that coincided with the onset of the intervention. In all three intervention areas, the number of days participants reported having driven after drinking too much declined 49\% (95\% CI -70\% to - 11\%). In Lacey 1986, a nonsignificant reduction in self-reported alcohol-impaired driving was reported (rate ratio $0.80,95 \%$ CI 0.43 to 1.50 ), although there was no apparent effect on impaired-driving events (data not reported).

In contrast, two studies showed adverse effects on alcohol-impaired driving despite beneficial effects on crash or injury outcomes. Jones 1995a examined two intervention areas using the same comparison area. In the first intervention area, where a reduction in injury crashes was observed, authors reported that there were no relative changes in alcohol-impaired driving (data not reported). In the other intervention area, where investigators found no beneficial effects of increased patrols on injuries or crashes, a nonsignificant increase in self-reported alcohol-impaired driving was observed (rate ratios at 6 and 12 months post-test: 1.89 and 1.05 , respectively, $95 \%$ CIs could not be calculated). The other study (Maynard-Moody 1986), which reported significant reductions in both fatal and injury crashes, showed a significantly greater increase in alcohol-impaired driving in the intervention area relative to the comparison area $(\mathrm{P}=0.048)$. A third study (Jones 1995b) found a significant reduction in injury crashes with intervention but no reported effect of the intervention on alcohol-impaired driving (although actual data were not reported for either measure). Jones $1995 \mathrm{~b}$ also reported no effect on total crashes or injuries in crashes.

The sixth study (Lacey 1988) found no change in total alcoholrelated crashes but a statistically significant relative decrease in the number of self-reported alcohol-impaired driving events with the intervention (rate ratio $0.64,95 \%$ CI 0.46 to 0.89 ) and a smaller relative decrease in the number of people reporting alcoholimpaired driving in the past month (rate ratio $0.72,95 \%$ CI 0.41 to 1.24$)$.

The seventh study that reported both alcohol-impaired driving and at least one selected outcome measure did not find any beneficial effects of the intervention on injuries or crashes (Lacey 1987). Consistent with this result there was a minimal increase in selfreported alcohol-impaired driving (rate ratio 1.01, 95\% CI 0.59 to 1.73 ) with intervention.

Two other studies (Marchetti 1995; Harrison 2001) did not collect any injury or crash outcome measures but did report effects of increased police patrols on alcohol-impaired driving. In their RCT, Harrison 2001 found a modest relative increase in self-reported alcohol-impaired driving in the past month after the first weekend 
of enforcement (RR 1.13, 95\% CI 0.67 to 1.90 ) and a modest relative reduction after the last weekend of enforcement, which also included random breath tests and foot patrols (RR 0.88, 95\% CI 0.51 to 1.52 ). The CBA study by Marchetti 1995 showed a 1.4-fold increase in self-reported drunk driving in the intervention group and a nearly 4 -fold increase in the control group; the increase for the control group was significantly greater $(P=0.019)$.

\section{Comparisons between increased patrols and other interventions}

Only one study (Stuster 1995) included a comparison between increased patrols and another intervention (that is, sobriety checkpoints), where both interventions also included a media component. Although the two groups were not compared directly, results from each were similar, with statistically significant pre-post reductions in alcohol-related injury crashes in both the intervention area $(18 \%)$ and the comparison areas (9\% to $40 \%)$. The authors also reported a significant pre-post reduction in single vehicle total crashes with increased patrols but not with sobriety checkpoints (data were not reported).

\section{Subgroup analysis}

We examined the effects of increased police patrols according to the presence or absence of other intervention elements such as media and education, special training, or sobriety checkpoints.

\section{Increased police patrols alone}

Only four studies evaluated the effect of increased patrols in isolation. Three of these evaluated increased patrols alone (Campbell 1981; Mallory 1984; Harrison 2001) while one evaluated the added effect of increased patrols to other interventions that were implemented similarly in both intervention and control areas (Sykes 1984). Two studies found greater pre-post reductions in the intervention versus comparison areas for all outcomes assessed (Mallory 1984; Sykes 1984), ranging from $22 \%$ to $23 \%$ for fatalities and fatal crashes to $8 \%$ to $11 \%$ for total crashes, $4 \%$ for injury crashes, and $2 \%$ for injuries. None of these reductions were tested for statistical significance. In contrast, Campbell 1981 reported 'no effect' of increased patrols alone on total crashes. The fourth study (Harrison 2001) did not measure alcohol-related injury or crash outcomes. Based on the few available studies, results for increased patrols alone appear to be consistent with the overall results of this review, that is, most studies reported beneficial effects on traffic fatalities and alcohol-related crashes or proxies for such crashes.

\section{Increased police patrols with a media or public education component}

Because the majority of studies (84\%) included analyses that evaluated increased police patrols combined with a paid or earned media or public information component, results from this subgroup were similar to that of the overall comparison. That is, increased patrols combined with a media or public information component resulted in reductions in total, fatal and injury crashes, and in traffic fatalities in the majority of studies (with imprecise effect estimates in a number of cases), and inconsistent effects on total and nonfatal traffic injuries.

\section{Increased police patrols with special training and equipment for police officers}

Half of the studies (50\%) included special DUI training or equipment, or both for police officers (Zador 1976; Aden 1981; St Louis Police 1981; Amick 1984; Pigman 1984; Wolfe 1984; Lacey 1986; Maynard-Moody 1986; Lacey 1987; Voas 1987; Lacey 1988; Jones 1995a; Marchetti 1995; Hingson 1996; Voas 1997; Wiliszowski 2003). In this subgroup, reductions in total crashes, fatal crashes, injury crashes, traffic fatalities, and traffic injuries were observed, with the least consistent effects for traffic injuries. These results were consistent with the overall results of the review.

\section{Increased police patrols with sobriety checkpoints or breath testing}

Sobriety checkpoints or breath testing were included in 28\% (n = 9) of studies (Hurst 1981; Lacey 1986; Lacey 1988; Lacey 1991; Jones 1995a; Jones 1995b; Marchetti 1995; Harrison 2001; Voas 2002), of which seven measured a selected primary outcome. Their results were generally consistent with the overall results, that is, there were reductions in fatalities (Hurst 1981; Lacey 1991), total crashes (Lacey 1986; Lacey 1988; Jones 1995a; Jones 1995b) and injury crashes (Hurst 1981; Jones 1995a; Jones 1995b) in the majority of studies (with imprecise effect estimates in most studies), and no evidence of a beneficial effect on injuries (Hurst 1981; Jones 1995a). Few of these studies reported actual numerical results, making it difficult to draw conclusions about differences in the magnitude of benefit when sobriety checkpoints were added to increased police patrols. However, the two studies that did report numerical data did not demonstrate consistently greater beneficial effects on fatalities (Hurst 1981; Lacey 1991) or injuries (Hurst 1981) than did studies evaluating increased police patrols without checkpoints.

\section{Other interventions}

Harrison 2001 examined self-reported alcohol-impaired driving combined with both random breath testing and foot patrols at licensed premises and in town, and showed relative decreases in the intervention versus comparison areas that were not statistically significant (rate ratios for two survey questions on alcohol-impaired driving: 0.88 and $0.97,95 \%$ CI 0.51 to 1.52 and 0.33 to 2.75 , 
respectively). Voas 2002 also implemented foot patrols at a border crossing with high pedestrian traffic and found a $45 \%$ reduction in the intervention area versus no change in the comparison area (data not provided, $\mathrm{P}>0.40$ ).

A few studies implemented public advocacy programs (MaynardMoody 1986; Jones 1995a; Marchetti 1995; Hingson 1996). Jones 1995a implemented a public advocacy program in one of two intervention areas and reported no change in injuries and crashes; and a nonsignificant increase in self-reported alcohol-impaired driving (rate ratios at 6 and 12 months post-test: 1.89 and 1.05, $95 \%$ CIs could not be calculated). Marchetti 1995 found a relative reduction of $65 \%$ in self-reported drunk driving $(P=0.019)$, and the remaining two studies reported substantial reductions in fatal crashes (Hingson 1996: RR 0.58 , 95\% CI 0.32 to 1.08 ; Maynard-Moody 1986: Intervention1 -37\%, $\mathrm{P}<.05$; Comparison $1-8 \%, \mathrm{P}>0.05)$. Hingson $1996 \mathrm{did}$ not find a decrease in injuries (data not reported), while Maynard-Moody 1986 reported significant reductions in injury crashes for both the intervention (60\%) and comparison areas (21\%).

A few studies included citizen reporting of DUI (Lacey 1987; Jones 1995a; Stuster 2001), all of which measured total crashes. Only Stuster 2001 found a decrease, which was substantial (-95 crashes per month, $\mathrm{P}=0.002)$. For total crashes, Jones $1995 \mathrm{a}$ reported no change (data not reported), and Lacey 1987 found a slight relative increase which was not subjected to statistical testing. Jones 1995a and Stuster 2001 also measured injury crashes.

Stuster 2001 reported a statistically significant reduction of $15 \%$ in the intervention versus control areas, while Jones 1995a found a reduction of $15 \%$ in the intervention group but did not compare the results to those from the control group.

Several studies (Zador 1976; Aden 1981; Amick 1984; McEwen 1985; Maynard-Moody 1986; Pigman 1988; Marchetti 1995) coordinated increased police patrols with changes in the judicial system (for example, facilitating prosecution of cases). Results from McEwen 1985 and Zador 1976 suggested no change in injury crashes $(+0.26$ crashes per month, $\mathrm{P}=0.83)$ or fatalities $(\mathrm{P}>0.5)$, respectively. Results from the other four studies suggested relative decreases in measured outcomes associated with the intervention. Marchetti 1995 found a relative decrease of $65 \%$ in alcohol-impaired driving ( $\mathrm{P}=0.019)$; Pigman 1988 found a relative decrease of $19 \%$ in total crashes and a statistically significant decrease in slope (mean change not reported). Injury crashes were reduced relative to controls in studies by Amick 1984 ( -4.6 per month versus 0.6 to 4.5 per month) and Maynard-Moody 1986 (2.38 per month versus 0.57 per month per 100,000 population). Maynard-Moody 1986 also reported a relative reduction in fatal crashes ( -0.11 per month versus -0.04 per month per 100,000 population), and Aden 1981 reported a change in slope of -0.88 crashes per quarter.

\section{DISCUSSION}

\section{Principal finding}

Studies examining increased police patrols have, for the most part, reported beneficial effects on traffic fatalities and alcohol-related crashes or proxies for such crashes. However, two-thirds of the studies were rated as 'not adequate' on at least one key design or conduct feature, and almost none of the studies reported methodological information in sufficient detail to evaluate their quality fully. Inadequate sample size, dissimilarity of baseline measures for outcomes (for example, intervention areas selected for high alcohol-related crash rates), and contamination were among the more common design flaws. Hence, we conclude that existing evidence does not establish that increased police patrols reduce the adverse outcomes of alcohol-impaired driving.

In 1994, Zobeck 1994 conducted a systematic review of increased police patrols, both alone and in combination with other enforcement programs or laws, and found small decreases in crashes and casualties. The authors noted then that many of the studies did not implement critical features of good research design and failed to report detailed results. Although our review excluded weaker study designs, like before-after studies, and added an additional decade of research literature our findings are generally consistent with those reported by Zobeck 1994. It is surprising that more high quality research studies evaluating increased police patrols have not been funded since the previous review, given that millions of dollars are spent annually to fund increased law enforcement activity targeting alcohol-impaired driving.

\section{Supporting findings}

Decreases in fatal crashes and traffic fatalities were less likely to be statistically significant than other outcomes, a finding that may be explained by lack of power to detect changes in these infrequently occurring outcomes.

Effects on injuries showed the greatest variability. It is difficult to explain why nearly all studies that evaluated injury crashes reported decreases, whereas half of those that evaluated injuries did not. Data on injuries and injury crashes were acquired from the same types of sources, mainly accident reporting systems and police reports. However, the methods of counting injuries and injury crashes were not specified and, therefore, may have differed. In addition, none of the studies reported adjusting for clustering of injuries within crashes.

Only four of nine studies that measured alcohol-impaired driving, either by self-report or breath alcohol content, showed any reduction in this outcome with increased police patrols. Perhaps, surprisingly, decreases in crash and injury outcomes were not consistently associated with decreases in alcohol-impaired driving. Hence, our results do not necessarily support prevention of alcohol-impaired driving as a mechanism for any reduction in crashes and injuries 
observed with increased police patrols. However, relatively few studies measured alcohol-impaired driving in a manner consistent with our minimum design criteria. Hence it is not clear whether the lack of association is due to the inadequate methods used in most studies or to a true failure of increased police patrols to reduce alcohol-impaired driving.

\section{Additional findings}

In general, increased patrols alone appeared to have effects on crashes and injuries similar to those of increased patrols implemented with adjuncts such as media, public education, special training and equipment, sobriety checkpoints, or other interventions. However, these findings are based on only a few studies since the vast majority of studies implemented media or public education, and often other adjuncts along with increased patrols. Media campaigns were implemented in the majority of studies, thus it is difficult to separate the effects of these intervention components. A systematic review of media campaigns for preventing alcoholimpaired driving (Elder 2004) used different inclusion criteria but also found overlap between enforcement efforts and media campaigns, although enforcement efforts other than increased patrols were implemented. Our results suggest, based on limited evidence, that increased patrols combined with sobriety checkpoints do not show a greater benefit than increased patrols without such checkpoints. Only a few studies evaluated foot patrols, public advocacy, citizen reporting of DUI, or coordination with judicial processes and their results were not entirely consistent.

\section{Strengths and weaknesses}

\section{Identification of studies}

To minimize selection bias, we attempted to be as comprehensive as possible in seeking eligible studies by searching diverse databases, employing free-text search terms, searching English and non-English language literature, and excluding methodological terms from our search strategy (since consistent terminology to identify study designs other than controlled trials is lacking). Nevertheless, eligible reports may have been missed. We did not use website searches, through which others have identified road safety interventions (Aeron-Thomas 2005). Although the fact that most included studies were from the United States is consistent with observations that behaviorally-based field assessment of impairment is primarily used in the United States (Voas 1991), it is also possible that the selected search terms introduced language bias. In addition, since increased police patrols are a common practice in the United States, it is likely that many programs have been implemented without evaluation, or that evaluations may have gone unreported unless beneficial effects were observed. Finally, since all identified studies took place in high income countries, the results of this review may not be generalizable to low and middle income countries.

\section{Quality of included studies}

ITS, CBA, and CITS study designs are considered stronger methodologically than before-after and post-test only designs (Campbell 1966; Cook 1979) and such designs are likely to be the best available evidence about population-based interventions in natural settings, where true experimental designs are difficult to implement. As expected, almost all programs were evaluated with CBA, ITS, or CITS designs. Inclusion of quasi-experimental designs, however, introduces concerns about validity. Two-thirds of the studies we identified had at least one methodological limitation that could affect the validity of our results, while only one study was 'adequate' on all criteria. CITS studies were generally of higher quality and more likely to earn ratings of 'adequate' than were either CBA or ITS studies, although the quality of ITS studies was improved by our re-analyses. Overall methodological quality of the review could have been improved by applying more stringent inclusion criteria for these study designs, such as better matching on CBAs or more data points for ITS designs.

Methodology was rarely reported in sufficient detail for adequate quality assessment, which prevented our stratifying findings by study quality. Dissimilarity of baseline measures for outcomes (for example, intervention areas selected for high alcohol-related crash rates) and contamination, which we found in many studies, have been identified as key quality criteria in other reviews pertaining to traffic safety (Bunn 2003; Aeron-Thomas 2005). The failure of many studies to report on such issues could have biased our conclusions. Other reviewers have noted a slight improvement in quality ratings when information from authors was obtained (Liberati 1986). Although several authors were deceased, untraceable, or did not respond, we did obtain additional methodological information from a number of authors, improving our ability to identify indicators of quality.

Another potential source of bias lies in selective reporting of outcomes (for example, Chan 2004, Chan 2005) in which authors do not completely report examined outcomes or do not report all outcomes collected. In our review, outcome data were often reported incompletely so that quantitative combination of results in a meta-analysis was not feasible. Only one author who replied to our requests for additional information indicated that he had collected an outcome that was not reported in his study, although not all authors could be contacted. On the other hand, many of the authors reported their results in lengthy, detailed technical reports, which are perhaps more likely to have included all measured outcomes than are, for example, in shorter journal articles.

Almost all included studies examined at least one primary outcome. However, most injury and crash outcomes were measured either directly or indirectly from police records. Knowledge of the 
intervention by police could have biased outcome assessment, although it is difficult to know the direction of any bias. Police officers in intervention communities often received additional training in the recognition of alcohol-impaired driving, which could increase identification and reporting of alcohol-related incidents (Amick 1984). On the other hand, desire to demonstrate effectiveness of the intervention program could lead to under-reporting of alcohol-related incidents. Waller 1986 found no systematic bias in police assessment of alcohol use, although this study was not conducted in the context of an intervention involving police. Our within-study comparison of alcohol-related crashes and highly associated proxies for alcohol-related crashes showed that these outcomes generally showed the same direction of effect and statistical significance (or lack of) and comparable magnitude of effect, demonstrating no evidence of systematic bias.

\section{Analysis}

One strength of this review is that we examined both immediate (change in level) and sustained (change in slope) effects of increased police patrols in our re-analyses of ITS designs. These analyses allowed us to assess whether there were consistent differences in immediate versus sustained effects of increased patrols on injuries or crashes. A number of studies did show differences in the direction of change in level versus change in slope, but these differences were not consistent as some studies had immediate but not sustained beneficial effects on outcomes, while others showed the opposite result.

Several CITS studies failed to test the differential change over time between intervention and comparison areas, which would have been helpful in determining relative effects of increased police patrols. However, potential problems with interpreting times series involving ratios of study events to comparison events have been noted (Jones 1995a; Jones 1995b). We preferentially selected ARIMA analyses when authors performed them. However, most ARIMA analyses examined pre-post changes within groups without considering relative effects.

\section{AUTHORS' CONCLUSIONS}

\section{Implications for practice}

We found many studies of increased police patrol programs, which in general showed at least some beneficial effect on fatalities and crashes although few results were statistically significant. The most consistent benefits were seen for total crashes, fatalities and fatal crashes. However, nearly three-quarters of the studies had at least one methodological limitation which could affect their results. Evidence about whether prevention of alcohol-impaired driving is a mechanism for the decrease in crashes and injuries that is observed with increased police patrols is also inconclusive. Thus, existing evidence, although suggestive, does not establish whether increased police patrols, implemented with or without other intervention elements, has an important effect on the adverse consequences of alcohol-impaired driving.

\section{Implications for research}

Although increased police patrols appeared to reduce alcohol-related crashes and traffic fatalities in the identified studies, the quality and reporting of these studies was often poor. Methodologically rigorous research is still needed to evaluate whether increased police patrols are an effective intervention for targeting alcoholimpaired driving. The identification of one relatively good quality randomized controlled trial suggests that studies of better design and quality can and should be implemented to evaluate increased police patrols, even though the studies must occur in a natural setting. The need for high quality evaluation is particularly vital in the context of the substantial resources currently being expended to implement this intervention, despite its unproven efficacy.

Additional directions for future research might include the following.

- Direct comparisons of enforcement strategies (sobriety checkpoints, increased patrols, random breath testing or behavior-based versus chemistry-based enforcement).

- Examination of specific additional interventional elements that may influence the effectiveness of increased police patrols.

- Evaluation of objective measurements of alcohol-impaired driving during increased police patrol interventions using controlled study designs.

- Determination of the cost-effectiveness of increased police patrol programs relative to other programs shown to reduce alcohol-impaired driving or its consequences.

Updates to this review will incorporate studies identified but not yet assessed and attempt to identify additional relevant literature.

\section{ACK NOW LEDGEMENTS}

We gratefully acknowledge all of the investigators who sent us information and unpublished data from their studies, and EPOC Review Group members Alain Mayhew and Drs. Craig Ramsay, Miranda Cumpston, and Roberto Grilli who shared their expertise in data re-analysis and quality assessment. Dr. Steven Lowenstein made valuable contributions to study conception and manuscript content. Rachel Rosenberg, Christel Taylor, and Kate Bartell assisted with data collection and screening. Dr. Dennis Lezotte and Rebecca Hills developed the data extraction database. The 
Cochrane Injuries Group's Review Group Co-ordinator Katherine Ker and Trials Search Co-ordinator Karen Blackhall and also assisted with this review.

This research was supported by Grant Number R49/CCR811509 to the Colorado Injury Control Research Center from the Centers for Disease Control and Prevention (CDC), US Department of Health and Human Services. Dr Van Bramer and Dr Porter were supported by Grant No. D33HP02610 for Preventive Medicine Residencies, from the Health Resources and Services Administration (HRSA). Its contents are solely the responsibility of the authors and do not necessarily represent the official views of the CDC, HRSA, or the Cochrane Injuries Group.

\section{REF E R E NCES}

\section{References to studies included in this review}

Aden 1981 \{published and unpublished data\}

Aden RJ. Driving under the influence team (project D.U.I.T). Final report and evaluation. Simi Valley (CA): Simi Valley Police Department; 1981.

Amick 1984 \{published and unpublished data\}

* Amick DR, Marshall PB. An evaluation of the Bonneville County DUI prevention program (Project Safety). Traffic Safety Evaluation Research Review 1984;3(3):7-21. Amick DR, Marshall PB. Evaluation of the Bonneville County, Idaho, DUI accident prevention program. Transportation Research Record 1983;910:81-93.

Brackett 1983 \{published data only\} Brackett RQ, Carnahan T, Womack K. Evaluation of DWI enforcement activities in 1983. College Station (TX): Texas Transportation Institute, Texas A \& M University; 1983 Nov. Report No.: (83)01-01-B1-JA Final Report.

Campbell 1981 \{published data only\}

Campbell BJ. An attempt to evaluate the impact on accidents of various selective traffic enforcement projects funded by North Carolina governor's highway safety program and carried out by several North Carolina cities. Chapel Hill (NC): University of North Carolina Highway Safety Research Center; 1981 Aug. Report No.: UNC/ HSRC-81/8/1.

Fuller 2001 \{published and unpublished data\}

Road traffic laws. Dail debates official report. http: //www.gov.ie/debates-00/5oct/sect6.htm (accessed 13 October 2005).

Fuller R. Mission impossible? A retrospective of the effectiveness of a high-intensity enforcement campaign. Behavioural Research in Road Safety: Eleventh Seminar; 2001. London (UK): Department for Transport, Local Government and the Regions. Road Safety Division, 2002: $88-98$.

* Fuller R, Farrell E. Operation lifesaver assessment. Project O.L.A. Dublin (IE): National Roads Authority; 2002 Jun. Report No.: NRA RS459.
Harrison 2001 \{published and unpublished data\}

Harrison WA. Drink driving and enforcement: theoretical issues and investigation of the effects of three enforcement programs in two rural communities in Australia. Sydney (AU): Austroads Incorporated; 2001. Report No.: APR181/01.

Hingson 1996 \{published and unpublished data\} Hingson R, McGovern T, Howland J, Heeren T, Winter M, Zakocs R. Reducing alcohol-impaired driving in Massachusetts: the saving lives program. American Journal of Public Health 1996;86(6):791-7.

Hurst 1981 \{published and unpublished data\}

* Hurst PM, Wright PG. Deterrence at last: the Ministry of Transport's alcohol blitzes. Proceedings of the 8th International Conference of Alcohol Drugs and Traffic Safety; 1980 Jun 15-19; Stockholm (SE). Stockholm (SE): Almqvist \& Winksell International, 1981:1283-97. Hurst PM, Wright PG. The Ministry of Transport's alcohol blitzes. Wellington (NZ): Traffic Research Section, Road Transport Division, Ministry of Transport; 1979. Traffic Research Report No.: 22.

Jansma 1978 \{published data only\} Jansma KC, Milton KR. DUI reduction month project. Executive summary and final report. Sacramento (CA): Department of California Highway Patrol; 1978 Aug. Report No.: PB301090.

Jones 1995a \{published data only\} Jones R, Joksch H, Lacey J, Wiliszowski C, Marchetti L. Site report: Knoxville, Tennessee field test of combined speed, alcohol, and safety belt enforcement strategies. Winchester (MA): Mid-America Research Institute; 1995 Mar. Report No.: DOT HS 808243.

Jones R, Joksch H, Lacey J, Wiliszowski C, Marchetti L. Site report: Lexington, Kentucky field test of combined speed, alcohol, and safety belt enforcement strategies. Winchester (MA): Mid-America Research Institute; 1995 Mar. Report No.: DOT HS 808245.

* Jones R, Joksch H, Lacey J, Wiliszowski C, Marchetti L. 
Summary report: field test of combined speed, alcohol and safety belt enforcement strategies. Winchester (MA): MidAmerica Research Institute; 1995 Mar. Report No.: DOT HS 808242 .

\section{Jones 1995b \{published data only\}}

* Jones R, Joksch H, Lacey J, Wiliszowski C, Marchetti L. Site report: Wichita, Kansas field test of combined speed, alcohol and safety belt enforcement strategies. Winchester (MA): Mid-America Research Institute; 1995 Mar. Report No.: 808244 .

Jones R, Joksch H, Lacey J, Wiliszowski C, Marchetti L. Summary report: field test of combined speed, alcohol and safety belt enforcement strategies. Winchester (MA): MidAmerica Research Institute; 1995 Mar. Report No.: DOT HS 808242.

Lacey 1986 \{published data only\}

Eskridge D. A model DWI program. Detected, tested, arrested and tracked: establishing and administering a dwi program with accountability. Jacksonville: Institute of Police Technology and Management, University of North Florida, 1989:39-42.

Klein S, Egger MJ. "Arrest drunk driving": chapter two. The Police Chief 1987;54(4):21-3.

Lacey JH, Marchetti LM, Stewart JR, Murphy PV, Jones RK. Combining enforcement and public information to deter DWI: the experience of three communities. Chapel Hill (NC): University of North Carolina Highway Safety Research Center; 1990 Apr. Report No.: DOT HS 807 601.

* Lacey JH, Stewart JR, Marchetti LM, Popkin CL, Murphy PV, Lucke RE, et al.Enforcement and public information strategies for DWI general deterrence: arrest drunk driving - the Clearwater and Largo, Florida experience. Chapel Hill (NC): University of North Carolina Highway Safety Research Center; 1986 Dec. Report No.: DOT HS 807 066.

Stewart JR. Estimation of the effects of changes in drinking and driving laws on alcohol related automobile crashes. Chapel Hill (NC): University of North Carolina Highway Safety Research Center; 1985 Aug. Report No.: HSRCA113.

Vaughn JR, Klein S. Arrest drunk driving: a comprehensive cooperative approach. The Police Chief 1984;51:32-4.

Lacey 1987 \{published data only\}

Lacey JH, Marchetti LM, Stewart JR, Murphy PV, Jones RK. Combining enforcement and public information to deter DWI: the experience of three communities. Chapel Hill (NC): University of North Carolina Highway Safety Research Center; 1990 Apr. Report No.: DOT HS 807 601.

* Lacey JH, Marchetti LM, Stewart JR, Popkin CL, Murphy PV, Lucke RE, et al.Enforcement and public information strategies for DWI general deterrence: the Boise City, Idaho experience. Chapel Hill (NC): University of North Carolina Highway Safety Research Center; 1987 Aug. Report No.: DOT HS 807191.

\section{Lacey 1988 \{published data only\}}

Lacey JH, Marchetti LM, Stewart JR, Murphy PV, Jones RK. Combining enforcement and public information to deter DWI: the experience of three communities. Chapel Hill (NC): University of North Carolina Highway Safety Research Center; 1990 Apr. Report No.: DOT HS 807 601.

* Lacey JH, Marchetti LM, Stewart JR, Popkin CL, Murphy PV, Lucke RE, et al.Enforcement and public information strategies for DWI general deterrence: the Indianapolis, Indiana experience. Chapel Hill (NC): University of North Carolina Highway Safety Research Center; 1988 Jul. Report No.: DOT HS 807434.

\section{Lacey 1991 \{published data only\}}

Lacey JH, Jones RK. Assessment of changes in DWI enforcement/level. Chapel Hill (NC): University of North Carolina Highway Safety Research Center and Winchester (MA): Mid-America Research Institute; 1991 Jan. Report No.: DOT HS 807690 21-5.

\section{Mallory 1984 \{published data only\}}

Mallory BL. Pennsylvania driving under the influence extra enforcement grants: how traffic records can assist a highway safety program. Transportation Research Record 1984;975: $7-11$.

\section{Marchetti 1995 \{published data only\}}

Marchetti LM, Tolbert WG, Lowrance JC, Stewart JR. Operation dry run: an enforcement and public information program to reduce drinking and driving by teenagers. Chapel Hill (NC): University of North Carolina Highway Research Center; 1995 Apr. Report No.: UNC/HSRC-95/ $4 / 2$.

\section{Maynard-Moody 1986 \{published data only\}}

Lacey JH, Jones RK. Assessment of changes in dwi enforcement/level. Chapel Hill (NC): University of North Carolina Highway Safety Research Center and Winchester (MA): Mid-America Research Institute; 1991 Jan. Report No.: DOT HS 807690 16-20.

* Maynard-Moody S, Palumbo D, Scheurich J, Kruger K. Final report for the Wichita comprehensive program to reduce driving while intoxicated. Lawrence (KA): Institute for Public Policy and Business Research, University of Kansas; 1986 May. Report No.: 121.

McEwen 1985 \{published data only\}

McEwen T, Brazil F. Sacramento, California selective traffic enforcement program. Final report. Sacramento (CA): Sacramento Police Department and McLean (VA): PRC Public Management Services; 1976 Aug. Report No.: DOT HS 801983.

Pigman 1984 \{published data only\} Lacey JH, Jones RK. Assessment of changes in dwi enforcement/level. Chapel Hill (NC): University of North Carolina Highway Safety Research Center and Winchester (MA): Mid-America Research Institute; 1991 Jan. Report No.: DOT HS 807690 26-30.

* Pigman JG, Agent KR. Impact evaluation of Lexington-Fayette County traffic alcohol program (Abridgment). Transportation Research Record 1984;974:4-7. 
Pigman 1988 \{published data only\}

Pigman JG, Agent KR, Hardyman PL, Johnson KW, McCleary R. Impact evaluation of the Louisville-ShivelyJefferson County traffic alcohol programs. Lexington (KY): Kentucky Transportation Center; 1988 Oct. Report No.: KTC-88-3.

Sali 1983 \{published and unpublished data\}

Sali GJ. Evaluation of Boise selective traffic enforcement project. Transportation Research Record 1983;910:68-74.

St Louis Police 1981 \{published data only\} St. Louis County Police Department. Driving while intoxicated enforcement: grant evaluation. Saint Louis (MO): St. Louis County Police Department; 1981.

Stuster 1995 \{published data only\}

Stuster JW, Blowers PA. Experimental evaluation of sobriety checkpoint programs. Santa Barbara (CA): Anacapa Sciences; 1995 Jun. Report No.: DOT HS 808287.

Stuster 2001 \{published and unpublished data\} Stuster J. Albuquerque police department's safe streets program. Anacapa Sciences; 2001 Jun. Report No.: DOT HS 809-278.

Sykes 1984 \{published data only\}

Sykes GW. Saturated enforcement: the efficacy of deterrence and drunk driving. Journal of Criminal Justice 1984;12: $185-97$.

Voas 1987 \{published and unpublished data\}

Hause J, Chavez E, Hannon R. Increased DUI enforcement program. Stockton, California third annual report. Stockton (CA): Stockton Police Department and University of the Pacific; 1979 Aug. Report No.: DOT HS 804838. Hause J, Matheson D, Hannon R, Chavez E. Increased DUI enforcement program. Stockton, California project evaluation. Stockton (CA): Stockton Police Department and University of the Pacific; 1977 Jan. Report No.: DOT HS 802205.

* Voas RB, Hause JM. Deterring the drinking driver: the Stockton experience. Accident Analysis and Prevention 1987; 19(2):81-90.

Voas 1997 \{published and unpublished data\}

Holder HD. Community prevention of alcohol problems. Addictive Behaviors 2000;25(6):843-59.

Holder HD, Gruenewald PJ, Ponicki WR, Treno AJ, Grube JW, Saltz RF, et al.Effect of community-based interventions on high-risk drinking and alcohol-related injuries. JAMA 2000;284(18):2341-7.

Holder HD, Saltz RF, Grube JW, Voas RB, Gruenewald PJ, Treno AJ. A community prevention trial to reduce alcoholinvolved accidental injury and death: overview. Addiction 1997;92 Suppl 2:155-71.

Holder HD, Saltz RF, Treno AJ, Grube JW, Voas RB. Evaluation design for a community prevention trial. Evaluation Review 1997;21(2):140-65.

Roeper PJ, Voas RB, Padilla-Sanchez L, Esteban R. A longterm community-wide intervention to reduce alcohol- related traffic injuries: Salinas, California. Drugs: education, prevention and policy 2000;7(1):51-60.

Treno AJ, Holder HD. Environmental approaches to reducing underage drinking. Juvenile Justice 1998;5(2): 20-7.

Voas RB. Drinking and driving prevention in the community: program planning and implementation. Addiction 1997;92(2 Suppl):201S-219S.

* Voas RB, Holder HD, Gruenewald PJ. The effect of drinking and driving interventions on alcohol-involved traffic crashes within a comprehensive community trial. Addiction 1997;92 Suppl 2:221-36.

Voas 2002 \{published and unpublished data\}

Voas RB, Lange JE, Tippetts AS, Johnson M. Operation safe crossing: using science within a community intervention. http://icadts.org/proceedings/show.php?paper=2000-117 (accessed 25 July 2007).

* Voas RB, Tippetts AS, Johnson MB, Lange JE, Baker J. Operation safe crossing: using science within a community intervention. Addiction 2002;97:1205-14.

\section{Wiliszowski 2003 \{published and unpublished data\}}

Wiliszowski CH, Jones RK. Evaluation of the Austin police department DWI enforcement unit. Winchester (MA): Mid-America Research Institute; 2003 Aug. Report No.: DOT HS 809641.

Wolfe 1984 \{published data only\}

Madsen BB. A multijurisdictional effort to improve safety. ITE Journal 1991;61(7):50-5.

Wolfe AC. Evaluation of the special alcohol enforcement/ education project in Oakland County, Michigan. Alcohol, drugs and traffic safety: Proceedings of the ninth International Conference on Alcohol, Drugs, and Traffic Safety; 1983; San Juan, Puerto Rico. Washington D.C.: United States Department of Transportation, National Highway Traffic Safety Administration, 1985; Vol. 3: 1575-95.

Wolfe AC. First evaluation report on the Oakland County alcohol enforcement/education project. Ann Arbor (MI): Highway Safety Research Institute; 1981 Feb. Report No.: UM-HSRI-81-6.

Wolfe AC. Interim (two-year) evaluation report on the Oakland County alcohol enforcement/education project. Ann Arbor (MI): Transportation Research Institute; 1983

Mar. Report No.: UMTRI-83-12.

* Wolfe AC, O’Day J. Evaluation report on the 1979-1983 Oakland County alcohol enforcement/education project. Ann Arbor (MI): Transportation Research Institute; 1984 Jul. Report No.: UMTRI-84-32.

\section{Zador 1976 \{published data only\}}

Johnson P, Levy P, Voas R. A critique of the paper "statistical evaluation of the effectiveness of alcohol safety action". Accident Analysis \& Prevention 1976;8:67-77.

Levy P, Voas R, Johnson P, Klein TM. An evaluation of the department of transportation's alcohol safety action projects. Journal of Safety Research 1978;10(4):162-76.

National Highway Traffic Safety Administration. Alcohol safety action projects: evaluation of operations- 
1974: Volume II, detailed analysis. Washington (DC): Department of Transportation, Office of Driver and Pedestrian Programs; 1974. Report No.: DOT HS-801 726.

National Highway Traffic Safety Administration. Summary of national alcohol safety action projects. Washington (DC): Department of Transportation, National Highway Traffic Safety Administration; 1979. Report No.: DOT-HS 804032.

National Highway Traffic Safety Administration, Office of Alcohol Countermeasures. Alcohol safety action projects: evaluation of operations, 1972. Washington (DC): U.S. National Highway Traffic Safety Administration Office of Alcohol Countermeasures; 1972; Report Nos. : DOT HS$800973,-800874$.

National Highway Transportation Safety Administration. Alcohol safety action projects evaluation methodology and overall program impact. Washington (DC): Department of Transportation, National Highway Traffic Safety Administration; 1979 Apr. Report No.: DOT HS-803 896. Zador P. A rejoinder to "a critique of the paper 'statistical evaluation of the effectiveness of alcohol safety action programs' by Johnson et al.". Accident Analysis \& Prevention 1977;9:15-9.

Zador P. Statistical evaluation of the effectiveness of "alcohol safety action projects”. Accident Analysis \& Prevention 1976; 8:51-66.

* Zador P. Statistical evaluation of the effectiveness of "alcohol safety programs". Washington (DC): Insurance Institute for Highway Safety; 1975.

\section{References to studies excluded from this review}

\section{Beirness 1997 \{published data only\}}

Beirness DJ, Foss RD, Mercer B. Roadside breath testing surveys to assess the impact of an enhanced DWI enforcement campaign in British Columbia. Alcohol, drugs and traffic safety - T'97: Proceedings of the 14th International Conference on Alcohol, Drugs and Traffic Safety; 1997 Sept 21-26; Annecy (FR). Annecy (FR): Centre d'Etudes et de Recherches en Médecine du Trafic, 1997.

\section{CA HWY Patrol 1972 \{published data only\}}

Operation 101: an accident and enforcement study. Sacramento (CA): State of California Department of California Highway Patrol; 1972 Apr. Report No.: CHP 772-300.

\section{CAAP 1988 \{published data only\}}

* Community alcohol action programme: Wanganui MayJuly 1987. Final report. Wellington (NZ): New Zealand Ministrry of Transport; 1988 Apr.

Bailey JPM. Community alcohol action drink driving programmes in New Zealand. Alcohol, Drugs and Traffic Safety, T92. Proceedings of the 12th International Conference on Alcohol, Drugs, and Traffic Safety; 1992 Sep 28 - Oct 2; Cologne (DE). 1993; Vol. 3:1422-30.
Calderwood 1986 \{published and unpublished data\}

* Calderwood R, Woods B. Impact evaluation of the breath alcohol testing mobile units (BAT mobiles) in Albuquerque, New Mexico. Traffic Safety Evaluation Research Review 1983;2(4):21-35.

Woods BD. Evaluation of innovative state and community alcohol projects: breath alcohol testing program effectiveness, impact and transferability. Washington (DC): National Highway Traffic Safety Administration, Department of Transportation; 1987 Mar. Report No.: DOT HS-807 124.

\section{Cameron 1981 \{published data only\}}

Cameron MH, Strang PM, Vulcan AP. Evaluation of random breath testing in Victoria, Australia. Proceedings of the 8th International Conference of Alcohol Drugs and Traffic Safety; 1980 Jun 15-19; Stockholm (SE). Stockholm (SE): Almqvist \& Winksell International, 1981; Vol. 3: 1364-81.

Castle 1996 \{published and unpublished data\} Castle SP, Woods BD, Davis JW, Romero I, Flint SF, Sewell CM. Outcome of a statewide sobriety checkpoint program. Proceedings of the 40th Annual Conference of the Association for the Advancement of Automotive Medicine. Vancouver, British Columbia, 1996:521-3.

\section{Clark 1982 \{published data only\}} Clark WE, Rockel HC. Maryland's effort to reduce drunk driving. Police Chief 1982;49:44-9.

\section{Cliff 2003 \{published data only\}} Cliff DM. Effective road policing in rural areas: an integrated approach. Proceedings of the road safety research, policing and education conference; 2003 Sept 24-26; Sydney (AU). Sydney (AU): Roads and Traffic Authority of NSW, 2003; Vol. 2:175-82.

\section{Cowart 1984 \{published data only\}}

Cowart GB. DWI countermeasures: avoid the 13. Police Chief 1984;51(7):35-7.

\section{Derby 1987 \{published data only\}}

Derby NM, Hurst PM. The effects of random stopping in New Zealand. Alcohol, drugs, and traffic safety T86. Proceedings of the 10th International Conference on Alcohol, Drugs and Traffic Safety; 1986 Sept 9-12; Amsterdam (NLD). New York: Excerpta Medica, 1987: 421-7.

\section{Diamantopoulou 2000 \{published data only\}} Diamantopoulou K. The effects of random breath testing operations and drink-driving publicity on alcohol-related crashes in rural areas. Alcohol, drugs and traffic safety- $T$ 2000. Proceedings of the 15th International Conference on Alcohol, Drugs, and Traffic Safety; 2000 May 22-26; Stockholm (SE). Stockholm (SE): ICADTS, 2000.

Epperlein 1987 \{published data only\} Epperlein T. Initial deterrent effects of the crackdown on drinking drivers in the state of Arizona. Accident Analysis and Prevention 1987;19(4):285-303. 
Finklestein 1971 \{published and unpublished data\}

Finklestein R. An optimum system for traffic enforcement/ driver control. Final report. GTE Sylvania Inc 1971; Vol. Vol 2.

\section{Glad 1997 \{published and unpublished data\}}

Glad A, Vaa T. Lower legal alcohol limit requires increased enforcement efforts [Lavere promillegrense krever mer kontroll]. Samferdsel; 1997 May.

Greenwood 1985 \{published data only\} Greenwood RE. A study of the widening and penetrating effects of a campaign against the folk crime of DUI [dissertation]. Univ. of Tennessee, 1984

Hocherman 1996 \{published and unpublished data\} Hocherman I, Zaidel D, Sheinfeld M, Hakkert S. Inherent operational limits to efficiency of urban traffic enforcement by police. Proceedings of the Conference Road Safety in Europe and Strategic Highway Research Program; 1995 Sep 20-22; Prague (CZ). Linkoping (SE): Swedish National Road and Transport Institute, 1996:271-2.

Homel 1987 \{published and unpublished data\} Homel R. Deterring the drinking driver: a theoretical model of the process. Alcohol, drugs, and traffic safety T86. Proceedings of the 10th International Conference on Alcohol, Drugs and Traffic Safety; 1986 Sept 9-12; Amsterdam (NLD). New York: Excerpta Medica, 1987: 443-6.

\section{Homel 1995 \{published and unpublished data\}}

Homel R, McKay P, Henstridge J. The impact on accidents of random breath testing in New South Wales: 1982-1992. Alcohol, drugs, and traffic safety, T'95: Proceedings of the 13th International Conference on Alcohol, Drugs, and Traffic Safety; 1995 Aug 13-18; Adelaide (AU). Adelaide (AU): NHMRC Road Accident Research Unit, University of Adelaide, 1995; Vol. 2:849-55.

Kearns 1984 \{published data only\}

Kearns IB, Goldsmith HJ. The impact on traffic crashes of the introduction of random breath testing in New South Wales. The 12th ARRB Conference; 1984 Aug 27-31; Hobart (TAS). Vermont South, Victoria: Australian Road Research Board, 1984; Vol. 12:81-95.

Kearns 1987 \{published data only\} Kearns IB, Vazey B, Carseldine D, Arthurson R. An overview of the random breath testing trial in New South Wales. Alcohol, Drugs, and Traffic Safety - T86. Proceedings of the 10th International Conference on Alcohol, Drugs and Traffic Safety; 1986 Sept 9-12; Amsterdam (NL). Amsterdam: Excerpta Medica, 1987:429-32.

Maher 1983 \{published data only\} Maher GM. Streamlining drunk driving enforcement. Police Chief 1983;50(12):60.

Mastrofski 1990 \{published data only\} Mastrofski SR, Ritti RR, Snipes J. Organization theory and police arrests: Expectancy theory and police productivity in DUI enforcement. Law and Society Review 1994;28: $113-48$.
Mathijssen 1992 \{published data only\}

Mathijssen R, Wesemann P. The role of police enforcement in the decrease of DWI in The Netherlands, 1983-1991. Alcohol, Drugs and Traffic Safety, T92: Proceedings of the 12th International Conference on Alcohol, Drugs, and Traffic Safety; 1992 Sept 28 - Oct 2; Cologne (DE). Cologne (DE): Verlag TUV Rheinland, 1993; Vol. 3: 1216-22.

Mathijssen 2001 \{published and unpublished data\} Mathijssen MPM. Drink-driving and police enforcement in the Netherlands: pre-test carried out in 1999/2000 to determine the effects of future enhanced police enforcement, accompanied by recommendations for the organisation of enforcement [Rijden onder invloed in Nederland en het politietoezicht daarop: voormeting uitgevoerd in 1999/ 2000 ter bepaling van de effecten van toekomstig verhoogd politietoezicht, vergezeld van aanbevelingen voor de inrichting van het toezicht]. Leidschendam (NL): Stichting Wetenschappelijk Onderzoek Verkeersveiligheid SWOV; 2001. Report No.: R-2001-8.

Mathijssen 2004 \{published and unpublished data\} Mathijssen MPM, de Craen S. Evaluation of the regional traffic enforcement plans: effects of intensified police surveillance on traffic behaviour and road safety [Evaluatie van de regionale verkeershandhavingsplannen: effecten van geintensiveerd politietoezicht op verkeersgedrag en verkeersonveiligheid]. Leidschendam (NL): Stichting Wetenschappelijk Onderzoek Verkeersveiligheid SWOV; 2004. Report No.: R-2004-4.

McCartt 1985 \{published and unpublished data\}

Foley D. Case study in DWI countermeasures. STOP DWI successful community responses to drunk driving. Lexington Books, 1986:33-54.

Friedman J. Analysis/discussion: accident trends since initiation of the special traffic options program for driving while intoxicated (STOP DWI) in New York state. Office of Alcohol and Highway Safety; 1983 Apr.

Legge JS. Traffic safety reform in the United States and Great Britain. University of Pittsburg Press, 1991.

* McCartt. An impact evaluation of the New York state STOP DWI program. Institute for Traffic Safety Management and Research; 1985.

Passidomo JA, McEwen HR. New York state's STOP DWI program. Police Chief 1984;51(7):50-1.

Mercer 1985 \{published and unpublished data\} Mercer GW. The relationships among driving while impaired charges, police drinking-driving roadcheck activity, media coverage and alcohol-related casualty traffic accidents. Accident Analysis and Prevention 1985;17(6): 467-74.

Mercer 1989 \{published and unpublished data\} Mercer GW. CounterAttack traffic research papers, 1988. Ministry of Labour and Consumer Services; 1989.

Miller 2004 \{published data only\}

Miller T, Blewden M, Zhang J-f. Cost savings from a sustained compulsory breath testing and media campaign 
in New Zealand. Accident Analysis and Prevention 2004;36: 783-94.

Mäki 1987 \{published and unpublished data\}

Mäki M. Integrated method of information and enforcement as a traffic safety method [Tiedotuksen ja liikennevalvonnan yhteensovittaminen liikenneturvallisuustyon menetelmana oulun seudulla]. Liikenneturvan Tutkimuksia 1987.

O'Connell 1983 \{published data only\}

O'Connell JP, Chadwick JR. DWI impact study: state of Washington 1977-1982. A study of the relationship between DWI enforcement and alcohol-related driving accidents. Olympia (WA): Washington State, Office of Financial Management, Forecasting and Estimation Division; 1983.

Price 1993 \{published data only\}

Price EJ. Local official's guide to drunk driving prevention. Washington DC: National League of Cities; 1993.

Rodriguez 2002 \{published data only\}

Rodriguez L. Communicating higway safety: what works. Report and executive summary. Ames (IA): Center for Transportation Research and Education, Iowa State University; 2002 Feb.

Ross 1987 \{published data only\}

Ross HL. Britain's Christmas crusade against drinking and driving. Alcohol, drugs, and traffic safety - T86. Proceedings of the 10th International Conference on Alcohol, Drugs and Traffic Safety; 1986 Sept 9-12; Amsterdam (NLD). New York: Excerpta Medica, 1987: $625-8$.

Savell 1984 \{published data only\}

Savell L. Proactive Dallas programs curb traffic deaths. Police Chief 1984;51(7):55-7.

Sharp 2002 \{published data only\} Sharp A. Curbing DUI. Law and Order 2002;50:129-32.

SMI 1976 \{published data only\}

Final evaluation report on the North Dakota selective traffic enforcement program (STEP). Safety Management Institute; 1976. Report No.: DOT HS 801874.

Thomson 1984 \{published data only\}

Thomson J, Mavrolefterou K. Assessing the effectiveness of random breath testing. The 12th ARRB Conference; 1984 Aug 27-31; Hobart (TAS). Vermont South, Victoria: Australian Road Research Board, 1984:72-80.

Verschuur 1988 \{published and unpublished data\} Verschuur W, Noordzij P. Random breath testing on a small scale. In: Rothengatter T, de Bruin R editor(s). Road user behaviour: theory and research. Assen/Maastricht (NLD): Van Gorcum, 1988:396-402.

Vingilis 1980 \{published data only\} Vingilis E, Salutin L. A prevention programme for drinking driving. Accident Analysis and Prevention 1980;12:267-74.

Vingilis 1981 \{published data only\}

Vingilis E, Chung L, Adlaf E. An evaluation of a prevention programme for drinking-driving called reduce impaired driving in Etobicoke (RIDE). 8th International Conference on Alcohol, Drugs and Traffic Safety. Stockholm, 1981; Vol. 3:1259-70.

Votey 1978 \{published data only\}

Votey HL. The deterrence of drunken driving accidents in Norway: an econometric analysis of existing policies. Drinking and driving in Scandinavia. New York: Columbia University Press, 1978:79-99.

Votey 1982 \{published data only\}

Votey HL. Scandanavian drinking-driving control: myth or intuition?. Journal of Legal Studies 1982;11:93-116.

Votey 1984 \{published data only\}

Votey HL. Recent evidence from Scandinavia on deterring alcohol impaired driving. Accident Analysis and Prevention 1984;16(2):123-38.

\section{Webb 1981 \{published and unpublished data\}}

Webb P. Evaluation of the California highway patrol's 1980 public information campaign to reduce driving under the influence. Final Report. Menlo Park (CA): Crain \& Associates; 1981 Mar. Final report.

Weiss 1996 \{published data only\}

Weiss A, Freels S. The effects of aggressive policing: the Dayton traffic enforcement experiment. American Journal of Police 1996;15(3):44-64.

White 2002 \{published data only\}

White M, Walker J. Update and overview of research on the effectiveness of the Victorian Transport Accident Commission's road safety television advertising campaigns. Walkerville (South Australia): Safety Strategy, Transport SA, South Australia; 2002 Dec.

\section{Williams 1995 \{published data only\}} Williams AF, Wells JK, Foss RD. The North Carolina governor's highway safety initiative: initial results from "booze it and lose it". Alcohol, drugs, and traffic safety, T'95: Proceedings of the 13th International Conference on Alcohol, Drugs, and Traffic Safety; 1995 Aug 13-18; Adelaide (AU). Adelaide (AU): NHMRC Road Accident Research Unit, University of Adelaide, 1995; Vol. 1: 347-51.

Wright 1989 \{published and unpublished data\} Wright SKB. Minnesota community traffic safety project. Final Report. St Paul (MN): Minnesota University; 1989.

Youngman 1988 \{published data only\} Youngman JHR. The Victorian myth: an examination of the effectiveness of drink driving countermeasures. Road Traffic Safety Seminar: seminar papers; 1988 Sept 14-16; Wellington (NZ). Wellington (NZ): Road Traffic Safety Research Council, 1988; Vol. 2:205-22.

\section{References to studies awaiting assessment}

Blais 2005 \{published data only\}

Blais E, Ouimet M. The Effect of Legal Interventions on Fatal Accidents and Associated to Driving While Impaired by Alcohol (Dwi) in Quebec Between 1980 and 2001 [Leffet des interventions legales sur les accidents mortels et associes a la conduite avec facultes affaiblies au Quebec 
entre 1980 et 2001]. Canadian Journal of Criminology and Criminal Justice 2005;47(3):545-78.

Carso 1984 \{published and unpublished data\}

Carso MP, Hoffman HJ. Alcohol selective traffic enforcement planning. Police Chief 1984;51(7):52-4.

Clapp 2005 \{published data only\}

Clapp JD, Johnson C, Voas RB, Lange JE, Shillington A, Russell C. Reducing DUI among US college students: results of an environmental prevention trial. Addiction 2005;100(3):327-34.

Fell 2005 \{published data only\}

* Fell JC, Langston EA, Lacey JH, Tippetts AS. Cotton R. Evaluation of Seven Publicized Enforcement Demonstration Programs to Reduce Impaired Driving: Georgia, Louisiana, Pennsylvania, Tennessee, Texas, Indiana. Pacific Institute for Research and Evaluation; September 2008. Draft report. Fell JC, Langston EA, Tippetts AS. Evaluation of four state impaired driving enforcement demonstration programs: Georgia, Tennessee, Pennsylvania and Louisiana. Annual Proceedings/Association for the Advancement of Automotive Medicine 2005;49:311-26.

LHSC 2002 \{published data only\}

Louisiana Highway Safety Commission. Targets of opportunity: state demonstration program for reducing impaired driving. Final report. Baton Rouge (LA): Louisiana Highway Safety Commission; 2002.

\section{NMDOH 2000 \{published data only\}}

New Mexico Department of Health. Draft: New Mexico Operation DWI and Operation Buckle Down evaluation: final project report. New Mexico Department of Health Public Health Division, Office of Epidemiology; 2000 Jan.

Tay 2005a \{published data only\}

Tay R. The effectiveness of enforcement and publicity campaigns on serious crashes involving young male drivers: Are drink driving and speeding similar?. Accident Analysis and Prevention 2005;37(5):922-9.

Tay 2005b \{published data only\}

Tay RS. Deterrent effects of drink driving enforcement: some evidence from New Zealand. International Journal of Transport Economics 2005;32(1):103-9.

* Tay RS. General and specific deterrent effects of traffic enforcement. Do we have to catch offenders to reduce crashes?. Journal of Transportation Economics and Policy 2005;39(2):209-23.

\section{Additional references}

\section{Aaserud 2006}

Aaserud M, Dahlgren AT, Kösters JP, Oxman AD, Ramsay C, Sturm H. Pharmaceutical policies: effects of reference pricing, other pricing, and purchasing policies. Cochrane Database of Systematic Reviews 2006, Issue 2. [DOI: 10.1002/14651858.CD005979]

\section{Aeron-Thomas 2005}

Aeron-Thomas AS, Hess S. Red-light cameras for the prevention of road traffic crashes. Cochrane Database of Systematic Reviews 2005, Issue 2. [DOI: 10.1002/

14651858.CD003862.pub2]

\section{Berlin 1997}

Berlin JA. Does blinding of readers affect the results of meta-analyses?. Lancet 1997;350:185-6.

\section{Blomberg 2005}

Blomberg R, Peck RC, Moskowitz H, Burns M, Fiorentino D. Crash risk of alcohol involved driving: a case-control study. Stamford (CT): Dunlap and Associates, Inc.; 2005 Sept. Final Report.

\section{Bunn 2003}

Bunn F, Collier T, Frost C, Ker K, Roberts I, Wentz R. Areawide traffic calming for preventing traffic related injuries. Cochrane Database of Systematic Reviews 2003, Issue 1. [DOI: 10.1002/14651858.CD003110]

\section{Campbell 1966}

Campbell DT, Stanley JC. Experimental and quasiexperimental designs for research. Chicago: Rand McNally, 1966.

Chan 2004

Chan A-W, Hróbjartsson A, Haahr MT, Gøtzsche PC, Altman DG. Empirical evidence for selective reporting of outcomes in randomized trials: comparison of protocols to published articles. JAMA 2004;291:2457-65.

Chan 2005

Chan A-W, Altman DG. Identifying outcome reporting bias in randomised trials on PubMed: review of publications and survey of authors. BMJ 2005;330(7494):753. [: 10.1136/ bmj.38356.424606.8F]

Chou 2006

Chou SP, Dawson DA, Stinson FS, Huang B, Pickering $\mathrm{RP}$, Zhou Y, et al.The prevalence of drinking and driving in the United States, 2001-2002: results from the national epidemiological survey on alcohol and related conditions. Drug and Alcohol Dependence 2006;83(2):137-46.

\section{Cook 1979}

Cook TD, Campbell DT. Quasi-experimentation : design \& analysis issues for field settings. Chicago: Rand McNally, 1979.

\section{Davis 2003}

Davis A, Quimby A, Odero W, Gururaj G, Hijar M. Improving road safety by reducing impaired driving in developing countries: a scoping study. Unpublished Project Report PR/INT/724/03. http://www.i-connect.ch/grsp/ grspdev/pdfs/Impaired driving full report.pdf (accessed 31 January 2007).

Elder 2004

Elder RW, Shults RA, Sleet DA, Nichols JL, Thompson RS, Rajab W. Effectiveness of mass media campaigns for reducing drinking and driving and alcohol-involved crashes: A systematic review. American Journal of Preventive Medicine 2004;27(1):57-65.

\section{EPOC 2002}

Cochrane Effective Practice and Organisation of Care Review Group. The Data Collection Checklist. http: 
//www.epoc.uottawa.ca/checklist2002.doc 2002:1-25.

Retrieved online Nov. 25, 2004.

\section{ETSC 1995}

European Transport Safety Council. Reducing injuries from alcohol impairment. Brussels: European Transport Safety Council, 1995.

\section{Fell 2004}

Fell JC, Lacey JH, Voas RB. Sobriety checkpoints: evidence of effectiveness is strong, but use is limited. Traffic Injury Prevention 2004;5:220-7.

\section{Gledec 2004}

Gledec M. The presence of alcohol in Croatian road traffic. Proceedings of the 15th International Conference on Alcohol, Drugs and Traffic Medicine. Stockholm, 2004.

\section{Grilli 1993}

Grilli R, Oxman AD, Julian JA. Chemotherapy for advanced non-small-cell lung cancer: how much benefit is enough? Journal of Clinical Oncology 1993;11(10):1866-72.

\section{Grilli 2002}

Grilli R, Ramsay C, Minozzi S. Mass media interventions: effects on health services utilisation. Cochrane Database of Systematic Reviews 2002, Issue 1. [DOI: 10.1002/ 14651858.CD000389]

\section{Gururaj 2004}

Gururaj G. The effect of alcohol on incidence, pattern, severity and outcome from traumatic brain injury. Journal of the Indian Medical Association 2004;3(102):157-61.

\section{Homel 1988}

Homel RJ. Random breath testing in Australia: a complex deterrent. Australian Drug and Alcohol Review. 1988;7: $231-41$.

\section{Liberati 1986}

Liberati A, Himel HN, Chalmers TC. A quality assessment of randomized control trials of primary treatment of breast cancer. Journal of Clinical Oncology 1986;4(6):942-51.

\section{Mock 2001}

Mock CN, Asiamah G, Amegashie J. A random, roadside breathalyzer survey of alcohol impaired drivers in Ghana. Journal of Crash Prevention and Injury Control 2001;2: 193-202.

\section{NHTSA 2005}

National Highway Traffic Safety Administration. Traffic safety facts 2004. Washington (DC): National Highway Traffic Safety Administration, National Center for Statistics and Analysis; 2005. Report No.: DOT HS-809 919.

\section{NIAAA 2000}

National Institute on Alcohol Abuse and Alcoholism. The alcohol and other drug thesaurus: a guide to concepts and terminology in substance abuse and addiction. 3rd Edition. Washington, DC: US Department of Health and Human Services, 2000.

\section{Peden 2002}

Peden M, McGee K, Krug E (Eds). Injury: A leading cause of the global burden of disease, 2000. Geneva: World Health Organization; 2002.

\section{Peden 2004}

Peden M, Scurfield R, Sleet D, Mohan D, Hyder AA, Jarawan E, et al.World Report on Road Traffic Injury Prevention. Geneva: World Health Organization; 2004.

\section{Peek-Asa 1999}

Peek-Asa C. The effect of random alcohol screening in reducing motor vehicle crash injuries. American Journal of Preventive Medicine 1999;16 Suppl 1:57-67.

\section{Ramsay 2003}

Ramsay CR, Matowe L, Grilli R, Grimshaw JM, Thomas RE. Interrupted time series designs in health technology assessment: lessons from two systematic reviews of behavior change strategies. International Journal of Technology Assessment in Health Care 2003;19:613-23.

\section{Ross 1984}

Ross HL. Deterring the drinking driver: Legal policy and social control. Lexington, MA: Lexington Books, 1984.

\section{Shults 2001}

Shults RA, Elder RW, Sleet DA, Nichols JL, Alao MO, Carande-Kulis VG, et al.Reviews of evidence regarding interventions to reduce alcohol-impaired driving. American Journal of Preventive Medicine 2001;21 Suppl 4:66-88.

\section{Sweedler 1995}

Sweedler, BM. Strategies for dealing with the persistent drinking driver. Alcohol, drugs, and traffic safety, T'95: Proceedings of the 13th International Conference on Alcohol, Drugs, and Traffic Safety; 1995 Aug 13-18; Adelaide (AU). Adelaide (AU): NHMRC Road Accident Research Unit, University of Adelaide, 1995; Vol. 2: 859-66.

\section{TRL 2006}

Blood alcohol levels in road accident fatalities for 2004 in Great Britain. Transport Research Library; 2006 Oct. Reference No.: LF 2098.

\section{Voas 1990}

Voas RB, Lacey JH. Drunk driving enforcement, adjudication, and sanctions in the United States. In: Wilson RJ, Mann RE editor(s). Drinking and driving: advances in research and prevention. New York: The Guilford Press, 1990:116-57.

Voas 1991

Voas RB. Enforcement of DUI laws. Alcohol, Drugs, and Driving 1991;7(3-4):173-96.

\section{Wagenaar 1995}

Wagenaar AC, Zobeck TS, Wililams GD, Hingson R. Methods used in studies of drink-drive control efforts: a meta-analysis of the literature from 1960 to 1961. Accident Analysis and Prevention 1995;27(3):307-16.

\section{Waller 1986}

Waller PF, Stewart JR, Hansen AR, Stutts JC, Popkin CL, Rodgman EA. The potentiating effects of alcohol on driver injury. JAMA 1986;256:1461-6.

\section{Zobeck 1994}

Zobeck TS, Williams GD. Evaluation synthesis of the impacts of DWI laws and enforcement methods. 
Washington (DC): CSR Incorporated; 1994 Apr. Final Report.

* Indicates the major publication for the study

Increased police patrols for preventing alcohol-impaired driving (Review)

Copyright $\odot 2008$ The Cochrane Collaboration. Published by John Wiley \& Sons, Ltd. 


\section{CHARACTERISTICS OF STUDIES}

\section{Characteristics of included studies [ordered by study ID]}

\section{Aden 1981}

\begin{tabular}{|c|c|c|}
\hline Methods & \multicolumn{2}{|c|}{$\begin{array}{l}\text { Design: ITS } \\
\text { Intervention occurred independently of other changes over time: NOT CLEAR } \\
\text { Intervention unlikely to affect data collection: NOT CLEAR } \\
\text { Rationale given for number of pre/post time points OR sample size calculation performed: NOT ADE- } \\
\text { QUATE } \\
\text { Rational explanation for effect shape: ADEQUATE }\end{array}$} \\
\hline Participants & \multicolumn{2}{|c|}{ Town $($ population $=75,000)$} \\
\hline Interventions & \multicolumn{2}{|c|}{$\begin{array}{l}\text { Targeted DUI only; New officers hired, regular officers reassigned; Daily patrols; 24-month duration; } \\
\text { Media campaign, training and equipment for police, school- and community-based public information } \\
\text { and education }\end{array}$} \\
\hline Outcomes & \multicolumn{2}{|c|}{$\begin{array}{l}\text { Selected primary outcomes: } \\
\text { Number of fatal crashes, all types combined } \\
\text { Number of injury crashes, all types combined } \\
\text { Number of total crashes, all types combined } \\
\text { Also measured property damage crashes (all types combined), DUI arrests, DUI citations, total citations, } \\
\text { speeding citations, and other traffic citations }\end{array}$} \\
\hline Notes & \multicolumn{2}{|c|}{$\begin{array}{l}\text { USA } \\
\text { ITS based on } 4 \text { observations before and } 7 \text { after the intervention; quarterly data }\end{array}$} \\
\hline \multicolumn{3}{|l|}{ Risk of bias } \\
\hline Item & Authors' judgement & Description \\
\hline Allocation concealment? & Unclear & D - Not used \\
\hline
\end{tabular}

\section{Amick 1984}

\begin{tabular}{l|l}
\hline Methods & Design: CITS \\
& Government agency assigned intervention \\
& Baseline outcomes similar: NOT ADEQUATE \\
& Other baseline characteristics similar: ADEQUATE \\
& Contamination not likely: ADEQUATE \\
& Intervention occurred independently of other changes over time: N/A \\
& Intervention unlikely to affect data collection: NOT CLEAR \\
& Rationale given for number of pre/post time points OR sample size calculation performed: ADEQUATE \\
& Rational explanation for effect shape: ADEQUATE \\
\hline Participants & $\begin{array}{l}\text { I) County (population=65,980) } \\
\text { C1) County (population }=65,421)\end{array}$ \\
\hline $\begin{array}{l}\text { Increased police patrols for preventing alcohol-impaired driving (Review) } \\
\text { Copyright } \odot \mathbf{2 0 0 8} \text { The Cochrane Collaboration. Published by John Wiley \& Sons, Ltd. }\end{array}$
\end{tabular}


Amick 1984 (Continued)

C2) County (population $=52,927)$

\begin{tabular}{|c|c|c|}
\hline Interventions & \multicolumn{2}{|c|}{$\begin{array}{l}\text { I) Targeted DUI only; New officers hired; Weekly patrols; } 15 \text {-month duration; Training and equipment for } \\
\text { police, community based-public information and education, media coverage, coordination of sentencing/ } \\
\text { parole processes, rehabilitation programs. } \\
\text { C1) No intervention. } \\
\text { C2) No intervention. }\end{array}$} \\
\hline Outcomes & \multicolumn{2}{|c|}{$\begin{array}{l}\text { Selected primary outcomes: } \\
\text { Number of injury crashes, night time } \\
\text { Also measured injury crashes (daytime) and DUI arrests }\end{array}$} \\
\hline Notes & \multicolumn{2}{|c|}{$\begin{array}{l}\text { USA } \\
\text { CITS based on } 57 \text { observations before and } 15 \text { after the intervention; monthly data }\end{array}$} \\
\hline \multicolumn{3}{|l|}{ Risk of bias } \\
\hline Item & Authors' judgement & Description \\
\hline Allocation concealment? & Unclear & D - Not used \\
\hline
\end{tabular}

\section{Brackett 1983}

\begin{tabular}{|c|c|}
\hline Methods & $\begin{array}{l}\text { Design: CBA } \\
\text { Government agency assigned intervention } \\
\text { Baseline outcomes similar: NOT ADEQUATE } \\
\text { Other baseline characteristics similar: NOT CLEAR } \\
\text { Contamination not likely: NOT ADEQUATE }\end{array}$ \\
\hline Participants & $\begin{array}{l}\text { I) } 18 \text { counties (population not specified) } \\
\text { C) Entire state (population not specified) }\end{array}$ \\
\hline Interventions & $\begin{array}{l}\text { I) Targeted DUI only; Officers worked overtime; Weekend patrols; 3-month duration; School- and } \\
\text { community-based public information and education. } \\
\text { C) No intervention. }\end{array}$ \\
\hline Outcomes & $\begin{array}{l}\text { Selected primary outcomes: } \\
\text { Number of fatal crashes, alcohol-related } \\
\text { Number of injury crashes, alcohol-related } \\
\text { Number of total crashes, alcohol-related } \\
\text { Also measured fatal crashes (single vehicle night time, all types combined), non-fatal crashes (single vehicle } \\
\text { night time, all types combined), total crashes (single vehicle night time, all types combined), property } \\
\text { damage crashes (alcohol-related, single vehicle night time, all types combined), DUI arrests, other arrests } \\
\text { (non-DUI), all traffic warnings, and DUI citations issued under normal enforcement }\end{array}$ \\
\hline Notes & USA \\
\hline
\end{tabular}

Risk of bias

Increased police patrols for preventing alcohol-impaired driving (Review) 
Brackett 1983 (Continued)

\begin{tabular}{lll}
\hline Item & Authors' judgement & Description \\
\hline Allocation concealment? & Unclear & D - Not used \\
\hline
\end{tabular}

\section{Campbell 1981}

\begin{tabular}{|c|c|c|}
\hline Methods & \multicolumn{2}{|c|}{$\begin{array}{l}\text { Design: CITS } \\
\text { Government agency assigned intervention } \\
\text { Baseline outcomes similar: NOT CLEAR } \\
\text { Other baseline characteristics similar: ADEQUATE } \\
\text { Contamination not likely: NOT CLEAR } \\
\text { Intervention occurred independently of other changes over time: NOT APPLICABLE } \\
\text { Intervention unlikely to affect data collection: NOT CLEAR } \\
\text { Rationale given for number of pre/post timepoints OR sample size calculation performed: NOT ADE- } \\
\text { QUATE } \\
\text { Rational explanation for effect shape: ADEQUATE }\end{array}$} \\
\hline Participants & \multicolumn{2}{|c|}{$\begin{array}{l}\text { I) } 17 \text { cities (population not specified) } \\
\text { C) } 11 \text { cities (population not specified) }\end{array}$} \\
\hline Interventions & \multicolumn{2}{|c|}{$\begin{array}{l}\text { I) Targeted DUI, speeding, all accidents, or all moving violations, depending on intervention city; New } \\
\text { officers hired, officers worked overtime, or regular officers reassigned, depending on intervention city; } \\
\text { Patrol frequency not specified; Program duration varied from } 12 \text { to } 48 \text { months. } \\
\text { C) No intervention. }\end{array}$} \\
\hline Outcomes & \multicolumn{2}{|c|}{$\begin{array}{l}\text { Selected primary outcomes: } \\
\text { Number of total crashes, alcohol-related } \\
\text { Also measured total crashes (speeding, all types combined) }\end{array}$} \\
\hline Notes & \multicolumn{2}{|c|}{$\begin{array}{l}\text { USA } \\
\text { ITS with varying number of timepoints before and after the intervention; quarterly data }\end{array}$} \\
\hline \multicolumn{3}{|l|}{ Risk of bias } \\
\hline Item & Authors' judgement & Description \\
\hline Allocation concealment? & Unclear & D - Not used \\
\hline
\end{tabular}




\begin{tabular}{ll} 
Methods & $\begin{array}{l}\text { Design: CBA } \\
\text { Police department assigned intervention } \\
\text { Baseline outcomes similar: ADEQUATE } \\
\text { Other baseline characteristics similar: ADEQUATE } \\
\text { Contamination not likely: NOT CLEAR }\end{array}$ \\
\hline Participants & $\begin{array}{l}\text { I) Divisional area (population not specified), rural and urban areas } \\
\text { C) Divisional area (population not specified), rural and urban areas }\end{array}$ \\
\hline Interventions & $\begin{array}{l}\text { I) Targeted DUI, speeding, seat-belt enforcement; New officers hired; Patrol frequency not specified; } 12- \\
\text { month duration; Local media campaign, community-based public information and education, national } \\
\text { media campaign. } \\
\text { C) Community based public information and education, national media campaign only }\end{array}$
\end{tabular}

Selected primary outcomes:
Number of fatalities, traffic crashes
Number of serious and minor injuries, traffic crashes
Rates of total crashes per 1000 registered vehicles, all types combined
Rates of total crashes per 1000 population, all types combined
Rates of total crashes per 10 million VKT, all types combined
Also measured hospital presentations (traffic crashes), hospitalizations or transfers (traffic crashes), fatal
crashes (speeding-related), injury crashes (speeding-related), DUI detections, speeding detections, traffic
offenses, and prosecutions for non-wearing of seat belts

Notes Ireland

\section{Risk of bias}

\begin{tabular}{lll}
\hline Item & Author' judgement & Description \\
\hline Allocation concealment? & Unclear & D - Not used \\
\hline
\end{tabular}

Harrison 2001

\begin{tabular}{l|l} 
Methods & Design: RCT \\
& Investigators assigned intervention by coin toss \\
& Baseline outcomes similar: ADEQUATE \\
Contamination not likely: ADEQUATE \\
80-100\% Follow-up: NOT ADEQUATE
\end{tabular}

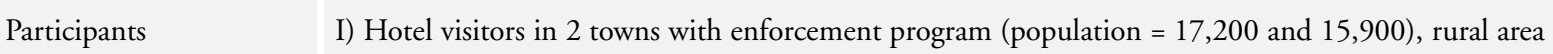
C) Hotel visitors in 2 towns without enforcement program (population $=14,500$ and 14,500), rural area

Interventions

I) Targeted DUI only; Recruited police from outside experimental and control communities; Sporadic patrols ( 3 weekends); 2-month duration; Random breath testing and foot patrols were added during the second and third enforcement weekends.

C) No intervention. 


\section{Harrison 2001 (Continued)}

\begin{tabular}{|c|c|c|}
\hline Outcomes & \multicolumn{2}{|c|}{$\begin{array}{l}\text { Selected primary outcomes: } \\
\text { None } \\
\text { Also measured self-reported alcohol-impaired driving }\end{array}$} \\
\hline Notes & \multicolumn{2}{|l|}{ Australia } \\
\hline \multicolumn{3}{|l|}{ Risk of bias } \\
\hline Item & Authors' judgement & Description \\
\hline Allocation concealment? & Yes & A - Adequate \\
\hline
\end{tabular}

Hingson 1996

\begin{tabular}{ll} 
Methods & $\begin{array}{l}\text { Design: CBA } \\
\text { Government agency assigned intervention } \\
\text { Baseline outcomes similar: NOT CLEAR } \\
\text { Other baseline characteristics similar: ADEQUATE } \\
\text { Contamination not likely: NOT CLEAR }\end{array}$ \\
\hline Participants & I) 6 cities (population $=318,974)$ \\
C1) 5 cities (population $=378,666)$ \\
C2) State, excluding intervention cities (population $=5,318,785)$
\end{tabular}

Interventions

I) Target, officer staffing, and patrol frequency not specified; 60-month duration; Training for police, media campaign, public advocacy/grassroots, school- and community-based public information and education, beer keg registration, liquor outlet surveillance.

C1) Traditional police enforcement and school programs concerning traffic safety.

C2) No intervention.

\begin{tabular}{ll}
\hline Outcomes & Selected primary outcomes: \\
& Rate of total injuries per 100 traffic crashes \\
& Number of fatal crashes, alcohol-related \\
& $\begin{array}{l}\text { Also measured pedestrian fatalities, visible injuries (traffic crashes), pedestrian injuries (traffic crashes), } \\
\text { fatal crashes (on local roadways, among drivers ages 15-25, involving speeding, all types combined), DUI } \\
\text { citations, speeding citations, and total traffic citations }\end{array}$ \\
\hline Notes & USA \\
\hline
\end{tabular}

\section{Risk of bias}

\begin{tabular}{|c|c|c|}
\hline Item & Authors' judgement & Description \\
\hline Allocation concealment? & Unclear & D - Not used \\
\hline
\end{tabular}


Intervention occurred independently of other changes over time: NOT ADEQUATE

Intervention unlikely to affect data collection: NOT CLEAR

Rationale given for number of pre/post timepoints OR sample size calculation performed (hospitalizations, proportion injury crashes): NOT ADEQUATE

Rationale given for number of pre/post timepoints OR sample size calculation performed (fatalities, number injury crashes): ADEQUATE

Rational explanation for effect shape: ADEQUATE

Participants Country (population not specified)

Interventions $\quad$ Targeted DUI only; Regular officers reassigned; Regular patrols conducted, exact frequency not specified; 1.5-month duration; Roadside breath tests, media campaign, drinking and driving laws

Outcomes $\quad$ Selected primary outcomes:

Number of fatalities, night-time traffic crashes

Number of hospitalizations, traffic crash injuries

Proportion of night-time injury crashes

Number of injury crashes, night time

Also measured proportion of single vehicle crashes, accident compensation claims for road injuries (night time, total)

New Zealand.
ITS for fatalities based on 18 observations before and 12 observations after the intervention; monthly
data.
ITS for hospitalizations based on 5 observations before and 5 after the intervention; fortnightly data.
ITS for proportion of injury crashes based on 16 observations before and 10 observations after the
intervention; monthly data.
ITS for number of injury crashes based on 27 observations before and 21 after the intervention; monthly
data

Risk of bias

\begin{tabular}{|c|c|c|}
\hline Item & Authors' judgement & Description \\
\hline Allocation concealment? & Unclear & D - Not used \\
\hline
\end{tabular}

Jansma 1978

$\begin{array}{ll}\text { Methods } & \text { Design: CBA } \\ \text { Government agency assigned intervention } \\ \text { Baseline outcomes similar: NOT ADEQUATE } \\ \text { Other baseline characteristics similar: NOT CLEAR } \\ \text { Contamination not likely: NOT CLEAR }\end{array}$




\begin{tabular}{|c|c|c|}
\hline Interventions & \multicolumn{2}{|c|}{$\begin{array}{l}\text { I) Targeted DUI Only; Officers worked overtime; Patrols emphasized holiday period; 1-month duration; } \\
\text { Media campaign, community-based public information and education. } \\
\text { C) No intervention. }\end{array}$} \\
\hline Outcomes & \multicolumn{2}{|l|}{$\begin{array}{l}\text { Selected primary outcomes: } \\
\text { Number of total crashes, alcohol-related } \\
\text { Also measured DUI arrests }\end{array}$} \\
\hline Notes & \multicolumn{2}{|l|}{ USA } \\
\hline \multicolumn{3}{|l|}{ Risk of bias } \\
\hline Item & Authors' judgement & Description \\
\hline Allocation concealment? & Unclear & D - Not used \\
\hline
\end{tabular}

\section{Jones 1995a}

\begin{tabular}{l} 
Design: CITS \\
National Highway Transportation Safety Administration \\
Baseline outcomes similar: ADEQUATE \\
Other baseline characteristics similar: ADEQUATE \\
Contamination not likely: ADEQUATE \\
Intervention occurred independently of other changes \\
Intervention unlikely to affect data collection: NOT C \\
Rationale given for number of pre/post timepoints OR \\
ADEQUATE \\
Rationale given for number of pre/post timepoints \\
ADEQUATE \\
Rational explanation for effect shape: ADEQUATE \\
\hline I1) City (population $=336,000$ ), urban and rural area \\
\hline Participants \\
I2) City (population $=225,000$ ), urban and rural area \\
C) City (population $=285,000)$, urban and rural area
\end{tabular}

Interventions

I1) Targeted DUI, speeding and seat-belt enforcement; Regular officers reassigned; Patrols conducted at least weekly, as well as during holidays and special events; 12-month duration; Sobriety checkpoints, training for police, media campaign, public advocacy/grassroots, school- and community-based public information and education.

I2) Targeted DUI, speeding and seat-belt enforcement; Regular officers reassigned; Patrols conducted at least weekly, as well as during holidays and special events; 13-month duration; Training for police, schooland community-based public information and education, citizen reporting of DUI.

C) Community-based public information and education; Speed enforcement campaign during last 6 months of intervention period

Outcomes

Selected primary outcomes:

Number of serious or fatal injuries, traffic crashes

Number of minor injuries, traffic crashes 
Number of injury crashes, single vehicle night time

Number of total crashes, alcohol-related

Also measured injury crashes (night time, daytime, single-vehicle, all types combined), total crashes (single vehicle night time, night time, daytime, single-vehicle, speeding-related, all types combined) property damage crashes (single vehicle night time, night time, daytime, all types combined), self-reported alcoholimpaired driving, DUI arrests, speeding citations, and seatbelt warnings

Notes USA

CITS based on 32 observations before and 6 after the intervention for I1 versus C, and 39 before and 21 after the intervention for $\mathrm{I} 2$ versus $\mathrm{C}$; monthly data

\section{Risk of bias}

\begin{tabular}{lll}
\hline Item & Authors' judgement & Description \\
\hline Allocation concealment? & Unclear & D - Not used \\
\hline
\end{tabular}

Jones 1995b

\begin{tabular}{|c|c|}
\hline Methods & $\begin{array}{l}\text { Design: CITS } \\
\text { National Highway Transportation Safety Administration and investigators assigned intervention } \\
\text { Baseline outcomes similar: ADEQUATE } \\
\text { Other baseline characteristics similar: ADEQUATE } \\
\text { Contamination not likely: ADEQUATE } \\
\text { Intervention occurred independently of other changes over time: N/A } \\
\text { Intervention unlikely to affect data collection: NOT CLEAR } \\
\text { Rationale given for number of pre/post timepoints OR sample size calculation performed: NOT ADE- } \\
\text { QUATE } \\
\text { Rational explanation for effect shape: ADEQUATE }\end{array}$ \\
\hline Participants & $\begin{array}{l}\text { I) City (population }=298,000) \\
\text { C) City (population }=143,000)\end{array}$ \\
\hline Interventions & $\begin{array}{l}\text { I) Targeted DUI, speeding and seat-belt enforcement; Officer staffing not specified; Weekly and holiday } \\
\text { patrols; } 10 \text {-month duration; Sobriety checkpoints, breath alcohol testing van, media campaign, commu- } \\
\text { nity-based public information and education. } \\
\text { C) No intervention. }\end{array}$ \\
\hline Outcomes & $\begin{array}{l}\text { Selected primary outcomes: } \\
\text { Number of serious or fatal injuries, traffic crashes } \\
\text { Number of minor injuries, traffic crashes } \\
\text { Number of injury crashes, single vehicle nighttime } \\
\text { Number of total crashes, alcohol-related } \\
\text { Also measured injury crashes (night time, single-vehicle, daytime, all types combined), total crashes (single } \\
\text { vehicle night time, night time, single-vehicle, daytime, speeding-related, all types combined), property } \\
\text { damage crashes (night time, daytime, all types combined), self-reported alcohol-impaired driving, DUI } \\
\text { arrests, citations for non-use of seatbelts, and speeding citations }\end{array}$ \\
\hline
\end{tabular}


Jones 1995b (Continued)

\begin{tabular}{|c|c|c|}
\hline Notes & \multicolumn{2}{|c|}{$\begin{array}{l}\text { USA } \\
\text { CITS based on } 44 \text { observations before and } 10 \text { after the intervention; monthly data }\end{array}$} \\
\hline \multicolumn{3}{|l|}{ Risk of bias } \\
\hline Item & Authors' judgement & Description \\
\hline Allocation concealment? & Unclear & D - Not used \\
\hline
\end{tabular}

\section{Lacey 1986}

\begin{tabular}{|c|c|c|}
\hline Methods & \multicolumn{2}{|c|}{$\begin{array}{l}\text { Design: CITS } \\
\text { Investigators assigned intervention } \\
\text { Baseline outcomes similar: NOT ADEQUATE } \\
\text { Other baseline characteristics similar: ADEQUATE } \\
\text { Contamination not likely: NOT CLEAR } \\
\text { Intervention occurred independently of other changes over time: N/A } \\
\text { Intervention unlikely to affect data collection: NOT CLEAR } \\
\text { Rationale given for number of pre/post timepoints OR sample size calculation performed: ADEQUATE } \\
\text { Rational explanation for effect shape: ADEQUATE }\end{array}$} \\
\hline Participants & \multicolumn{2}{|c|}{$\begin{array}{l}\text { I) } 2 \text { cities (population }=105,000) \\
\text { C) } 2 \text { cities (population }=88,000 \text { ) }\end{array}$} \\
\hline Interventions & \multicolumn{2}{|c|}{$\begin{array}{l}\text { I) Targeted DUI only; Regular officers reassigned; Daily patrols; } 15 \text {-month duration; Sobriety checkpoints, } \\
\text { training and equipment for police, media campaign, community-based public information and education. } \\
\text { C) No intervention. }\end{array}$} \\
\hline Outcomes & \multicolumn{2}{|c|}{$\begin{array}{l}\text { Selected primary outcomes: } \\
\text { Number of total crashes, alcohol-related } \\
\text { Number of total crashes (defined as injury or vehicle disablement crashes), alcohol-related } \\
\text { Also measured total crashes (night time), total crashes defined as injury or vehicle disablement crashes } \\
\text { (night time), self-reported alcohol-impaired driving, and DUI arrests }\end{array}$} \\
\hline Notes & \multicolumn{2}{|c|}{$\begin{array}{l}\text { USA } \\
\text { CITS based on } 45 \text { observations before and } 15 \text { after the intervention; monthly data }\end{array}$} \\
\hline \multicolumn{3}{|l|}{ Risk of bias } \\
\hline Item & Authors' judgement & Description \\
\hline Allocation concealment? & Unclear & D - Not used \\
\hline
\end{tabular}




\begin{tabular}{|c|c|c|}
\hline Methods & \multicolumn{2}{|c|}{$\begin{array}{l}\text { Design: CITS } \\
\text { Investigators assigned intervention } \\
\text { Baseline outcomes similar: NOT CLEAR } \\
\text { Other baseline characteristics similar: ADEQUATE } \\
\text { Contamination not likely: ADEQUATE } \\
\text { Intervention occurred independently of other changes over time: N/A } \\
\text { Intervention unlikely to affect data collection: NOT CLEAR } \\
\text { Rationale given for number of pre/post timepoints OR sample size calculation performed: ADEQUATE } \\
\text { Rational explanation for effect shape: ADEQUATE }\end{array}$} \\
\hline Participants & \multicolumn{2}{|c|}{$\begin{array}{l}\text { I) City (population }=100,000) \\
\text { C) City (population }=70,000)\end{array}$} \\
\hline Interventions & \multicolumn{2}{|c|}{$\begin{array}{l}\text { I) Targeted DUI only; Regular officers reassigned; Daily patrols; 13-month duration; Training and equip- } \\
\text { ment for police, media campaign, community-based public information and education, citizen reporting } \\
\text { of DUI. } \\
\text { C) No intervention. }\end{array}$} \\
\hline Outcomes & \multicolumn{2}{|c|}{$\begin{array}{l}\text { Selected primary outcomes: } \\
\text { Number of total crashes, alcohol-related } \\
\text { Also measured total crashes (night time) and self-reported alcohol-impaired driving }\end{array}$} \\
\hline Notes & \multicolumn{2}{|c|}{$\begin{array}{l}\text { USA } \\
\text { CITS based on } 25 \text { observations before and } 17 \text { after the intervention; monthly data }\end{array}$} \\
\hline \multicolumn{3}{|l|}{ Risk of bias } \\
\hline Item & Authors' judgement & Description \\
\hline Allocation concealment? & Unclear & D - Not used \\
\hline
\end{tabular}

Lacey 1988

\begin{tabular}{ll} 
Methods & Design: CITS \\
Investigators assigned intervention \\
Baseline outcomes similar: NOT ADEQUATE \\
Other baseline characteristics similar: ADEQUATE \\
Contamination not likely: ADEQUATE \\
Intervention occurred independently of other changes over time: N/A \\
Intervention unlikely to affect data collection: NOT CLEAR \\
Rationale given for number of pre/post timepoints OR sample size calculation performed: ADEQUATE \\
Rational explanation for effect shape: ADEQUATE \\
\hline Participants & $\begin{array}{l}\text { I) City (population }=700,000), \text { metropolitan area } \\
\text { C) City (population }=385,000), \text { metropolitan area }\end{array}$ \\
\hline Interventions & $\begin{array}{l}\text { I) Targeted DUI, high accident, and high incident locations; Regular officers reassigned; Daily patrols } \\
\text { conducted; } 12 \text {-month duration; Sobriety checkpoints, training and equipment for police, community- }\end{array}$
\end{tabular}


based public information and education, media campaign.

C) No intervention.

\begin{tabular}{|c|c|c|}
\hline Outcomes & \multicolumn{2}{|c|}{$\begin{array}{l}\text { Selected primary outcomes: } \\
\text { Number of total crashes, alcohol-related } \\
\text { Also measured total crashes (night time) and self-reported alcohol-impaired driving }\end{array}$} \\
\hline Notes & \multicolumn{2}{|c|}{$\begin{array}{l}\text { USA } \\
\text { CITS based on } 28 \text { observations before and } 13 \text { after the intervention }\end{array}$} \\
\hline \multicolumn{3}{|l|}{ Risk of bias } \\
\hline Item & Authors' judgement & Description \\
\hline Allocation concealment? & Unclear & D - Not used \\
\hline
\end{tabular}

\section{Lacey 1991}

\begin{tabular}{ll}
\hline Methods & $\begin{array}{l}\text { Design: ITS } \\
\text { Intervention occurred independently of other changes over time: NOT CLEAR } \\
\text { Intervention unlikely to affect data collection: NOT CLEAR } \\
\text { Rationale given for number of pre/post timepoints OR sample size calculation performed: NOT ADE- } \\
\text { QUATE } \\
\text { Rational explanation for effect shape: ADEQUATE }\end{array}$ \\
\hline Participants & City (population $=349,000)$ \\
\hline Interventions & $\begin{array}{l}\text { Targeted DUI only; Officer staffing, patrol frequency, and program duration not specified; Sobriety } \\
\text { checkpoints, community-based public information and education, media coverage }\end{array}$ \\
\hline Outcomes & $\begin{array}{l}\text { Selected primary outcomes: } \\
\text { Number of fatalities, traffic crashes }\end{array}$ \\
\hline Notes & $\begin{array}{l}\text { USA } \\
\text { ITS based on } 5 \text { observations before and } 8 \text { after the intervention; annual data }\end{array}$ \\
\hline Risk of bias & \begin{tabular}{l} 
Anclear \\
\hline Alem
\end{tabular} \\
\hline
\end{tabular}


Mallory 1984

\begin{tabular}{|c|c|c|}
\hline Methods & \multicolumn{2}{|c|}{$\begin{array}{l}\text { Design: CBA } \\
\text { Government agency assigned intervention } \\
\text { Baseline outcomes similar: NOT CLEAR } \\
\text { Other baseline characteristics similar: NOT CLEAR } \\
\text { Contamination not likely: NOT CLEAR }\end{array}$} \\
\hline Participants & \multicolumn{2}{|c|}{$\begin{array}{l}\text { I) Municipalities that were awarded grants within selected counties (population not specified) } \\
\text { C1) Municipalities that were not awarded grants within selected counties (population not specified) } \\
\text { C2) Entire state (population not specified) }\end{array}$} \\
\hline Interventions & \multicolumn{2}{|c|}{$\begin{array}{l}\text { I) Targeted DUI only; Officer staffing not specified; Weekend patrols; } 12 \text {-month duration. } \\
\text { C1) No intervention. } \\
\text { C2) No intervention. }\end{array}$} \\
\hline Outcomes & \multicolumn{2}{|c|}{$\begin{array}{l}\text { Selected primary outcomes: } \\
\text { Number of fatalities, traffic crashes } \\
\text { Number of total injuries, traffic crashes } \\
\text { Number of fatal crashes, all types combined } \\
\text { Number of injury crashes, all types combined } \\
\text { Number of total crashes, alcohol-related } \\
\text { Also measured total crashes (night time, all types combined) and property damage crashes (all types } \\
\text { combined) }\end{array}$} \\
\hline Notes & \multicolumn{2}{|l|}{ USA } \\
\hline \multicolumn{3}{|l|}{ Risk of bias } \\
\hline Item & Authors' judgement & Description \\
\hline Allocation concealment? & Unclear & D - Not used \\
\hline
\end{tabular}

Marchetti 1995

\begin{tabular}{ll}
\hline Methods & $\begin{array}{l}\text { Design: CBA } \\
\text { Government agency assigned intervention } \\
\text { Baseline outcomes similar: ADEQUATE } \\
\text { Other baseline characteristics similar: ADEQUATE } \\
\text { Contamination not likely: ADEQUATE }\end{array}$ \\
\hline Participants & $\begin{array}{l}\text { I) County (population }=66,061) \\
\text { C1) County (population }=57,274)\end{array}$ \\
\hline C2) Entire state (population not specified)
\end{tabular}


Marchetti 1995 (Continued)

\begin{tabular}{|c|c|c|}
\hline Outcomes & \multicolumn{2}{|c|}{$\begin{array}{l}\text { Selected primary outcomes: } \\
\text { None } \\
\text { Also measured self-reported alcohol-impaired driving }\end{array}$} \\
\hline Notes & \multicolumn{2}{|l|}{ USA } \\
\hline \multicolumn{3}{|l|}{ Risk of bias } \\
\hline Item & Authors' judgement & Description \\
\hline Allocation concealment? & Unclear & D - Not used \\
\hline
\end{tabular}

Maynard-Moody 1986

\begin{tabular}{|c|c|}
\hline Methods & $\begin{array}{l}\text { Design: CITS } \\
\text { Government agency assigned intervention } \\
\text { Baseline outcomes similar: ADEQUATE } \\
\text { Other baseline characteristics similar: NOT ADEQUATE } \\
\text { Contamination not likely: NOT ADEQUATE } \\
\text { Intervention occurred independently of other changes over time: N/A } \\
\text { Intervention unlikely to affect data collection: NOT CLEAR } \\
\text { Rationale given for number of pre/post timepoints OR sample size calculation performed: ADEQUATE } \\
\text { Rational explanation for effect shape: ADEQUATE }\end{array}$ \\
\hline Participants & $\begin{array}{l}\text { I) City (population }=289,000) \\
\text { C) Entire state (population not specified) }\end{array}$ \\
\hline Interventions & $\begin{array}{l}\text { I) Targeted DUI only; Regular officers reassigned; Regular patrols conducted, exact frequency not spec- } \\
\text { ified; 29-month duration; Training and equipment for police, media campaign, public advocacy/grass- } \\
\text { roots, school- and community-based public information and education, improved pre-sentence and case } \\
\text { processing, DUI offender treatment, breath alcohol testing mobile vans, drinking and driving laws. } \\
\text { C) Drinking and driving laws only. }\end{array}$ \\
\hline Outcomes & $\begin{array}{l}\text { Selected primary outcomes: } \\
\text { Rate of fatal crashes per 100,000 people, single vehicle night time } \\
\text { Rate of injury crashes per 100,000 people, multiple vehicle night time } \\
\text { Also measured fatal crashes (night-time multiple vehicle, daytime single vehicle, daytime multiple vehicle) } \\
\text { and injury crashes (daytime multiple vehicle, all types combined), self-reported alcohol-impaired driving, } \\
\text { and DUI arrests }\end{array}$ \\
\hline Notes & $\begin{array}{l}\text { USA } \\
\text { CITS based on } 60 \text { observations before and } 26 \text { after the intervention; monthly data }\end{array}$ \\
\hline
\end{tabular}

Risk of bias

\begin{tabular}{lll}
\hline Item & Authors' judgement & Description
\end{tabular}

Increased police patrols for preventing alcohol-impaired driving (Review) 


\section{Maynard-Moody 1986 (Continued)}

\begin{tabular}{l|l|l} 
Allocation concealment? Unclear & D - Not used
\end{tabular}

\section{McEwen 1985}

\begin{tabular}{ll} 
Methods & $\begin{array}{l}\text { Design: ITS } \\
\text { Intervention occurred independently of other changes over time: NOT CLEAR } \\
\text { Intervention unlikely to affect data collection: NOT CLEAR } \\
\text { Rationale given for number of pre/post timepoints OR sample size calculation performed: ADEQUATE } \\
\text { Rational explanation for effect shape: ADEQUATE }\end{array}$ \\
\hline Participants & City (Population $=255,201)$ \\
\hline Interventions & $\begin{array}{l}\text { Targeted DUI, speeding, general patrol; Regular officers reassigned; Weekend patrols; 30-month duration; } \\
\text { Media campaign, community-based public information and education, streamlined court procedures }\end{array}$ \\
\hline Outcomes & $\begin{array}{l}\text { Selected primary outcomes: } \\
\text { Number of injury crashes, nighttime } \\
\text { Also measured injury crashes (daytime) }\end{array}$ \\
\hline Notes & $\begin{array}{l}\text { USA } \\
\text { ITS based on } 12 \text { observations before and } 24 \text { after the intervention; monthly data }\end{array}$
\end{tabular}

\section{Risk of bias}

\begin{tabular}{|c|c|c|}
\hline Item & Authors' judgement & Description \\
\hline Allocation concealment? & Unclear & D - Not used \\
\hline
\end{tabular}

\section{Pigman 1984}

\begin{tabular}{ll} 
Methods & $\begin{array}{l}\text { Design: ITS } \\
\text { Intervention occurred independently of other changes over time: NOT CLEAR } \\
\text { Intervention unlikely to affect data collection: NOT CLEAR } \\
\text { Rationale given for number of pre/post timepoints OR sample size calculation perform } \\
\text { Rational explanation for effect shape: ADEQUATE }\end{array}$ \\
\hline Participants & County (population $=204,000)$, urban and rural area \\
\hline Interventions & $\begin{array}{l}\text { Targeted DUI only; Officers worked overtime; Patrols conducted } 6 \text { days/week; 29-mon } \\
\text { ing for police, public information and education }\end{array}$ \\
\hline Outcomes & $\begin{array}{l}\text { Selected primary outcomes: } \\
\text { Number of total crashes, alcohol-related } \\
\text { Also measured total crashes (alcohol-related during program hours) and DUI arrests }\end{array}$
\end{tabular}


Pigman 1984 (Continued)

\begin{tabular}{|c|c|c|}
\hline Notes & \multicolumn{2}{|c|}{$\begin{array}{l}\text { USA } \\
\text { ITS for total crashes based on } 121 \text { observations before and } 52 \text { after the intervention; weekly data }\end{array}$} \\
\hline \multicolumn{3}{|l|}{ Risk of bias } \\
\hline Item & Authors' judgement & Description \\
\hline Allocation concealment? & Unclear & D - Not used \\
\hline
\end{tabular}

Pigman 1988

Methods

Design: ITS and CBA

Government agency assigned intervention

Baseline outcomes similar: NOT CLEAR

Other baseline characteristics similar: NOT CLEAR

Contamination not likely: NOT CLEAR

Intervention occurred independently of other changes over time: NOT CLEAR

Intervention unlikely to affect data collection: NOT CLEAR

Rationale given for number of pre/post timepoints OR sample size calculation performed: ADEQUATE

Rational explanation for effect shape: ADEQUATE

$\begin{array}{lll}\text { Participants } & \text { I) County (population at least 50,000) }\end{array}$

C1) County (population not specified), "some characteristics of an urban area"

C2) State, excluding intervention county (population not specified)

Interventions

I) Targeted DUI only; Officer staffing not specified; Patrol frequency not specified; 24-month duration; Coordinated effort with judicial personnel, local media, drinking and driving laws.

C1) Drinking and driving laws only.

C2) Drinking and driving laws only.

\begin{tabular}{ll} 
Outcomes & $\begin{array}{l}\text { Selected primary outcomes: } \\
\text { Number of total crashes, alcohol-related } \\
\text { Also measured total crashes (alcohol-related during program hours, alcohol-related outside program hours, } \\
\text { non-alcohol-related, all types combined), BAC of arrested drivers, DUI arrests, and DUI citations }\end{array}$ \\
\hline Notes & USA \\
& ITS for total crashes based on 36 observations before and 24 after the intervention; monthly data. \\
& ITS for blood alcohol content of arrested drivers based on 21 observations before and 27 after the \\
& intervention; monthly data. \\
In one small city within the intervention county, the intervention began 6 months earlier
\end{tabular}

Risk of bias

\begin{tabular}{|c|c|c|}
\hline Item & Authors' judgement & Description \\
\hline Allocation concealment? & Unclear & D - Not used \\
\hline
\end{tabular}

Increased police patrols for preventing alcohol-impaired driving (Review) 


\begin{tabular}{|c|c|c|}
\hline Methods & \multicolumn{2}{|c|}{$\begin{array}{l}\text { Design: CITS } \\
\text { Government agency assigned intervention } \\
\text { Baseline outcomes similar: ADEQUATE } \\
\text { Other baseline characteristics similar: NOT ADEQUATE } \\
\text { Contamination not likely: NOT CLEAR } \\
\text { Intervention occurred independently of other changes over time: N/A } \\
\text { Intervention unlikely to affect data collection: NOT CLEAR } \\
\text { Rationale given for number of pre/post timepoints OR sample size calculation performed: ADEQUATE } \\
\text { Rational explanation for effect shape: NOT CLEAR }\end{array}$} \\
\hline Participants & \multicolumn{2}{|c|}{$\begin{array}{l}\text { I) City (Population }=100,000) \text {, metropolitan area } \\
\text { C) Areas in rest of state lacking a selective traffic enforcement program (population not specified) }\end{array}$} \\
\hline Interventions & \multicolumn{2}{|c|}{$\begin{array}{l}\text { I) Targeted hazardous moving violations; New officers hired, regular officers reassigned; Regular patrols } \\
\text { conducted, exact frequency not specified; 22-month duration; Media coverage, community-based public } \\
\text { information and education. } \\
\text { C) No intervention. }\end{array}$} \\
\hline Outcomes & \multicolumn{2}{|c|}{$\begin{array}{l}\text { Selected primary outcomes: } \\
\text { Number of injury crashes, all types combined } \\
\text { Also measured DUI arrests }\end{array}$} \\
\hline Notes & \multicolumn{2}{|c|}{$\begin{array}{l}\text { USA } \\
\text { CITS based on } 69 \text { observations before and } 22 \text { after the intervention; monthly data }\end{array}$} \\
\hline \multicolumn{3}{|l|}{ Risk of bias } \\
\hline Item & Authors' judgement & Description \\
\hline Allocation concealment? & Unclear & D - Not used \\
\hline
\end{tabular}

St Louis Police 1981

\begin{tabular}{ll}
\hline St Louis Police 1981 & \\
\hline Methods & $\begin{array}{l}\text { Design: ITS } \\
\text { Intervention occurred independently of other changes over time: NOT CLEAR } \\
\text { Intervention unlikely to affect data collection: NOT CLEAR } \\
\text { Rationale given for number of pre/post timepoints OR sample size calculation performed: NOT ADE- } \\
\text { QUATE } \\
\text { Rational explanation for effect shape: ADEQUATE }\end{array}$ \\
\hline Participants & County (population not specified) \\
\hline Interventions & $\begin{array}{l}\text { Targeted DUI only; Officers worked overtime; Daily patrols; 40-month duration; Media campaign, } \\
\text { training for police }\end{array}$ \\
\hline Outcomes & $\begin{array}{l}\text { Selected primary outcomes: } \\
\text { Number of fatalities, traffic crashes } \\
\text { Number of total injuries, traffic crashes } \\
\text { Number of fatal crashes, all types combined }\end{array}$ \\
\hline
\end{tabular}


St Louis Police 1981 (Continued)

Number of injury crashes, all types combined

Number of total crashes, all types combined

Also measured non-fatal injuries (traffic crashes), property damage crashes (all types combined), and DUI

arrests

Notes USA

ITS based on 10 observations before and 40 after the intervention; monthly data

\section{Risk of bias}

\begin{tabular}{|c|c|c|}
\hline Item & Authors' judgement & Description \\
\hline Allocation concealment? & Unclear & D - Not used \\
\hline
\end{tabular}

\section{Stuster 1995}

\begin{tabular}{|c|c|}
\hline Methods & $\begin{array}{l}\text { Design: CITS } \\
\text { Investigators assigned intervention } \\
\text { Baseline outcomes similar: ADEQUATE } \\
\text { Other baseline characteristics similar: ADEQUATE } \\
\text { Contamination not likely: ADEQUATE } \\
\text { Intervention occurred independently of other changes over time: N/A } \\
\text { Intervention unlikely to affect data collection: NOT CLEAR } \\
\text { Rationale given for number of pre/post timepoints OR sample size calculation performed: NOT ADE- } \\
\text { QUATE } \\
\text { Rational explanation for effect shape: ADEQUATE }\end{array}$ \\
\hline Participants & $\begin{array}{l}\text { I1) City (population not specified) } \\
\text { I2) City (population not specified) } \\
\text { C1) City (population not specified) } \\
\text { C2) Entire state (population not specified) }\end{array}$ \\
\hline Interventions & $\begin{array}{l}\text { I1) Targeted DUI only; Officer staffing not specified; Regular patrols conducted } 6 \text { nights/month, Thursday, } \\
\text { Friday, or Saturday; 9-month duration; Community-based public information and education, media } \\
\text { campaign. } \\
\text { I2) Sobriety checkpoints, community-based public information and education, media campaign. } \\
\text { C1) No intervention. } \\
\text { C2) No intervention. }\end{array}$ \\
\hline Outcomes & $\begin{array}{l}\text { Selected primary outcomes: } \\
\text { Number of injury crashes, alcohol-related } \\
\text { Number of total crashes, single vehicle (CBA) } \\
\text { Also measured injury crashes (non-alcohol-related) and total crashes (hit-and-run) }\end{array}$ \\
\hline Notes & $\begin{array}{l}\text { USA } \\
\text { CITS for injury crashes based on } 67 \text { observations before and } 9 \text { after the intervention; monthly data }\end{array}$ \\
\hline
\end{tabular}

\section{Risk of bias}


Stuster 1995 (Continued)

\begin{tabular}{|c|c|c|}
\hline Item & Authors' judgement & Description \\
\hline Allocation concealment? & Unclear & D - Not used \\
\hline
\end{tabular}

Stuster 2001

\begin{tabular}{|c|c|c|}
\hline Methods & \multicolumn{2}{|c|}{$\begin{array}{l}\text { Design: CBA and ITS } \\
\text { Police department assigned intervention } \\
\text { Baseline outcomes similar: NOT ADEQUATE } \\
\text { Other baseline characteristics similar: NOT CLEAR } \\
\text { Contamination not likely: NOT CLEAR } \\
\text { Intervention occurred independently of other changes over time: NOT CLEAR } \\
\text { Intervention unlikely to affect data collection: NOT CLEAR } \\
\text { Rationale given for number of pre/post timepoints OR sample size calculation performed: ADEQUATE } \\
\text { Rational explanation for effect shape: ADEQUATE }\end{array}$} \\
\hline Participants & \multicolumn{2}{|c|}{$\begin{array}{l}\text { I) City (population not specified), urban area } \\
\text { C) Remainder of state's urban areas (population not specified), urban area }\end{array}$} \\
\hline Interventions & \multicolumn{2}{|c|}{$\begin{array}{l}\text { I) Targeted all traffic violations, focusing on DUI, speeding, and seat belt use; Officers worked overtime, } \\
\text { regular officers reassigned; Daily patrols; } 12 \text {-month duration; Community-based public information and } \\
\text { education, citizen reporting of DUI, media campaign, Operation DWI - a statewide checkpoint and } \\
\text { saturation patrol program. } \\
\text { C) Media campaign, Operation DWI - a statewide checkpoint and saturation patrol program only }\end{array}$} \\
\hline Outcomes & \multicolumn{2}{|c|}{$\begin{array}{l}\text { Selected primary outcomes: } \\
\text { Number of injury crashes, all types combined } \\
\text { Number of total crashes, all types combined }\end{array}$} \\
\hline Notes & \multicolumn{2}{|c|}{$\begin{array}{l}\text { USA } \\
\text { ITS based on } 12 \text { observations before and } 12 \text { after the intervention; monthly data }\end{array}$} \\
\hline \multicolumn{3}{|l|}{ Risk of bias } \\
\hline Item & Authors' judgement & Description \\
\hline Allocation concealment? & Unclear & D - Not used \\
\hline
\end{tabular}


Sykes 1984

\begin{tabular}{l|l}
\hline Methods & $\begin{array}{l}\text { Design: CBA } \\
\text { Police department assigned intervention } \\
\text { Baseline outcomes similar: NOT ADEQUATE } \\
\text { Other baseline characteristics similar: NOT CLEAR } \\
\text { Contamination not likely: NOT ADEQUATE }\end{array}$ \\
\hline Participants & $\begin{array}{l}\text { I) } 2 \text { patrol areas in city (population not specified) } \\
\text { C) Remaining (non-program) patrol areas in same city (population not specified) }\end{array}$ \\
\hline Interventions & I) Targeted DUI only; Officers worked overtime; Weekend patrols; 5-month duration; Media coverage. \\
\hline C) Media coverage only.
\end{tabular}

Voas 1987

Methods

Design: CITS

Government agency assigned intervention

Baseline outcomes similar: NOT CLEAR

Other baseline characteristics similar: ADEQUATE

Contamination not likely: NOT CLEAR

Intervention occurred independently of other changes over time: N/A

Intervention unlikely to affect data collection: NOT CLEAR

Rationale given for number of pre/post timepoints OR sample size calculation performed: ADEQUATE

Rational explanation for effect shape: ADEQUATE

$\begin{array}{ll}\text { Participants } & \text { I) City (population }=200,000) \\ \text { C1) } 4 \text { Cities (population not specified) }\end{array}$

Interventions

I) Targeted DUI only; Officers worked overtime, regular officers reassigned; Weekend patrols; 33-month duration; Training and equipment for police, media coverage.

C1) No intervention.

C2) No intervention.

Outcomes

Selected primary outcomes:

Number of total crashes, night-time weekend

Also measured total crashes (night time, daytime, night-time weekday) and DUI arrests

Increased police patrols for preventing alcohol-impaired driving (Review) 
Voas 1987 (Continued)

\begin{tabular}{|c|c|c|}
\hline Notes & \multicolumn{2}{|c|}{$\begin{array}{l}\text { USA } \\
\text { CITS based on } 36 \text { observations before and } 60 \text { after the intervention; monthly data }\end{array}$} \\
\hline \multicolumn{3}{|l|}{ Risk of bias } \\
\hline Item & Authors' judgement & Description \\
\hline Allocation concealment? & Unclear & D - Not used \\
\hline
\end{tabular}

\section{Voas 1997}

\begin{tabular}{ll}
\hline Methods & Design: CITS \\
Investigators assigned intervention \\
Baseline outcomes similar: NOT CLEAR \\
Other baseline characteristics similar: ADEQUATE \\
Contamination not likely: NOT CLEAR \\
Intervention occurred independently of other changes over time: N/A \\
Intervention unlikely to affect data collection: NOT CLEAR \\
Rationale given for number of pre/post timepoints OR sample size calculation performed: ADEQUATE \\
Rational explanation for effect shape: ADEQUATE
\end{tabular}

Participants I1) City (population approximately 100,000), urban, suburban, and rural areas

I2) City (population approximately 100,000), urban, suburban, and rural areas

I3) County (population approximately 100,000), urban, suburban, and rural areas

C1) City (population approximately 100,000), urban, suburban, and rural areas

C2) City (population approximately 100,000), urban, suburban, and rural areas

C3) County (population approximately 100,000), urban, suburban, and rural areas

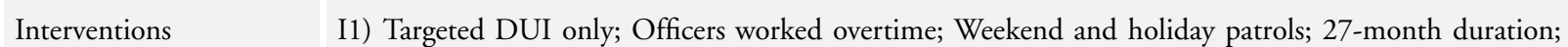
Training and equipment for police, community task force, sobriety checkpoints, media campaign, drinking and driving laws.

I2) Targeted DUI only; New officers hired; Weekend and holiday patrols; 27-month duration; Community task force, sobriety checkpoints, equipment for police, media campaign, drinking and driving laws.

I3) Targeted DUI only; 18.5-month duration; Community task force, training and equipment for police, media campaign, sobriety checkpoints.

C1) Sobriety checkpoints, media campaign, drinking and driving laws only.

C2) Sobriety checkpoints, equipment for police, media campaign, drinking and driving laws only.

C3) Equipment for police; Media campaign; Checkpoints with random breath testing only

Outcomes

Selected primary outcomes:

Relative rates of injury crashes, nighttime

Relative rates of total crashes, alcohol-related

Also measured injury crashes (night time, daytime weekend, weekend), total crashes (single vehicle night time, night time, daytime), injuries (weekend traffic crashes), assaults (emergency department visits, hospitalizations), blood alcohol content of randomly selected drivers, self-reported alcohol-impaired driving, and DUI arrests 
Voas 1997 (Continued)

\begin{tabular}{ll}
\hline Notes & USA \\
CITS for crashes based on 66 observations before and 42 after the intervention; monthly data. \\
ITS for blood alcohol content based on 5 observations before and 17 after the intervention; biweekly data \\
were aggregated into quarterly data. \\
CITS for self-reported alcohol-impaired driving based on ongoing survey data which were aggregated into \\
5 quarters before and 17 quarters after the intervention
\end{tabular}

Risk of bias

\begin{tabular}{|c|c|c|}
\hline Item & Authors' judgement & Description \\
\hline Allocation concealment? & Unclear & D - Not used \\
\hline
\end{tabular}

Voas 2002

\begin{tabular}{|c|c|c|}
\hline Methods & \multicolumn{2}{|c|}{$\begin{array}{l}\text { Design: CITS } \\
\text { Elected government official assigned intervention } \\
\text { Baseline outcomes similar: NOT CLEAR } \\
\text { Other baseline characteristics similar: ADEQUATE } \\
\text { Contamination not likely: ADEQUATE } \\
\text { Intervention occurred independently of other changes over time: NOT ADEQUATE } \\
\text { Intervention unlikely to affect data collection: NOT CLEAR } \\
\text { Rationale given for number of pre/post timepoints OR sample size calculation performed: ADEQUATE } \\
\text { Rational explanation for effect shape: ADEQUATE }\end{array}$} \\
\hline Participants & \multicolumn{2}{|c|}{$\begin{array}{l}\text { I) County (population not specified) } \\
\text { C) County (population not specified) }\end{array}$} \\
\hline Interventions & \multicolumn{2}{|c|}{$\begin{array}{l}\text { I) Targeted DUI only; Officers worked overtime; Patrols conducted every } 60 \text { days, on holidays, and on } \\
\text { spring break; 34-month duration; Sobriety checkpoints, media campaign, foot patrols. } \\
\text { C) No intervention. }\end{array}$} \\
\hline Outcomes & \multicolumn{2}{|c|}{$\begin{array}{l}\text { Selected primary outcomes: } \\
\text { Ratio of alcohol-related, night-time weekend injury crashes among ages } 16-20 \text { to total non-alcohol-related, } \\
\text { night-time weekend injury crashes among ages } 16-20 \\
\text { Also measured night-time weekend injury crashes (alcohol-related among ages } 21-30 \text { ) }\end{array}$} \\
\hline Notes & \multicolumn{2}{|c|}{$\begin{array}{l}\text { USA } \\
\text { CITS based on } 14 \text { observations before and } 34 \text { after the intervention; monthly data }\end{array}$} \\
\hline \multicolumn{3}{|l|}{ Risk of bias } \\
\hline Item & Authors' judgement & Description \\
\hline Allocation concealment? & Unclear & D - Not used \\
\hline
\end{tabular}

Increased police patrols for preventing alcohol-impaired driving (Review) 


\begin{tabular}{|c|c|c|}
\hline Methods & \multicolumn{2}{|c|}{$\begin{array}{l}\text { Design: CITS } \\
\text { Police department assigned intervention } \\
\text { Baseline outcomes similar: NOT CLEAR } \\
\text { Other baseline characteristics similar: NOT ADEQUATE } \\
\text { Contamination not likely: NOT CLEAR } \\
\text { Intervention occurred independently of other changes over time: N/A } \\
\text { Intervention unlikely to affect data collection: NOT CLEAR } \\
\text { Rationale given for number of pre/post timepoints OR sample size calculation performed: NOT ADE- } \\
\text { QUATE } \\
\text { Rational explanation for effect shape: NOT CLEAR }\end{array}$} \\
\hline Participants & \multicolumn{2}{|c|}{$\begin{array}{l}\text { I) City (population }=1,000,000) \text {, metropolitan area } \\
\text { C) Rest of state (population not specified) }\end{array}$} \\
\hline Interventions & \multicolumn{2}{|c|}{$\begin{array}{l}\text { I) Targeted DUI only; Regular officers reassigned; Daily patrols; 24-month duration; Training and equip- } \\
\text { ment for police. } \\
\text { C) No intervention. }\end{array}$} \\
\hline Outcomes & \multicolumn{2}{|c|}{$\begin{array}{l}\text { Selected primary outcomes: } \\
\text { Number of drivers in fatal crashes, BAC }>=0.01 \\
\text { Also measured drivers in fatal crashes, BAC }>=0.10 \text { and DUI arrests }\end{array}$} \\
\hline Notes & \multicolumn{2}{|c|}{$\begin{array}{l}\text { USA } \\
\text { CITS based on } 18 \text { observations before and } 6 \text { after the intervention; semi-annual data }\end{array}$} \\
\hline \multicolumn{3}{|l|}{ Risk of bias } \\
\hline Item & Authors' judgement & Description \\
\hline Allocation concealment? & Unclear & D - Not used \\
\hline
\end{tabular}

\section{Wolfe 1984}

Methods Design: CBA and ITS

Government agency assigned intervention

Baseline outcomes similar: NOT CLEAR

Other baseline characteristics similar: NOT CLEAR

Contamination not likely: NOT CLEAR

Intervention occurred independently of other changes over time: NOT CLEAR

Intervention unlikely to affect data collection: NOT CLEAR

Rationale given for number of pre/post timepoints OR sample size calculation performed: NOT ADEQUATE

Rational explanation for effect shape: ADEQUATE

Participants

I) County (population $=1,000,000)$, suburban area

C) Rest of state (population not specified) 


\section{Wolfe 1984 (Continued)}

Interventions
week; 38-month duration; Training and equipment for police, school- and community-based public
information and education.
C) No intervention.

\begin{tabular}{ll}
\hline Outcomes & Selected primary outcomes: \\
& Number of fatal crashes, alcohol-related (ITS) \\
& Number of injury crashes, alcohol-related (CBA) \\
Number of total crashes, alcohol-related (ITS) & Also measured fatal crashes (all types combined), injury crashes (non-alcohol-related, all types combined, \\
alcohol-related during program hours, non-alcohol-related during program hours, all types combined \\
during program hours), total crashes (all types combined), and property damage crashes (alcohol-related, \\
all types combined) \\
\hline
\end{tabular}

$\begin{array}{ll}\text { Notes } & \text { USA } \\ \text { ITS for total crashes and fatal crashes based on } 13 \text { observations before and } 12 \text { after the intervention; } \\ \text { quarterly data }\end{array}$

\section{Risk of bias}

\begin{tabular}{l|ll}
\hline Item & Authors' judgement & Description \\
\hline Allocation concealment? & Unclear & D - Not used \\
\hline
\end{tabular}

\section{Zador 1976}

Methods Design CBA

US Department of Transportation assigned intervention

Baseline outcomes similar: ADEQUATE

Other baseline characteristics similar: ADEQUATE

Contamination not likely: NOT CLEAR

Participants $\quad$ I) Combination of cities, counties, states, and metropolitan areas (combined population $=15,542,000$ )

C) Combination of cities, counties, states, and metropolitan areas

Interventions

I) Targeted DUI only; Officers worked overtime, regular officers were reassigned; generally, patrols conducted 4 days/week; duration ranged from 24 to 60 months; Training and equipment for officers, community-based public information and education, coordination with court presentence investigation, rehabilitation for problem drinkers.

C) No intervention.

\begin{tabular}{ll} 
Outcomes & $\begin{array}{l}\text { Selected primary outcomes: } \\
\text { Number of fatalities, traffic crashes }\end{array}$ \\
\hline Notes & $\begin{array}{l}\text { USA } \\
\text { Zador's evaluation includes } 28 \text { of the } 35 \text { ASAP programs. }\end{array}$
\end{tabular}


Zador 1976 (Continued)

\section{Risk of bias}

\begin{tabular}{|c|c|c|}
\hline Item & Authors' judgement & Description \\
\hline Allocation concealment? & Unclear & D - Not used \\
\hline
\end{tabular}

$\mathrm{BAC}=$ blood alcohol content

$\mathrm{CBA}=$ controlled before-after

CITS $=$ controlled interrupted time series

DUI = driving under the influence of alcohol

ITS $=$ interrupted time series

$\mathrm{N} / \mathrm{A}=$ not applicable

$\mathrm{VKT}=$ vehicle kilometers traveled

\section{Characteristics of excluded studies [ordered by study ID]}

\begin{tabular}{|c|c|}
\hline Study & Reason for exclusion \\
\hline Beirness 1997 & Road blocks only; study design not eligible. \\
\hline CA HWY Patrol 1972 & Study design not eligible. \\
\hline CAAP 1988 & $\begin{array}{l}\text { Random stopping only; intervention did not include increased police patrols for which a primary goal was } \\
\text { to reduce alcohol-impaired driving }\end{array}$ \\
\hline Calderwood 1986 & Intervention did not include police patrols for which a primary goal was to reduce alcohol-impaired driving \\
\hline Cameron 1981 & $\begin{array}{l}\text { Random breath testing only; intervention did not include increased police patrols for which a primary goal } \\
\text { was to reduce alcohol-impaired driving }\end{array}$ \\
\hline Castle 1996 & Intervention did not include police patrols for which a primary goal was to reduce alcohol-impaired driving \\
\hline Clark 1982 & Study design not eligible. \\
\hline Cliff 2003 & Study design not eligible. \\
\hline Cowart 1984 & Study design not eligible. \\
\hline Derby 1987 & $\begin{array}{l}\text { Random stopping only; intervention did not include increased police patrols for which a primary goal was } \\
\text { to reduce alcohol-impaired driving }\end{array}$ \\
\hline Diamantopoulou 2000 & Study design not eligible; random breath testing only. \\
\hline
\end{tabular}


(Continued)

\begin{tabular}{|c|c|}
\hline Epperlein 1987 & $\begin{array}{l}\text { Of the two intervention cities, one city never assembled a police squad to enforce alcohol-impaired driving } \\
\text { laws, and one city deployed police patrols before the start of the intervention; therefore the intervention } \\
\text { did not involve increased police patrols }\end{array}$ \\
\hline Finklestein 1971 & Study design, intervention, and population eligible, but only arrests were measured as an outcome \\
\hline Glad 1997 & Study did not evaluate an intervention. \\
\hline Greenwood 1985 & Relevant outcome measures were not reported. Author could not be traced \\
\hline Hocherman 1996 & Intervention was not intended to reduce alcohol-impaired driving either wholly or in part \\
\hline Homel 1987 & Study design not eligible; random breath testing only. \\
\hline Homel 1995 & $\begin{array}{l}\text { Random breath testing only; intervention did not include increased police patrols for which a primary goal } \\
\text { was to reduce alcohol-impaired driving }\end{array}$ \\
\hline Kearns 1984 & $\begin{array}{l}\text { Random breath testing only; intervention did not include increased police patrols for which a primary goal } \\
\text { was to reduce alcohol-impaired driving }\end{array}$ \\
\hline Kearns 1987 & $\begin{array}{l}\text { Random breath testing; intervention did not include increased police patrols for which a primary goal was } \\
\text { to reduce alcohol-impaired driving }\end{array}$ \\
\hline Maher 1983 & $\begin{array}{l}\text { Study design not eligible; intervention did not include increased police patrols for which a primary goal } \\
\text { was to reduce alcohol-impaired driving }\end{array}$ \\
\hline Mastrofski 1990 & Study design not eligible. \\
\hline Mathijssen 1992 & Study design not eligible. \\
\hline Mathijssen 2001 & $\begin{array}{l}\text { Random breath testing only; intervention did not include increased police patrols for which a primary goal } \\
\text { was to reduce alcohol-impaired driving }\end{array}$ \\
\hline Mathijssen 2004 & $\begin{array}{l}\text { Random breath testing only; intervention did not include police patrols for which a primary goal was to } \\
\text { reduce alcohol-impaired driving }\end{array}$ \\
\hline McCartt 1985 & $\begin{array}{l}\text { The intervention was a legislative act to establish increased monetary penalties for alcohol-impaired drivers. } \\
\text { Funds were given to counties that subsequently funded increased police patrols }\end{array}$ \\
\hline Mercer 1985 & $\begin{array}{l}\text { Road blocks only; intervention did not include increased police patrols for which a primary goal was to } \\
\text { reduce alcohol-impaired driving }\end{array}$ \\
\hline Mercer 1989 & $\begin{array}{l}\text { Road blocks only; intervention did not include police patrols for which a primary goal was to reduce } \\
\text { alcohol-impaired driving }\end{array}$ \\
\hline Miller 2004 & $\begin{array}{l}\text { Compulsory breath testing; intervention did not include increased police patrols for which a primary goal } \\
\text { was to reduce alcohol-impaired driving }\end{array}$ \\
\hline
\end{tabular}


(Continued)

\begin{tabular}{|c|c|}
\hline Mäki 1987 & $\begin{array}{l}\text { Road blocks only; intervention did not include police patrols for which a primary goal was to reduce alcohol } \\
\text { impaired driving }\end{array}$ \\
\hline O’Connell 1983 & $\begin{array}{l}\text { Intervention did not include increased police patrols for which a primary goal was to reduce alcohol- } \\
\text { impaired driving }\end{array}$ \\
\hline Price 1993 & Study design not eligible. \\
\hline Rodriguez 2002 & Study design not eligible. \\
\hline Ross 1987 & $\begin{array}{l}\text { The intervention involved an increase in breath testing for drivers stopped for moving traffic offenses but } \\
\text { did not include an increase in the number of officers or in the frequency or duration of police patrols }\end{array}$ \\
\hline Savell 1984 & Study design not eligible. \\
\hline Sharp 2002 & Study design not eligible. \\
\hline SMI 1976 & $\begin{array}{l}\text { Intervention did not include increased police patrols for which a primary goal was to reduce alcohol- } \\
\text { impaired driving }\end{array}$ \\
\hline Thomson 1984 & $\begin{array}{l}\text { Random breath testing only; intervention did not include increased police patrols for which a primary goal } \\
\text { was to reduce alcohol-impaired driving }\end{array}$ \\
\hline Verschuur 1988 & $\begin{array}{l}\text { Random breath testing only; intervention did not include increased police patrols for which a primary goal } \\
\text { was to reduce alcohol-impaired driving }\end{array}$ \\
\hline Vingilis 1980 & $\begin{array}{l}\text { Road blocks only; intervention did not include increased police patrols for which a primary goal was to } \\
\text { reduce alcohol-impaired driving }\end{array}$ \\
\hline Vingilis 1981 & Intervention did not include police patrols for which a primary goal was to reduce alcohol-impaired driving \\
\hline Votey 1978 & $\begin{array}{l}\text { Study design not eligible; intervention did not include increased police patrols for which a primary goal } \\
\text { was to reduce alcohol-impaired driving }\end{array}$ \\
\hline Votey 1982 & Study design not eligible. \\
\hline Votey 1984 & Study design not eligible. \\
\hline Webb 1981 & olice patrols for which a primary goal was to reduce alcohol-impaired driving \\
\hline
\end{tabular}

Weiss 1996 Intervention did not include increased police patrols for which a primary goal was to reduce alcoholimpaired driving, as defined by an increase in the number of officers or time spent by officers on patrol. The intervention was a change in policing style

White 2002 Intervention did not include police patrols for which a primary goal was to reduce alcohol-impaired driving

Williams 1995 Study design not eligible. 
(Continued)

Wright 1989 Study design not eligible; intervention did not include increased police patrols for which a primary goal was to reduce alcohol-impaired driving

Youngman 1988

Random breath testing; intervention did not include increased police patrols for which a primary goal was to reduce alcohol-impaired driving 


\section{DATA ANDANALYSES}

This review has no analyses.

\section{ADDITIONAL TABLES}

Table 1. Within-study comparison of results from alcohol-related and alcohol-proxy measures

\begin{tabular}{|c|c|c|c|c|}
\hline $\begin{array}{l}\text { Type of Alcohol-Re- } \\
\text { lated Measure }\end{array}$ & $\begin{array}{l}\text { Result from Alcohol- } \\
\text { Related Measure }\end{array}$ & $\begin{array}{l}\text { Type of Alcohol-Proxy } \\
\text { Measure }\end{array}$ & $\begin{array}{l}\text { Result from Alcohol- } \\
\text { Proxy Measure }\end{array}$ & $\begin{array}{l}\text { Result from Alcohol- } \\
\text { Proxy Measure }\end{array}$ \\
\hline Brackett 1983 & $\begin{array}{l}\text { Alcohol-related fatal } \\
\text { crashes }\end{array}$ & $\begin{array}{l}\text { Rate ratio }(95 \% \mathrm{CI}): 0 . \\
84(0.45,1.87)\end{array}$ & $\begin{array}{l}\text { Single vehicle night-time } \\
\text { fatal crashes }\end{array}$ & $\begin{array}{l}\text { Rate ratio }(95 \% \mathrm{CI}): 0 . \\
64(0.26,1.53)\end{array}$ \\
\hline Brackett 1983 & $\begin{array}{l}\text { Alcohol-related injury } \\
\text { crashes }\end{array}$ & $\begin{array}{l}\text { Rate ratio }(95 \% \mathrm{CI}): 0 . \\
70(0.60,0.94)\end{array}$ & $\begin{array}{l}\text { Single vehicle night-time } \\
\text { injury crashes }\end{array}$ & $\begin{array}{l}\text { Rate ratio }(95 \% \mathrm{CI}): 0 . \\
70(0.52,0.94)\end{array}$ \\
\hline Brackett 1983 & $\begin{array}{l}\text { Alcohol-related total } \\
\text { crashes }\end{array}$ & $\begin{array}{l}\text { Rate ratio }(95 \% \mathrm{CI}): 0 . \\
76(0.65,0.90)\end{array}$ & $\begin{array}{l}\text { Single vehicle night-time } \\
\text { total crashes }\end{array}$ & $\begin{array}{l}\text { Rate ratio }(95 \% \mathrm{CI}): 0 . \\
71(0.56,0.89)\end{array}$ \\
\hline Jones 1995a & $\begin{array}{l}\text { Alcohol-related } \\
\text { crashes }\end{array}$ & $\begin{array}{l}\text { Intervention (I1) mean } \\
\text { change: not reported, P- } \\
\text { value ns } \\
\text { Intervention (I2) mean } \\
\text { change: not reported, P- } \\
\text { value ns } \\
\text { Comparison mean } \\
\text { change: not reported, P- } \\
\text { value ns }\end{array}$ & $\begin{array}{l}\text { Single vehicle night-time } \\
\text { total crashes }\end{array}$ & $\begin{array}{l}\text { Intervention (I1) mean } \\
\text { change: no change (ex- } \\
\text { act value not reported), } \\
\text { P-value ns } \\
\text { Intervention (I2) mean } \\
\text { change: reduced crashes } \\
\text { (exact value not re- } \\
\text { ported), P-value ns } \\
\text { Com- } \\
\text { parison mean change: no } \\
\text { change (exact value not } \\
\text { reported), P-value ns }\end{array}$ \\
\hline Jones $1995 b$ & $\begin{array}{l}\text { Alcohol-related total } \\
\text { crashes }\end{array}$ & $\begin{array}{l}\text { Intervention } \\
\text { mean change* (compari- } \\
\text { son area as control): pos- } \\
\text { itive value (i.e., increased } \\
\text { crashes), exact value not } \\
\text { reported, P-value ns } \\
\text { *Authors used time series } \\
\text { models }\end{array}$ & $\begin{array}{l}\text { Single vehicle night-time } \\
\text { total crashes }\end{array}$ & $\begin{array}{l}\text { Intervention } \\
\text { mean change* (compar- } \\
\text { ison area as control):not } \\
\text { reported, } \mathrm{P}<0.005 \text {, per- } \\
\text { cent change: }-35 \% \text { (i. } \\
\text { e., relative reduction in } \\
\text { crashes) } \\
* \text { Authors performed } \\
\text { ARIMA analysis }\end{array}$ \\
\hline Lacey 1986 & $\begin{array}{l}\text { Alcohol-related } \\
\text { crashes }\end{array}$ & $\begin{array}{l}\text { Shift parameter for per- } \\
\text { centage of intervention- } \\
\text { to- total crashes }=-20.3 \\
\text { (reduction of } 20.3 \text { per- } \\
\text { centage points), } \mathrm{P}<0 \text {. } \\
0005\end{array}$ & Night-time total crashes & $\begin{array}{l}\text { Shift parameter for per- } \\
\text { centage of intervention- } \\
\text { to- total crashes }-8.0 \text { (re- } \\
\text { duction of } 8.0 \text { percent- } \\
\text { age points), } \mathrm{P}=0.0001\end{array}$ \\
\hline
\end{tabular}


Table 1. Within-study comparison of results from alcohol-related and alcohol-proxy measures (Continued)

\begin{tabular}{|c|c|c|c|c|}
\hline Lacey 1986 & $\begin{array}{l}\text { Alcohol-related total } \\
\text { crashes (sensitivity anal- } \\
\text { ysis) }\end{array}$ & $\begin{array}{l}\text { Shift parameter for in- } \\
\text { tervention area:Negative } \\
\text { value (i.e., reduction in } \\
\text { crashes), } \mathrm{p}=0.023 \\
\text { Shift parameter for com- } \\
\text { parison area: Positive } \\
\text { value (i.e., increase in } \\
\text { crashes), } \mathrm{P}>0.05\end{array}$ & $\begin{array}{l}\text { Night-time total crashes } \\
\text { (sensitivity analysis) }\end{array}$ & $\begin{array}{l}\text { Shift parameter for dif- } \\
\text { ference between inter- } \\
\text { vention and comparison } \\
\text { area: Negative value (i. } \\
\text { e., relative reduction in } \\
\text { crashes), } \mathrm{P}=0.001\end{array}$ \\
\hline Lacey 1987 & $\begin{array}{l}\text { Alcohol-related total } \\
\text { crashes }\end{array}$ & $\begin{array}{l}\text { Ratio of intervention- } \\
\text { to- comparison area: Au- } \\
\text { thors reported a pattern } \\
\text { of a constant ratio dur- } \\
\text { ing the pretest period } \\
\text { and a slightly higher ra- } \\
\text { tio (i.e., relative increase } \\
\text { in crashes) in the posttest } \\
\text { period, statistical signifi- } \\
\text { cance not tested }\end{array}$ & Night-time total crashes & $\begin{array}{l}\text { Ratio of intervention- } \\
\text { to- comparison area: Au- } \\
\text { thors reported a pattern } \\
\text { of a constant crash ratio } \\
\text { during the pretest period } \\
\text { and a slightly higher ra- } \\
\text { tio (i.e., relative increase) } \\
\text { in the post-test period, ns }\end{array}$ \\
\hline Lacey 1988 & $\begin{array}{l}\text { Alcohol-related total } \\
\text { crashes }\end{array}$ & $\begin{array}{l}\text { Shift parameter for ratio } \\
\text { of intervention-to- com- } \\
\text { parison }=-0.001 \text { (i. } \\
\text { e. relative decrease in } \\
\text { crashes), } P>0.10\end{array}$ & Night-time total crashes & $\begin{array}{l}\text { Shift parameter for ra- } \\
\text { tio of intervention-to- } \\
\text { comparison }=-0.131 \text { (i. } \\
\text { e., relative decrease in } \\
\text { crashes), } 0.05>\mathrm{P}<0.10\end{array}$ \\
\hline Mallory 1984 & $\begin{array}{l}\text { Alcohol-related total } \\
\text { crashes }\end{array}$ & $\begin{array}{l}\text { Rate ratio: } 0.89 \text { ( } 95 \% \text { CI } \\
\text { could not be calculated) }\end{array}$ & Night-time total crashes & $\begin{array}{l}\text { Rate ratio: } 0.92 \text { ( } 95 \% \mathrm{CI} \\
\text { could not be calculated) }\end{array}$ \\
\hline Voas 1997 & $\begin{array}{l}\text { Alcohol-related total } \\
\text { crashes }\end{array}$ & $-6 \%(-8 \%,-3 \%)$ & $\begin{array}{l}\text { Single vehicle night-time } \\
\text { total crashes }\end{array}$ & $\begin{array}{l}\text { Significant decrease in } \\
\text { crashes. SURE analysis: } \\
\Delta \mathrm{G}^{\wedge} 2=10.078, \mathrm{P}=0 . \\
018\end{array}$ \\
\hline
\end{tabular}

Table 2. Traffic crashes, traffic injuries, and alcohol-impaired driving

\begin{tabular}{l|l|l}
\hline Study & Results & Notes \\
\hline Aden 1981 & $\begin{array}{l}\text { Number of fatal crashes, all types combined } \\
\text { Mean before (SD): } 1.8(1.0) \\
\text { Mean after (SD): } 1.6(1.3) \\
\text { Absolute change: }-0.1 \\
\text { Percent relative change: }-7.1 \% \\
\text { Change in level }(\mathrm{SE}): 0.12(1.17), \mathrm{t}=0.10, \mathrm{P}=0.92 \\
\text { Change in slope }(\mathrm{SE}):-0.88 \text { crashes/quarter }(0.39), \\
\mathrm{t}=-2.29, \mathrm{P}=0.06\end{array}$ & $\begin{array}{l}\text { No statistical test reported in original paper. } \\
\text { ciated with a decrease in injury crashes despite an } \\
\text { increase in overall crashes }\end{array}$ \\
\hline \begin{tabular}{l} 
Number of injury crashes, all types combined \\
\hline
\end{tabular} & \\
\hline
\end{tabular}


Mean before (SD): 84.0 (8.5)

Mean after (SD): 104.1 (13.7)

Absolute change: 20.1

Percent relative change: $24.0 \%$

Change in level (SE): 0.68 (10.62), $t=0.06, p=0$.

95

Change in slope (SE): -5.53 crashes/quarter (3.52), $\mathrm{t}=-1.57, \mathrm{P}=0.16$

Author-calculated percent injury crashes before: $43 \%$

Author-calculated percent injury crashes after (year 1): $37 \%$

Author-calculated percent injury crashes after (year 2): $31 \%$

Number of total crashes, all types combined

Mean before (SD): 199.8 (7.0)

Mean after (SD): 309.1 (61.4)

Absolute change: 109.4

Percent relative change: $54.8 \%$

Change in level (SE): 52.40 (61.52), $\mathrm{t}=0.85, \mathrm{P}=0$.

42

Change in slope (SE): 10.75 crashes/quarter (20.36)

$, \mathrm{t}=0.53, \mathrm{P}=0.61$

Amick 1984
Number of injury crashes, nighttime

Intervention mean change (SE): -4.6 crashes/month (2.2), $\mathrm{t}=-2.09, \mathrm{P}<0.05$

Intervention percent change: not reported

Comparison mean change (C1): 0.64 crashes/month

(1.79), $\mathrm{t}=0.36, \mathrm{P}>0.05$

Comparison percent change (C1): not reported

Comparison mean change (C2): 4.5 crashes/month

(1.2), $\mathrm{t}=3.75, \mathrm{P}<0.05$

Comparison percent change (C2): not reported

Number of fatal crashes, alcohol-related

Intervention before: 22

Intervention after: 23

Comparison before: 130

Comparison after: 162

Rate ratio (95\% CI): $0.84(0.45,1.57)$

Number of injury crashes, alcohol-related

Intervention before: 175

Intervention after: 189

Comparison before: 1022

Comparison after: 1464

Rate ratio (95\% CI): 0.75 (0.60, 0.94)
All results shown were calculated by the authors. Authors performed an ARIMA analysis for selected outcome measure.

Authors concluded that there was a significant reduction of nighttime injury crashes in only the intervention group, "although the direction of daytime accident trends was similar for all counties studied."

No statistical test reported in original paper.

Authors calculated the percent change in the intervention area and comparison area, concluding that the intervention slowed the rate of increase in accidents involving alcohol 
Number of total crashes, alcohol-related

Intervention before: 322

Intervention after: 355

Comparison before: 1913

Comparison after: 2767

Rate ratio (95\% CI): $0.76(0.65,0.90)$

Campbell $1981 \quad$ Number of total crashes, alcohol-related Intervention before: Not calculated Intervention after: Not calculated Comparison before: Not calculated Comparison after: Not calculated Rate ratio (95\%CI): Not calculated Authors report a reduction in 40/92 (43\%) quarters when the intervention was occurring and a reduction in 163/356 (46\%) quarters when the intervention was not occurring (including both control areas that received no intervention and intervention areas before the intervention was implemented)

Fuller 2001 Number of fatalities, traffic crashes Intervention before: 44 Intervention after: 35 Comparison before: 40 Comparison after: 32

Rate ratio (95\%CI): 0.99 (0.52, 1.89)

Author-calculated change in intervention relative to comparison: $0 \%$

Author-calculated Chi-square $=1.0(\mathrm{df}=1), \mathrm{ns}$

Number of serious injuries, traffic crashes

Intervention before: 229

Intervention after: 189

Comparison before: 109

Comparison after: 110

Rate ratio (95\%CI): $0.82(0.59,1.13)$

Author-calculated change in intervention relative to comparison: $18 \%$ decrease

Author-calculated Chi-square $=1.44(\mathrm{df}=1)$, ns

Number of minor injuries, traffic crashes

Intervention before: 878

Intervention after: 986

Comparison before: 435

Comparison after: 536

Rate ratio (95\% CI): $0.91(0.78,1.07)$

Author-calculated change in intervention relative to comparison: $9 \%$ decrease
No statistical test reported in original paper.

Authors concluded that the results failed to show an effect of the program on alcohol-related crashes

For numbers of fatalities and numbers of injuries, authors performed a chi-square test and $\mathrm{k}$ test comparisons. Authors concluded that there was no effect of the program on fatalities and that the program reduced serious and minor injuries, but that these reductions were not statistically reliable.

Data for hospital presentations (traffic crashes) and hospitalizations or transfers (traffic crashes) were extrapolated by the authors and therefore are not shown here.

* Asterisk indicates pretest rates were averaged across 6 baseline years 
Author-calculated chi-square $=1.36(\mathrm{df}=1)$, ns

Rates of total crashes per 1000 population per year, all types combined

Intervention before*: 5.7

Intervention after: 5.9

Comparison before*: 5.8

Comparison after: 6.9

Rate ratio (95\%CI): $0.87(0.18,4.27)$

Author-calculated change in intervention relative to comparison: $17 \%$ reduction, $\mathrm{P}>0.05$.

Rates of total crashes per 10 million VKT per year, all types combined

Intervention before* 6.3

Intervention after: 5.4

Comparison before*: 6.9

Comparison after: 5.6

Rate ratio (95\%CI): 1.06 (0.21, 5.29)

Author-calculated change in intervention relative to comparison: $13 \%$ increase, $\mathrm{P}>0.05$

Rates of total crashes per 1000 registered vehicles per year, all types combined

Intervention before*: 18.3

Intervention after: 15.0

Comparison before*: 15.2

Comparison after: 18.7

Rate ratio (95\%CI): $0.67(0.25,1.74)$

Author-calculated change in intervention relative to comparison: $32 \%$ reduction, $\mathrm{P}>0.05$

Proportion of survey respondents who reported driving in previous month when potentially just over the limit

After first weekend of enforcement

Intervention before: $42 / 133$

Intervention after: $28 / 133$

Comparison before: $48 / 134$

Comparison after: $25 / 134$

Relative risk (95\% CI): $1.13(0.67,1.90)$

Author-calculated X^2: not reported, $\mathrm{P}>0.05$

After last weekend of enforcement

Intervention before: $32 / 111$

Intervention after: 22/111

Comparison before: $41 / 111$

Comparison after: 25/111

Relative risk (95\% CI): $0.88(0.51,1.52)$

Author-calculated X^2: not reported, $\mathrm{P}>0.05$
Authors did not collect primary outcome measures.

Author measured differences between areas in selfreported drinking and driving using Chi-square test for independence. Follow up rates were $79 \%$ for the first survey wave and $65 \%$ for the second wave. For all comparisons, only respondents who participated in pretest and posttest surveys were included. Author found that drink driving behaviors did not change significantly following the intervention 
Proportion of survey respondents who reported driving home from the hotel after their most recent visit (among those whose reported driving to the hotel and drinking heavily during their most recent visit) After first weekend of enforcement Intervention before: $6 / 32$ Intervention after: $5 / 32$

Comparison before: $16 / 52$

Comparison after: $9 / 52$

Relative risk (95\% CI): $0.90(0.28,2.69)$

Author-calculated X^2: not reported, P > 0.05

After last weekend of enforcement

Intervention before: 13/37

Intervention after: $6 / 37$

Comparison before: 18/54

Comparison after: $9 / 54$

Relative risk (95\% CI): 0.97 (0.33, 2.75)

Author-calculated X^2: not reported, P > 0.05

Hingson 1996
Rate of total injuries per 100 traffic crashes Intervention before: 48.2

Intervention after: 47.3

Comparison (C1) before: Data not reported Comparison (C1) after: Data not reported Rate ratio (95\% CI): Could not be calculated Author-calculated RR: not reported, ns

Number of fatal crashes, alcohol-related Intervention before: 69

Intervention after: 36

Comparison (C1) before: Data not reported

Comparison (C1) after: Data not reported

Rate ratio (95\% CI): Could not be calculated

Author-calculated RR $(95 \% \mathrm{CI})=0.58(0.32,1.08)$

, $\mathrm{P}=0.08$
Number of fatalities, nighttime traffic crashes Mean before (SD): 23.2 (5.2)

Mean after (SD): 17.4 (6.0)

Absolute change: -5.8

Percent relative change: $-25.0 \%$ Change in level (SE): $-0.18(3.80), \mathrm{t}=-0.05, \mathrm{P}=0$. 96

Change in slope (SE): -0.96 deaths/month (0.49), $\mathrm{t}$ $=-1.95, \mathrm{P}=0.06$

Number of hospitalizations, traffic crash injuries
For primary outcome measures, authors calculated RR using Poisson log-linear regression.

For number of alcohol-related fatal crashes per year, authors also performed a repeated measures analysis of variance using the city as the unit of analysis. Crashes in the intervention cities declined $24 \%$ relative to $\mathrm{C} 1(\mathrm{p}<0.001)$ and $31 \%$ relative to $\mathrm{C} 2(\mathrm{p}=$ $0.05)$.

Authors concluded that the program reduced alcohol-impaired driving and traffic casualties

For the proportion of night-time injury crashes and for the number of fatalities, no statistical test was reported in original paper. For number of hospitalizations, authors reported that there was no way to determine degrees of freedom for a statistical comparison.

For the number of night-time injury crashes, authors performed a time series analysis using Poisson-error analysis of variance. 
Mean before (SD): 177.4 (14.5)

Mean after (SD): 153.0 (21.1)

Absolute change: -24.4

Percent relative change: $-13.8 \%$

Change in level (SE): $-17.21(19.82), \mathrm{t}=-0.87, \mathrm{p}=$ 0.43

Change in slope (SE): 14.37 hospitalizations/week (6.29), $\mathrm{t}=2.28, \mathrm{P}=0.07$

Proportion of night-time injury crashes

Mean before (SD): $0.314(0.024)$

Mean after (SD): $0.291(0.037)$

Absolute change: -0.02

Percent relative change: $-7.3 \%$

Change in level (SE): $-0.012(-0.012), \mathrm{t}=-0.50, \mathrm{P}=$ 0.62

Change in slope (SE): $0.000(.004), \mathrm{t}=-0.10, \mathrm{P}=0$. 92

Number of injury crashes, nighttime

Author-calculated change: $44 \%$ reduction, change multiplier at intervention start $=0.61(95 \%$ CI 0 . $51,0.72$ )

Jansma 1978

Number of total crashes, alcohol-related

Intervention before: $611^{*}$

Intervention after: 707

Comparison before: 1191*

Comparison after: 1514

Rate ratio (95\%CI): 0.91 (0.80, 1.04)

Authors reported that alcohol-related crashes were significantly lower than trend line projection, $\mathrm{P}<0$. 10

Jones 1995 a
Authors concluded that the enforcement blitzes "reduced the road losses that normally accrue from alcohol impaired driving."
Authors projected five-year trend lines for control and intervention groups, with adjustments for the energy crisis years of 1974 and 1975 and for the Christmas-New Year's accident reduction project. Authors concluded that the intervention was effective in reducing DUI crashes.

* Asterisk indicates counts were averaged over three baseline years
First intervention area (I1) versus Comparison area:

Results were the same for all selected outcomes.

Number of serious or fatal injuries, traffic crashes; Number of minor injuries, traffic crashes; Number of injury crashes, single vehicle nighttime; Number of total crashes, alcohol-related;

Intervention mean change (SE): not reported, Pvalue ns

Intervention percent change: not reported

Comparison mean change (SE): not reported, Pvalue ns

Comparison percent change: not reported

Among those who reported drinking, percentage re-
Results for all selected primary outcomes were calculated by the authors.

Intervention area (I1) v. Comparison area:

For all primary outcomes, authors performed a time series regression, with time trends, seasonal effects, and unemployment rates included in the model. For self-reported alcohol-impaired outcomes, statistical tests were not reported. Respondent attributes differed across cities and waves, so authors reported weighted percentages.

Intervention area (I2) v. Comparison area: For all primary outcomes, authors performed an ARIMA analysis. For self-reported alcohol-impaired 
porting alcohol-impaired driving at all in past 3 months (CBA)

Intervention before: $9 \%$

Intervention after (1st phase): $20 \%$

Intervention after (2nd phase): $11 \%$

Comparison before: $10 \%$

Comparison after (1st phase): $11 \%$

Comparison after (2nd phase): $11 \%$

Rate ratio before v. 1st phase (95\% CI): 1.89 (95\%

CI could not be calculated)

Rate ratio before v. 2nd phase (95\% CI): 1.05 (95\%

CI could not be calculated)

\section{Second intervention area (I2) v. Comparison} area:

Number of injury crashes, single vehicle night time Intervention mean change (SE): not reported, $\mathrm{P}<0$. 2

Intervention percent change: $-15 \%$

Comparison mean change (SE): not reported, $\mathrm{p}>0$. 2

Comparison percent change: not reported

Number of total crashes, alcohol-related

Intervention mean change (SE): not reported, $\mathrm{p}>0$. 2

Intervention percent change: not reported

Comparison mean change (SE): not reported, $\mathrm{P}>0$. 2

Comparison percent change: not reported

Among those who reported drinking, percentage reporting alcohol-impaired driving at all in past 3 months (CBA)

Intervention before: not reported

Intervention after (1st phase): not reported

Intervention after (2nd phase): not reported

Comparison before: not reported

Comparison after (1st phase): not reported

Comparison after (2nd phase): not reported

Author-calculated pre-post changes were not statistically significant for $\mathrm{C} 1$ or I2.

Results were not reported for any other selected outcomes. driving outcomes, authors used a generalized linear model to predict self-reported drinking and driving behavior with survey site, survey wave, reason for being at the Department of Motor Vehicles age, sex, and drinking frequency as independent variables.

Authors concluded that the intervention in I2, but not I1, was effective in reducing alcohol-related crashes relative to the comparison group
Number of injury crashes, single vehicle nighttime, with comparison area as a control Intervention mean change (SE): not reported, $\mathrm{P}<0$. 005
Results for all selected primary outcomes were calculated by the authors.

For number of injury crashes (single vehicle night 
Percent relative change: $-23 \%$

Number of total crashes, alcohol-related, with comparison area as a control

Intervention mean change (SE): positive value (exact value not reported), $\mathrm{P}>0.05$

Percent relative change: not reported

Among those who reported drinking, percentage reporting alcohol-impaired driving at all in past 3 months (CBA)

Intervention before: not reported

Intervention after (1st phase): not reported

Intervention after (2nd phase): not reported

Comparison before: not reported

Comparison after (1st phase): not reported

Comparison after (2nd phase): not reported

Author-calculated pre-post changes were not statistically significant for either site.

Results were not reported for any other selected outcomes. time), authors reported an ARIMA analysis with the comparison injury crashes (single vehicle night time) as a control. For number of alcohol-related total crashes, authors used time series models, accounting for time trends and seasonal effects, with comparison alcohol-related total crashes as a control. For self-reported alcohol-impaired driving outcomes, authors used a generalized linear model to predict self-reported drinking and driving behavior with survey site, survey wave, reason for being at the Department of Motor Vehicles, age, sex, and drinking frequency as independent variables.

Authors concluded that the intervention was effective in reducing alcohol-related crashes relative to the comparison
Lacey 1986

Increased police patrols for preventing alcohol-impaired driving (Review)

Copyright (־ 2008 The Cochrane Collaboration. Published by John Wiley \& Sons, Ltd.

disablement crashes), alcohol-related

Shift parameter in intervention area: Negative value (exact value not reported), $\mathrm{P}>0.05$

Shift parameter in comparison area: Positive value (exact value not reported), $\mathrm{P}>0.05$

Difference between alcohol-related personal injury or vehicle disablement crashes in the intervention area and the comparison area

Shift parameter: Negative value (exact value not reported), $\mathrm{P}=0.023$

Among survey respondents who reported drinking, number of respondents reporting driving after drinking too much in the past month (CBA)*

Intervention before: 53

Intervention after: 33

Comparison before: 45

Comparison after: 34
Results for all selected primary outcomes were calculated by the authors. For percentage of alcohol-related crashes in intervention area relative to total, alcohol-related crashes in intervention and control areas, authors calculated shift parameters using a time series model with a shift in level and a 2 nd order moving average.
Authors examined alcohol-related personal injury or vehicle disablement crashes post hoc due to changes in reporting standards for total crashes. Authors calculated shift parameters using autocorrelational regression analysis.

Authors concluded that the intervention program was effective in reducing alcohol-related crashes.

* Counts for all groups were back-calculated from percentages and/or means, and sample sizes provided in text 
Rate ratio (95\% CI): $0.80(0.43,1.50)$

Among survey respondents who reported drinking, number of self-reported impaired driving events $(\mathrm{CBA})^{*}$

Intervention before: 114

Intervention after: 352

Comparison before: not reported

Comparison after: not reported

Rate ratio (95\% CI): Could not be calculated

Results were not reported for any other selected outcomes.

Alcohol-related crashes as a percentage of total crashes (ITS)

Intervention mean change (SE): not reported, Pvalue $=$ not reported

Intervention percent change: not reported

Ratio of percentage of total crashes that are alcoholrelated in the intervention area to the percentage of total crashes that are alcohol-related in the comparison area

Mean change (SE): not reported, $\mathrm{P}$-value $=$ not reported

Percent change: not reported

Authors reported a pattern of a constant crash ratio during the pretest period and a slightly higher ratio in the post-test period.

Among survey respondents who reported drinking, number of respondents reporting driving after drinking too much in the past month (CBA)*

Intervention before: 48

Intervention after: 48

Comparison before: 60

Comparison after: 60

Rate ratio (95\% CI): $1.01(0.59,1.73)$

Among survey respondents who reported drinking, number of self-reported impaired driving events (CBA)

Intervention before: not reported

Intervention after: not reported

Comparison before: not reported

Comparison after: not reported

Rate ratio (95\% CI): Could not be calculated
Results for all selected primary outcomes were calculated by the authors. Authors did not analyze alcohol-related crashes because this series was shorter than but similar to a series of nighttime crashes, for which authors performed an ARIMA analysis.

Authors concluded that the program did not have an effect on alcohol-related or night-time crashes.

* Counts for all groups were back-calculated from percentages and/or means, and sample sizes provided in text

Increased police patrols for preventing alcohol-impaired driving (Review) 
Lacey 1988

Lacey 1991
Percentage of total crashes that are alcohol-related (ITS)

Shift parameter at start of intervention $=1.146(\mathrm{an}$ increase of 1.1 percentage points), $\mathrm{P}<0.05$

Shift parameter at end of intervention $=0.847$ (an increase of 0.9 percentage points), $0.05<\mathrm{P}<0.10$ Authors noted that the intervention series had a fairly constant level of about $8.5 \%$ and that the comparison series begins at much higher levels ... (about 14) and decreases steadily over time to about $7 \%$.

Ratio of alcohol-related total crashes in intervention area to alcohol-related total crashes in comparison area

Shift parameter at start of intervention $=-0.001(\mathrm{a}$ decrease of 0.001 in the ratio of I1-to-C1 crashes), $\mathrm{P}>0.10$

Shift parameter at end of intervention $=0.098(\mathrm{an}$ increase of 0.098 in the ratio of 11 -to-C1 crashes), $\mathrm{P}$ $>0.10$

Among survey respondents who reported drinking, number of respondents reporting driving after drinking too much in the past month (CBA)*

Intervention before: 57

Intervention after: 42

Comparison before: 52

Comparison after: 54

Rate ratio (95\% CI): $0.72(0.41,1.24)$

Among survey respondents who reported drinking, number of self-reported impaired driving events (CBA)*

Intervention before: 167

Intervention after: 108

Comparison before: 142

Comparison after: 144

Rate ratio (95\% CI): $0.64(0.46,0.89)$
Results for all selected primary outcomes were calculated by the authors. For primary outcome measures, authors calculated shift parameters using an ARIMA analysis.

Authors concluded that the program had no effect on alcohol-related crashes.

Authors re-analysed the ratio series using a different intervention start point, which was believed to correspond with actual (rather than planned) increases in enforcement. Results indicated a reduction in alcohol-related crashes that was not statistically significant.

* Counts for all groups were back-calculated from percentages and/or means, and sample sizes provided in text
No statistical test performed. Authors concluded that the decreasing trend in crash fatalities occurred during the pretest and posttest periods and therefore "cannot be attributed to the program"
Number of fatalities, traffic crashes

Mean before (SD): 41.6 (8.0)

Mean after (SD): 32.4 (6.5)

Absolute change: -9.2

Percent relative change: $-22.2 \%$

Change in level (SE): $-7.53(8.59), \mathrm{t}=-0.88, \mathrm{P}=0$.

41

Change in slope (SE): -0.96 deaths/year $(2.34), \mathrm{t}=$ $-0.41, P=0.69$ 
Mallory 1984

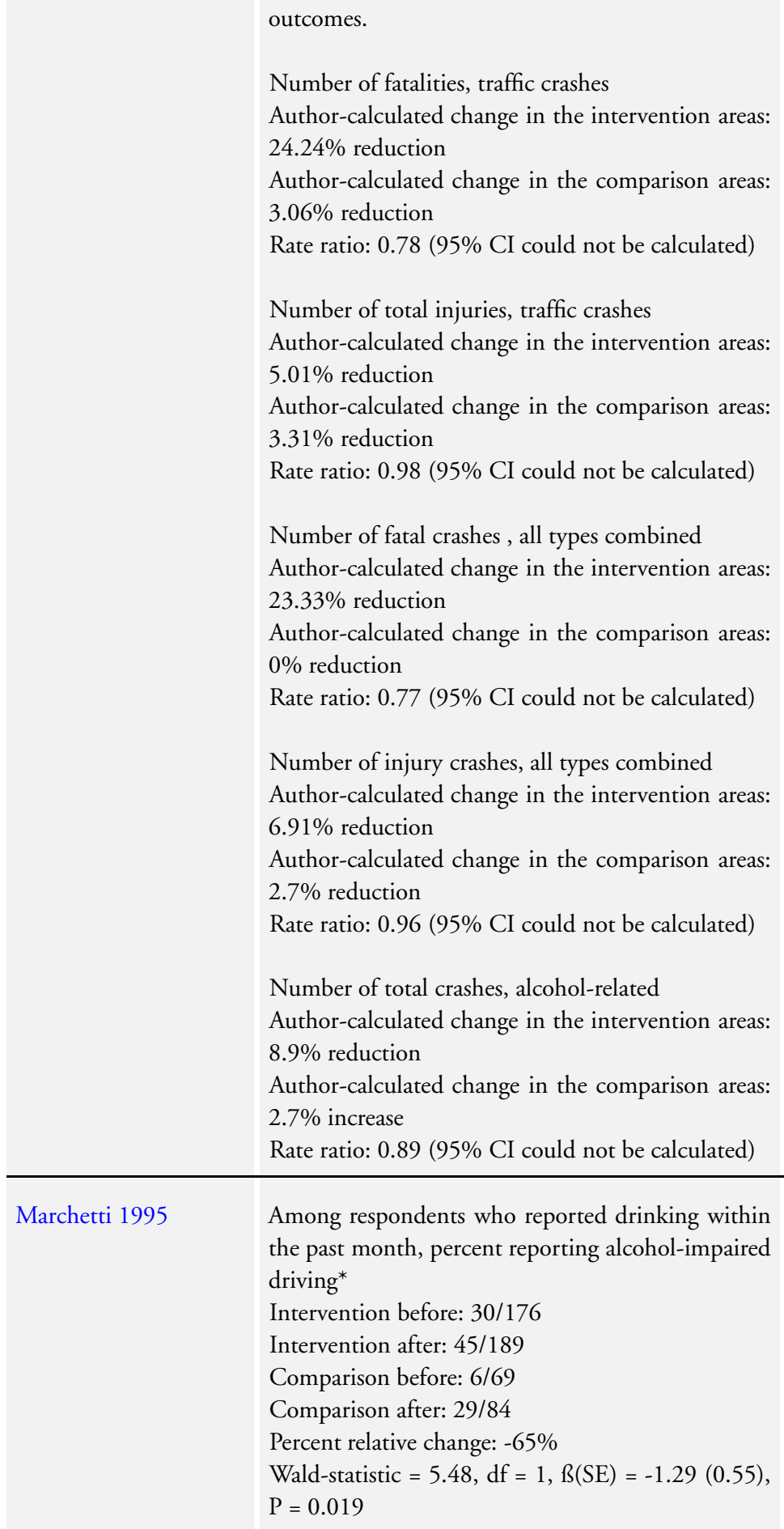

No statistical tests performed. Author calculated the percentage pre-post change for intervention and comparison groups.

Author concludes that "It is too early to make statistically significant statements about the impact of the grants on the frequency of alcohol-related accidents.

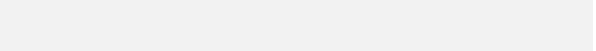




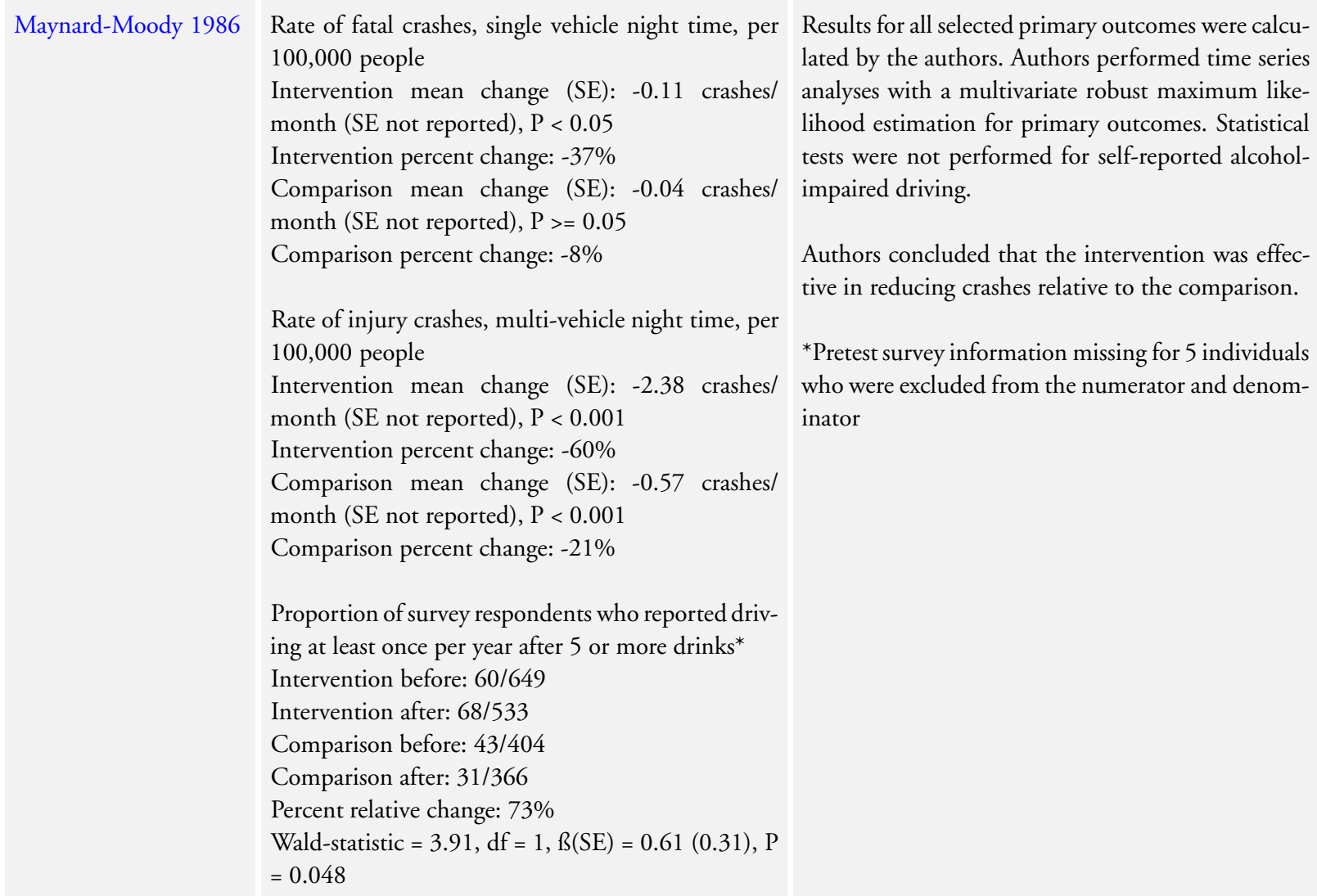

McEwen $1985 \quad$ Number of injury crashes, nighttime

Mean before(SD): 67.9 (11.9)

Mean after (SD): 65.2 (10.9)

No statistical test performed. Authors concluded that injury crashes were not affected by the enforcement program

Absolute change: -2.7

Percent relative change: $-4.0 \%$

Change in level (SE): $-1.86(9.82), \mathrm{t}=-0.19, \mathrm{P}=0$.

85

Change in slope (SE): 0.26 crashes/month (1.23), $\mathrm{t}$

$=0.21, \mathrm{P}=0.83$

Pigman $1984 \quad$ Number of total crashes, alcohol-related Intervention mean change (SE): -2.23 crashes/week (SE not reported), $\mathrm{P}<0.05$

Intervention percent change: $-21 \%$
Results for all selected primary outcomes were calculated by the authors. Authors performed a time series analysis, adjustment for serial correlation not specified. Authors concluded that the intervention was effective in reducing alcohol-related crashes
Number of total crashes, alcohol-related (ITS and CBA)

Author-calculated intervention mean change (SE): not reported, $\mathrm{P}<0.05$

Author-calculated intervention percent change: -26 .
Authors performed an ARIMA analysis for number of alcohol-related total crashes for the intervention area. Authors also performed traditional before-after comparisons, using a chi-square test. 
$1 \%$

Intervention before: $1915^{*}$

Intervention after: 1333

Comparison before: not reported

Comparison after: not reported

Author-calculated percent change in intervention area: $-30.4 \%$, Chi-square $=$ not reported, $\mathrm{P}<0.05$.

Author-calculated percent change in comparison area $(\mathrm{C} 1):-14.2 \%$, Chi-square $=$ not reported, $\mathrm{P}>$ 0.05 .

Rate ratio (95\%CI): 0.81 (95\% CI could not be calculated)

Sali 1983

Number of injury crashes, all types combined

Intervention mean change (SE): -14.1 crashes/ month (-2.7), $\mathrm{p}<0.01$

Intervention percent change: Not reported

Comparison mean change (SE): -8.0 crashes/month

(10.5), $\mathrm{P}>0.05$

Comparison percent change: Not reported

St Louis Police 1981

Number of fatalities, traffic crashes

Mean before (SD): 3.5 (2.6)

Mean after (SD): 3.1 (1.5)

Absolute change: -0.4

Percent relative change: $-12.1 \%$

Change in level (SE): $-3.81(1.76), t=-2.17, \mathrm{P}=0$.

04

Change in slope (SE): -0.47 deaths/month (0.21), $\mathrm{t}$

$=-2.29, \mathrm{P}=0.03$

Number of total injuries, traffic crashes

Mean before (SD): 235.0 (58.0)

Mean after (SD): 302.9 (39.7)

Absolute change: 67.9

Percent relative change: $28.9 \%$

Change in level (SE): 9.78 (44.23), $\mathrm{t}=0.22, \mathrm{P}=0$.

83

Change in slope (SE): -10.13 injuries/month (5.20)

$, \mathrm{t}=-1.95, \mathrm{P}=0.06$

Number of fatal crashes, all types combined

Mean before (SD): 3.1 (2.1)

Mean after (SD): 2.8 (1.3)

Absolute change: -0.3

Percent relative change: $-9.7 \%$

Change in level (SE): $-2.40(1.47), t=-1.64, \mathrm{P}=0$.

11

Change in slope (SE): -0.32 crashes/month (0.17), t
Authors concluded that the program was effective in reducing alcohol-related total crashes.

* Counts were averaged over three baseline years and two posttest years

Results for all selected primary outcomes were calculated by the author. Author performed an ARIMA analysis and concluded that the intervention was effective in reducing injury crashes

No statistical test performed. Authors concluded that there was a decrease in fatal, injury, and total crashes of all types combined

Increased police patrols for preventing alcohol-impaired driving (Review) 
$=-1.83, \mathrm{P}=0.07$

Number of injury crashes, all types combined

Mean before (SD): 174.1 (66.4)

Mean after (SD): 203.5 (26.0)

Absolute change: 29.4

Percent relative change: $16.9 \%$

Change in level (SE): -2.23 (34.53), $\mathrm{t}=-0.06, \mathrm{P}=$ 0.95

Change in slope (SE): -6.26 crashes/month (4.09), t

$=-1.53, \mathrm{P}=0.13$

Number of total crashes, all types combined

Mean before (SD): 612.4 (309.8)

Mean after (SD): 572.8 (84.9)

Absolute change: -39.6

Percent relative change: $-6.5 \%$

Change in level (SE): 109.41 (122.96), $t=0.89, \mathrm{p}=$

0.38

Change in slope (SE): 5.24 crashes/month (14.65), $\mathrm{t}=0.36, \mathrm{P}=0.72$

Number of injury crashes, alcohol-related Intervention (I1) mean change (SE): not reported, $\mathrm{t}$ $=-2.13, \mathrm{P}=0.0181$

Intervention (I1) percent change: $-18 \%$

Comparison (C1) mean change (SE): not reported, $\mathrm{t}=-1.82, \mathrm{P}=0.0362$

Comparison (C1) percent change: $-11 \%$

Number of total crashes, single vehicle (CBA) Pretest and posttest data were not reported. Intervention (I1) $\mathrm{t}=$ not reported, $\mathrm{P}<0.05$

Comparison $(\mathrm{C} 1) \mathrm{t}=$ not reported, $\mathrm{P}>=0.05$
Results for all selected primary outcomes were calculated by the authors. Authors performed an ARIMA analysis, with non-alcohol-related injury crashes as a control series for the number of alcohol-related injury crashes.

Although 9 pretest and 9 post-test data points were collected for number of total crashes (single vehicle) , authors performed paired t-tests.

Authors concluded that both areas experienced a decrease in alcohol-related injury crashes. Although the no-treatment comparison area also experienced a decrease in crashes, this was offset by a decrease in all injury crashes

For selected outcome measures, author reported results of chi square analysis. The author concluded that the reduction in crashes during the intervention period strongly suggests that the intervention was effective

Author-calculated comparison percent change: $-3 \%$ Author-calculated Chi-square value $=$ not reported, $\mathrm{P}<0.002$

Rate ratio (95\%CI): 0.85 (95\% CI could not be calculated)

Number of total crashes, all types combined (ITS 
and CBA)

Mean before (SD): 1932.5 (363.5)

Mean after (SD): 1708.4 (224.5)

Absolute change: -224.1

Percentage relative change: $-11.6 \%$

Change in level (SE): $-651.34(189.27), \mathrm{t}=-3.44$,

$\mathrm{P}=0.003$

Change in slope (SE): -95.21 crashes/month (26.85)

$, \mathrm{t}=-3.55, \mathrm{P}=0.002$

Author-calculated intervention percent change: -

$12 \%$

Author-calculated comparison percent change: $4 \%$

Author-calculated Chi-square value $=$ not reported,

$\mathrm{P}<0.002$

Rate ratio (95\%CI): 0.85 (95\% CI could not be calculated)

Sykes 1984
Mean number of total crashes per hour, during patrol hours

Intervention before: 3.21

Intervention after: 2.31

Control before: 3.41

Control after: 2.68

Rate ratio* (95\% CI): 0.92 (95\% CI could not be calculated)

Author-calculated t-value for intervention area: 2 .

$30, \mathrm{P}<0.05$

Author-calculated t-value for comparison area: 3.93,

$\mathrm{P}<0.01$
Author examined differences between means using groups t-test. Author concluded that increasing the certainty of arrest was effective in decreasing drunk driving.

* Rate ratio imputed from mean crash rates.
Number of total crashes, nighttime weekend Intervention mean change (SE): -5.3 crashes/month (1.98), $\mathrm{t}=-2.68, \mathrm{P}<0.01$

Intervention percent change: $-15 \%$

Comparison (C1) mean change (SE): 2.7 crashes/ month (7.26), $\mathrm{t}=0.37$, ns

Comparison (C1) percent change: varied across individual cities, ranging from $-8 \%$ to $24 \%$
Log of relative ratio of nighttime injury crashes in the intervention areas to nighttime injury crashes in the comparison areas

Mean change (SE): not reported, P-value not reported

Percent relative change (95\% CI): $-10 \%(-14,-4)$

Wald statistic $=13.60, \mathrm{df}=4, \mathrm{~B}=-0.02, \mathrm{P}=0.009$

Log of relative ratio of total alcohol-related crashes in
Results for all selected primary outcomes were calculated by the authors. Authors performed Box-Tiao time series analysis. Authors concluded that the intervention decreased night-time weekend crashes
Results for all selected primary outcomes were calculated by the authors. For RRs of night-time injury crashes, alcohol-related total crashes, and self-reported alcohol-impaired driving, authors calculated Wald statistic using Seemingly Unrelated Regression Analysis. For blood alcohol content, authors did not specify the analysis performed but noted a significant decline in the rate of drivers with positive blood alcohol content after the intervention, compared to 
Table 2. Traffic crashes, traffic injuries, and alcohol-impaired driving

the intervention areas to total alcohol-related crashes in the comparison areas

Mean change (SE): not reported, P-value not reported

Percent relative change (95\% CI): $-6 \%(-8,-3)$

Wald Chi-square $=19.56, \mathrm{df}=4, ß=-0.01, \mathrm{P}=0$. 001

Log of relative ratio of number of days in past 6 months respondent drove after having too much to drink

Mean change (SE): not reported, P-value not reported

Percent relative change (95\% CI): $-49 \%(-70,-11)$

Wald statistic $=11.53, \mathrm{df}=3, \mathrm{~B}=-0.39, \mathrm{P}=0.009$

Log of relative ratio of number of days respondent drove in past 6 months when over the legal limit for alcohol consumption

Mean change (SE): not reported, P-value not reported

Percent relative change ( $95 \% \mathrm{CI}):-51 \%(-70$ to -21$)$

Wald statistic $=5.052, \mathrm{df}=3, \mathrm{~B}=-0.51, \mathrm{P}=0.002$

Voas 2002

Wiliszowski 2003
Natural $\log$ of the ratio of alcohol-related, nighttime weekend injury crashes among ages 16-20 to nonalcohol-related nighttime weekend injury crashes among ages 16-20

Intervention mean change (SE): $-0.002(0.001), \mathrm{t}=$ $-2.22, p=0.032$

Intervention percent change: $-45.3 \%$

Comparison mean change (SE): not reported, $\mathrm{t}=$ not reported, $\mathrm{P}>0.40$

Comparison percent change: not reported, although authors state that there was no change in the comparison area

Number of drivers with a blood alcohol content >= 0.01 in fatal crashes

Intervention mean change (SE): -5.7 crashes/half year (SE not reported), $\mathrm{t}=$ not reported, $\mathrm{P}=0.037$

Intervention percent change: $-40 \%$

Comparison mean change (SE): not reported, $\mathrm{t}=$ not reported, $\mathrm{P}=0.807$

Comparison percent change: not reported

Authors calculated a $25 \%$ reduction in the intervention area relative to the comparison area before, for $\mathrm{I} 1$ versus $\mathrm{C} 1$ only.

For daytime crashes, authors reported no reduction, percent change $(95 \% \mathrm{CI})=2(-7,14)$; Wald statistic $=4.51, \mathrm{df}=4, \mathrm{P}=0.34, ß=0.042$.

Authors concluded that the intervention reduced nighttime injury and alcohol-related crashes while daytime crashes did not change

Results for all selected primary outcomes were calculated by the authors. Authors performed ARIMA intervention time series modeling. Authors concluded that the intervention was associated with a reduction in alcohol-related, nighttime weekend injury crashes among ages 16-20

Results for all selected primary outcomes were calculated by the authors. Authors performed ARIMA analyses. Missing blood alcohol content data were imputed. Authors concluded that the intervention was effective in reducing fatal alcohol-related crashes 
Wolfe 1984

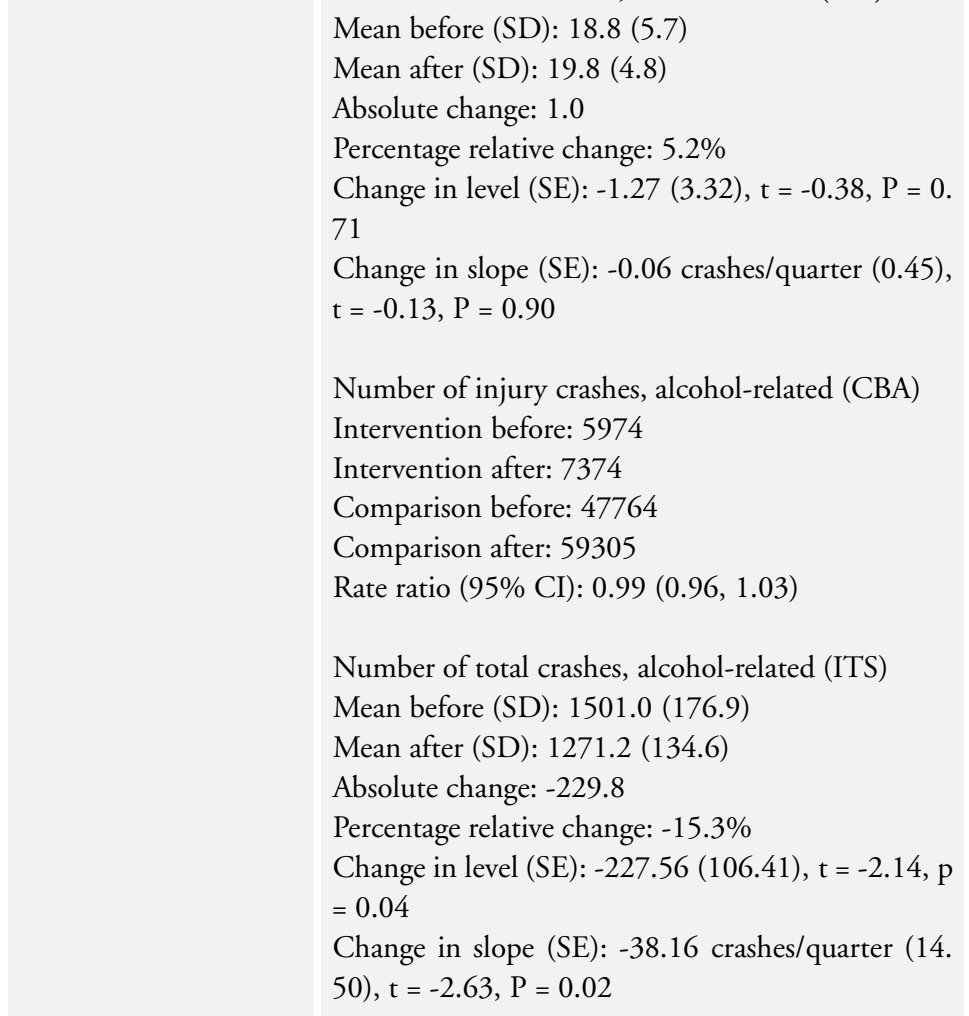

Zador 1976

\author{
Number of fatal crashes, alcohol-related (ITS) \\ Percentage relative change: $5.2 \%$ \\ $\mathrm{t}=-0.13, \mathrm{P}=0.90$
}

Number of injury crashes, alcohol-related (CBA)

Comparison before: 47764

Comparison after: 59305

Number of total crashes, alcohol-related (ITS)

Absolute change: -229.8

Change in slope (SE): -38.16 crashes/quarter (14.
Proportion of traffic crash fatalities in the intervention and comparison areas that occurred in the intervention areas

Pre-test and post-test data were not reported.

For programs beginning in $1971, \mathrm{~F}$-value $=1.33(\mathrm{df}=$ 4.16), $\mathrm{P}>0.50$

For programs beginning in 1972, F-value $=0.42(\mathrm{df}$

= 3.21), $\mathrm{P}>0.50$
Results for all selected primary outcomes were calculated by the authors. No statistical test performed. Authors concluded that it was difficult to assess the effect of the program on reducing alcohol-related crashes
Results for all selected primary outcomes were calculated by the author. Author applied a weighted analysis of variance to a transform of the proportions. The author reports no change in fatalities in the intervention areas relative to the comparison areas 


\section{A P P E N D I C E S}

\section{Appendix I. Eligibility criteria for study designs}

A. Randomized controlled trial (RCT)

1. The study must be prospective.

2. The study must compare two or more interventions.

3. The study must incorporate random assignment of participants to the interventions utilizing a known randomization technique (e.g., random numbers table or electronic pseudo-random generator), or the study must state that subjects were assigned randomly (without any explanation of how).

B. Controlled trial (CT)

Criteria 1 and 2 are the same as for an RCT.

3. The study must incorporate assignment of participants to the interventions utilizing a means of quasi- or pseudo-randomization (e.g., alternation), or the study must state that participants were assigned to intervention conditions (without any explanation of how).

C. Controlled before-after (CBA) study

1. A CBA must compare an intervention group or area with at least one external comparison group or area.

2. Pretest and posttest outcome measurements must be available for both groups.

3. Pretest and posttest outcomes for both groups must be measured concurrently.

4. Groups must be assigned by an entity other than the participants themselves.

D. Interrupted time series (ITS)

1. The investigators must report having made at least three pretest and three posttest observations of the outcome measure from the single group in the study.

2. The intervention must occur at a specific point in time.

3. An entity other than the participant must control who receives the intervention.

E. Controlled interrupted time series (CITS)

1. The investigators must report having made at least three pretest and three posttest observations of the outcome measure from the intervention group or area and concurrently from at least one external comparison group or area.

Criteria 2 and 3 are the same as for an ITS.

\section{Appendix 2. Search strategies}

Injuries Group Specialised Register (May 31, 2006)

(drink* or drunk* or intoxicat* or alcoholi* or impaired or alcohol or ethanol or BAC)

AND (road* or traffic* or driv* or vehicles or accident* or crash* or car* or cars or motorcycl* or automobil*)

AND ("social control" or enforc* or deter OR deters OR deterr* or law or laws or government or legal or legislation or jurisprudence or justice or coerc* or police* or officer* or patrol* or checkpoint* or blitz* or crime* or criminal* or offender* or "breath test*" or "breath analy" or breathaly* or "mass medi*” or "mass communication" or "media advocacy" or "public polic" or campaign* or adverti* or "Communit* Program*”)

OR (driving under the influence) OR DUI or DWI

CENTRAL (The Cochrane Library 2006, Issue 2)

\#1 MeSH descriptor Automobile Driving explode all trees in MeSH products

\#2 driv* OR road* OR traffic* in All Fields, from 1800 to 2004 in all products

\#3 MeSH descriptor Motor Vehicles explode all trees in MeSH products

\#4 vehicles OR car OR cars OR motorcycl* OR automobil* in All Fields, from 1800 to 2004 in all products

\#5 MeSH descriptor Accidents explode all trees in MeSH products

$\# 6$ accident* OR crash* in All Fields in all products

\#7 (\#1 OR \#2 OR \#3 OR \#4 OR \#5 OR \#6)

\#8 MeSH descriptor Alcohol Drinking explode all trees in MeSH products

\#9 drink* OR drunk* in All Fields, from 1800 to 2004 in all products

\#10 MeSH descriptor Alcoholic Intoxication explode all trees in MeSH products

\#11 MeSH descriptor Alcoholism explode all trees in MeSH products

\#12 alcoholi* OR intoxicat* in All Fields in all products

\#13 impaired in All Fields in all products

Increased police patrols for preventing alcohol-impaired driving (Review)

Copyright $\odot 2008$ The Cochrane Collaboration. Published by John Wiley \& Sons, Ltd. 
\#14 MeSH descriptor Alcohols explode all trees in MeSH products

\#15 alcohol OR ethanol in All Fields in all products

\#16 BAC not (bacter* OR gene OR geno* OR chromo* OR amino OR cyto* OR virus OR stroke OR athero* OR viral OR cardi*

OR cell OR coeff* OR dentin OR MAPK OR RAS) in All Fields in all products

$\# 17$ blood NEXT alcohol in All Fields in all products

\#18 (\#8 OR \#9 OR \#10 OR \#11 OR \#12 OR \#13 OR \#14 OR \#15 OR \#16 OR \#17)

\#19 MeSH descriptor Social Control, Formal explode all trees in MeSH products

\#20 social control OR enforc* OR deter OR deters OR deterr* OR police* OR officer* in All Fields, from 1800 to 2004 in all products \#21 law OR laws OR government OR legal OR legislation OR jurisprudence OR justice OR coerc* in All Fields, from 1800 to 2004 in all products

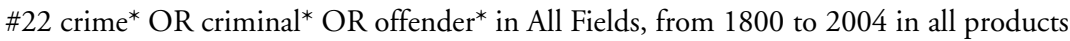

\#23 patrol* OR checkpoint* OR blitz* in All Fields, from 1800 to 2004 in all products

\#24 MeSH descriptor Breath Tests explode all trees in MeSH products

\#25 (breath NEXT test*) OR (breath NEXT analy*) OR breathaly* in All Fields in all products

\#26 MeSH descriptor Mass Media explode all trees in MeSH products

\#27 (mass NEXT medi*) OR (mass NEXT communication) OR ("media advocacy”) OR (public NEXT polic*) OR campaign* OR (communit* NEAR/2 program*) in All Fields, from 1800 to 2004 in all products

$\# 28$ adverti* in All Fields, from 1800 to 2004 in all products

\#29 (\#19 OR \#20 OR \#21 OR \#22 OR \#23 OR \#24 OR \#25 OR \#26 OR \#27 OR \#28)

\#30 (\#7 AND \#18 AND \#29)

\#31 driv* NEAR/3 influence in All Fields and \#30 in All Fields, from 1800 to 2004 in all products

\#32 dui in All Fields in all products

\#33 dwi NOT ((diffusion NEAR/5 weighted) OR (diffusion NEAR/5 magnetic) OR (diffusion NEAR/5 nmr) OR (diffusion NEAR/ 5 mri)) in All Fields, from 1800 to 2004 in all products

\#34 (\#30 OR \#31 OR \#32 OR \#33)

\section{Medline (to May, week 4 2006)}

1. exp Automobile Driving/

2. driv\$.mp.

3.vehicles.mp. or exp MOTOR VEHICLES/

4. accident\$.mp. or exp ACCIDENTS/

5. $\operatorname{crash} \$ . \mathrm{mp}$.

6. 1 or 2 or 3 or 4 or 5

7. exp Alcohol Drinking/

8. exp alcoholic intoxication/ or exp alcoholism/

9. (intoxication or alcoholism).mp.

10. impaired.mp.

11. exp ALCOHOLS/ or alcohol.mp.

12. ethanol.mp.

13. (BAC not (bacter\$ or gene or geno $\$$ or chromo $\$$ or amino or cyto $\$$ or virus or stroke or athero $\$$ or cardi $\$$ or viral or cell or coeff $\$$ or dentin or MAPK or RAS)).mp.

14.7 or 8 or 9 or 10 or 11 or 12 or 13

15. social control.mp. or exp Social Control, Formal/

16. (enforcement or law or police).mp.

17. (patrol\$ or checkpoint $\$$ or blitz\$).mp.

18. breath test $\$$.mp. or exp Breath Tests/

19. mass media.mp. or exp Mass Media/

20. campaign $\$ . m p$.

21. (community adj2 program).mp.

22. 15 or 16 or 17 or 18 or 19 or 20 or 21

23. 6 and 14 and 22

24. dr?nk driv\$.mp.

25. 22 and 24

26. dui.mp.

Increased police patrols for preventing alcohol-impaired driving (Review)

Copyright @ 2008 The Cochrane Collaboration. Published by John Wiley \& Sons, Ltd. 
27. (DWI not ((diffusion adj5 weighted) or (diffusion adj5 magnetic) or (diffusion adj5 nmr) or (diffusion adj5 MRI))).mp.

28. 23 or 25 or 26 or 27

29. Animals/

30. Human/

31. 29 not (29 and 30)

32. 28 not 31

TRANSPORT (to May 2006)

$\# 1$ dui

\#2 dwi

\#3 madd

\#4 dui or dwi or madd

\#5 drinking

\#6 drunk

\#7 intoxicated

\#8 bars

\#9 breathalyzer

\#10 drinking or drunk or intoxicated or bars or breathalyzer

\#11 alcohol

\#12 bac

$\# 13$ (alcohol or bac) in TI

\#14 \#10 or \#13

\#15 driving

\#16 drivers

$\# 17$ crashes

\#18 driver

$\# 19$ accidents

\#20 traffic

\#21 vehicle

\#22 crash

\#23 driving or drivers or crashes or driver or accidents or traffic or vehicle or crash

\#24 recidivism

\#25 license

\#26 offenders

\#27 enforcement

\#28 project

\#29 deterrent

\#30 revocation

\#31 suspended

\#32 suspension

\#33 advocacy

\#34 deterrence

\#35 arrest

\#36 convicted

\#37 violations

\#38 panels

\#39 sanction

\#40 merchants

\#41 cmca

\#42 impounding

\#43 recidivate

\#44 recidivism or license or offenders or enforcement or project or deterrent or revocation or suspended or suspension or advocacy or deterrence or arrest or convicted or violations or panels or sanction or merchants or cmca or impounding or recidivate \#45 judicial

Increased police patrols for preventing alcohol-impaired driving (Review)

Copyright $\odot 2008$ The Cochrane Collaboration. Published by John Wiley \& Sons, Ltd. 
\#46 impoundment

\#47 unlicensed

\#48 deterring

\#49 checkpoints

\#50 comply

\#51 mobilizing

\#52 borders

\#53 minors

\#54 holders

\#55 servers

\#56 adjudicated

\#57 penalties

\#58 licenses

\#59 jail

\#60 probation

\#61 judicial or impoundment or unlicensed or deterring or checkpoints or comply or mobilizing or borders or minors or holders or servers or adjudicated or penalties or licenses or jail or probation

\#62 \#44 or \#61

\#63 community

\#64 prevention

\#65 program

\#66 communities

\#67 minimum

\#68 legislation

\#69 raising

\#70 graduated

\#71 (community or prevention or program or communities or minimum or legislation or raising or graduated) in TI

$\# 72 \# 62$ or \#71

\#73 \#14 and \#23

\#74 \#14 and \#72

$\# 75 \# 23$ and \#72

$\# 76$ \#4 or \#73 or \#74 or \#75

\#77 animal $^{*}$

$\# 78$ (animal $^{*}$ ) in DE

\#79 human*

$\# 80$ (human*) in DE

\#81 \#78 and \#80

\#82 \#78 not \#81

\#83 \#76 not \#82

\section{C2SPECTR (searched latest version “2-17-2005” in May 2006)}

( $\{$ road $\}$ or $\{$ traffic $\}$ or $\{$ driv $\}$ or $\{$ vehicles $\}$ or $\{$ car $\}$ or $\{$ automobil $\}$ or $\{$ motorcycl $\}$ or $\{$ accident $\}$ or $\{$ crash $\}$

AND $\{$ drink $\}$ or $\{$ drunk $\}$ or $\{$ intoxicat $\}$ or $\{$ alcoholi $\}$ or $\{$ impaired $\}$ or $\{$ alcohol $\}$ or $\{$ ethanol $\}$ or $\{$ BAC $\}$ or $\{$ blood alcohol $\}$ or $\{$ alcohol blood $\}$

AND $\{$ social control\} or $\{$ enforc $\}$ or $\{$ deter $\}$ or $\{$ law $\}$ or \{government $\}$ or $\{$ legal $\}$ or $\{$ legislation $\}$ or $\{$ jurisprudence $\}$ or $\{$ justice $\}$ or $\{$ coerc $\}$ or $\{$ police $\}$ or $\{$ officer $\}$ or $\{$ patrol $\}$ or $\{$ checkpoint $\}$ or $\{$ blitz $\}$ or $\{$ crime $\}$ or $\{$ criminal $\}$ or $\{$ offender $\}$ or $\{$ breath test $\}$ or $\{$ breath analy $\}$ or \{breathaly\} or \{mass medi\} or \{mass communication\} or \{media advocacy\} or \{public polic or $\{$ campaign $\}$ or $\{$ adverti\} or $\{$ communit program $\})$

OR (\{Driving under the influence $\}$ OR $\{$ DUI $\}$ OR $\{$ DWI $\})$

NCJRS (to May 2006)

1. DUI

2. DWI

3. (driving influence within 3)

Increased police patrols for preventing alcohol-impaired driving (Review) 
4. ((drink* or drunk* $^{*}$ or intoxicat* ${ }^{*}$ or alcoholi* or impaired or alcohol or ethanol or BAC) AND (road* or traffic* or driv* or vehicles or accident* or crash* or car or cars or motorcycl* or automobil*) AND ("social control” or enforc* or deter OR deters OR deterr* or law or laws or government or legal or legislation or jurisprudence or justice or coerc* or police* or officer* or patrol* or checkpoint* or blitz* or crime* or criminal* or offender* or "breath test*" or "breath analy*" or breathaly* or "mass medi*" or "mass communication" or "media advocacy" or "public polic*" or campaign* or adverti* or "Communit* Program*”))

1 or 2 or 3 or 4

PsycINFO (Week 4, May 2006)

1. (exp motor traffic accidents/ or exp driving behavior/)

2. exp drivers/

3. driv\$.mp.

4. (exp motor vehicles/ or vehicles.mp.)

5. (accident\$.mp. or exp accidents/)

6. crash\$.mp.

7. exp highway safety/

8. exp accident prevention/

9. or/1-8

10. exp alcohol drinking patterns/

11. (exp alcoholic intoxication/ or exp alcoholism/)

12. (intoxication or alcoholism).mp.

13. exp sobriety/

14. impaired.mp.

15. (alcohol.mp. or exp alcohols/)

16. ethanol.mp.

17. exp blood alcohol concentration/

18. (blood adj1 alcohol).mp.

19. (bac not (bacter\$ or gene or geno\$ or chromo $\$$ or amino or cyto $\$$ or virus or stroke or athero $\$$ or cardi $\$$ or viral or cell or coeff $\$$ or dentin or mapk or ras)).mp.

20. or/10-19

21. (social control.mp. or exp social control/)

22. exp social influences/

23. exp law enforcement/

24. exp law enforcement personnel/

25. exp laws/

26. (enforcement or law or police).mp.

27. (patrol\$ or checkpoint $\$$ or blitz $\$$ ).mp.

28. exp crime prevention/

29. exp criminal justice/

30. (breath test\$.mp. or exp breath tests/)

31. (mass media.mp. or exp mass media/)

32. campaign $\$ . m p$.

33. (community adj 2 program).mp.

34. or/21-33

35.9 and 20 and 34

36. exp driving under the influence/

37. dr?nk driv\$.mp.

38. 34 and (36 or 37$)$

39. dui.mp.

40. (dwi not ((diffusion adj5 weighted) or (diffusion adj5 magnetic) or (diffusion adj5 nmr) or (diffusion adj5 mri))).mp.

41.35 or 38 or 39 or 40

42. exp animals/ or animal.po.

43. exp human/ or (human or inpatient or patient).po.

44. exp human females/

45. exp human males/

Increased police patrols for preventing alcohol-impaired driving (Review)

Copyright (c) 2008 The Cochrane Collaboration. Published by John Wiley \& Sons, Ltd. 
46. 42 not (42 and ( 43 or 44 or 45$))$

47. 41 not 46

Social Science Citation Index, Science Citation Index Expanded (to May 2006)

1. TS=(road\$ OR traffic* OR driv* OR vehicles OR accident* OR crash* OR automobil ${ }^{*}$ OR car OR cars OR motorcycl*) AND TS= (dr\$nk* OR intoxicat* OR alcoholi* OR impaired OR alcohol OR ethanol OR (BAC not (bacter* OR gene OR geno* OR chromo* OR amino OR cyto* OR virus OR stroke OR athero* OR viral OR cardi* OR cell OR coeff* OR dentin OR MAPK OR RAS)) OR (blood SAME alcohol))

2. $\left(\mathrm{TS}=\left(\right.\right.$ communit $^{*}$ SAME program*) OR TS=(social control OR enforc* OR deterr* OR deter OR deters OR police* OR officer* OR law\$ OR government OR legal OR legislation OR jurisprudence OR justice OR coerc* OR crime* OR criminal* OR offender* OR patrol* OR checkpoint* OR blitz* OR breath test* OR breath analy* OR breathaly* OR mass medi* OR mass communication OR media advocacy OR public polic* OR campaign* OR adverti*)) AND TS=(road\$ OR traffic* OR driv* OR vehicles OR accident* OR crash* OR automobil* OR car OR cars OR motorcycl*)

3. \#1 AND \#2

4. TS=(driv* SAME influence) AND $\left(\mathrm{TS}=\left(\right.\right.$ communit $^{*}$ SAME program*) OR TS=(social control OR enforc* OR deterr* OR deter OR deters OR police* OR officer* OR law\$ OR government OR legal OR legislation OR jurisprudence OR justice OR coerc* OR crime* OR criminal* OR offender* OR patrol* OR checkpoint* OR blitz* OR breath test* OR breath analy* OR breathaly* OR mass medi* OR mass communication OR media advocacy OR public polic* OR campaign* OR adverti*))

5. $\mathrm{TS}=\mathrm{dui}$

6. TS=(dwi not ((diffusion SAME weighted) OR (diffusion SAME magnetic) OR (diffusion SAME nmr) OR (diffusion SAME mri))) 7. \#3 OR \#4 OR \#5 OR \#6

SIGLE (System for Information on Grey Literature in Europe) (to February 2006)

1. dui or dwi or madd

2. drinking or drunk or intoxicated or bars or breathalyzer

3. (alcohol or bac).ti

4. 2 or 3

5. driving or drivers or crashes or driver or accidents or traffic or vehicle or crash

6. recidivism or license or offenders or enforcement or project or deterrent or revocation or suspended or suspension or advocacy or deterrence or arrest or convicted or violations or panels or sanction or merchants or cmca or impounding or recidivate or judicial or impoundment or unlicensed or deterring or checkpoints or comply or mobilizing or borders or miners or holders or servers or adjudicated or penalties or licenses or jail or probation

7. (community or prevention or program or communities or minimum or legislation or raising or graduated).ti.

8. 6 or 7

9.4 and 5

10. 4 and 8

11. 5 and 8

12. 1 or 9 or 10 or 11

13. animals/

14. humans/

15. 13 and 14

16. 13 not 15

17. 12 not 16

Dissertation Abstracts (to May 2006)

1. drink? or drunk? or intoxicat? or alcoholi? or impaired or alcohol or ethanol or BAC

2. road? or traffic? or driv? or vehicles or accident? or crash? or car or cars or motorcycl? or automobil?

3. social control or enforc? or deter OR deters OR deterr? or law or laws or government or legal or legislation or jurisprudence or justice or coerc? or police? or officer?

4. patrol? or checkpoint? or blitz? or crime? or criminal? or offender? or breath test? or breath analy? or breathaly? or mass medi? or mass communication or media advocacy or public polic? or campaign? or adverti? or Communit? Program?

5. (Driv? W/3 influence) OR DUI OR DWI

6. \#3 or \#4

7. \#1 and \#2 and \#6

8. \#7 or \#5

National Technical Information Service Database (to December 2004)

Increased police patrols for preventing alcohol-impaired driving (Review)

Copyright @ 2008 The Cochrane Collaboration. Published by John Wiley \& Sons, Ltd. 
1. DR?NK* OR INTOXICAT* OR ALCOHOLI* OR IMPAIRED OR ALCOHOL OR ETHANOL

2. BAC NOT (BACTER* OR GENE OR GENO* OR CHROMO* OR AMINO OR CYTO* OR VIRUS OR STROKE OR

ATHERO* OR CARDI* OR VIRAL OR CELL OR “COEFF”* OR DENTIN OR MAPK OR RAS)

3. \#1 or \#2

4. ROAD? OR TRAFFIC* OR DRIV* OR VEHICLES OR ACCIDENT* OR CRASH* OR CAR OR CARS OR "MOTORCYCL”*

OR AUTOMOBIL*

5. "SOCIAL CONTROL” OR "ENFORC”* OR DETER OR DETERS OR DETERR* OR LAW? OR GOVERNMENT OR LEGAL OR LEGISLATION OR JURISPRUDENCE OR JUSTICE OR COERC* OR POLICE* OR OFFICER* OR PATROL* OR CHECKPOINT* OR BLITZ* OR CRIME* OR CRIMINAL* OR OFFENDER* OR BREATH TEST* OR BREATH ANALY* OR BREATHALY* OR “MASS MEDI*” O“MASS COMMUNICATION" OR “MEDIA ADVOCACY” OR "PUBLIC POLIC”* OR CAMPAIGN* OR ADVERTI* OR (COMMUNIT* NEAR2 PROGRAM*)

6. \#3 AND \#4 AND \#5

7. DRIV* NEAR3 "INFLUENCE"

8. \#5 AND \#7

9. DUI

10. DWI NOT ((DIFFUSION NEAR5 MAGNETIC) OR (DIFFUSION NEAR5 WEIGHTED) OR (DIFFUSION NEAR5 NMR) OR (DIFFUSION NEAR5 MRI))

11. \#6 OR \#8 OR \#9 OR \#10

\section{Appendix 3. Quality criteria for included studies}

\section{RCTs, CTs, CBAs}

The criteria were as follows:

1. Concealment of allocation (RCTs and CTs only)

Adequate:

- unit of allocation was by site and any random process was described explicitly, e.g. the use of random number tables or coin flips, OR,

- unit of allocation was by participant and the study used some form of centralized randomization scheme, an on-site computer system or sealed opaque envelopes.

Not adequate:

- authors assigned participants to groups by case record numbers, dates of birth, day of the week, alternation or any other such approach OR

- unit of allocation was by participant and authors report using any allocation process that is entirely transparent before assignment, such as open list of random numbers or assignments OR

- allocation was altered by investigators, police, government officials, or participants

2. Similarity of baseline outcomes

Adequate:

- outcomes were measured prior to intervention and no substantial differences were present across study groups.

Not adequate:

- baseline differences in outcome measures were present and likely to undermine post intervention differences

3. Similarity of other baseline characteristics (CBAs only)

Adequate:

- specific characteristics were shown in figures or tables to be similar OR

- specific characteristics were stated to be similar OR

- sites were reported to have been matched or selected based on similar characteristics.

Not adequate:

- characteristics were stated as different or shown in tables or figures to be different, or populations were evidently different (e.g., a city was compared to the rest of the state).

Increased police patrols for preventing alcohol-impaired driving (Review)

Copyright (c) 2008 The Cochrane Collaboration. Published by John Wiley \& Sons, Ltd. 
4. Protection against contamination

Adequate:

- allocation was by community and it is unlikely that the control received the intervention due to separation by geography, time, or other factor.

Not adequate:

- the control likely received the intervention (e.g., increased police patrols also operated in comparison area or comparison and intervention areas overlapped).

5. Follow-up of participants

Adequate:

- outcome measures were obtained for $80-100 \%$ of participants assigned to groups. This criterion was not applied to studies that assessed outcomes on population cross-sections.

\section{ITS}

The criteria used to assess ITS were as follows:

1. Protection against secular changes

Adequate:

- authors made compelling arguments that intervention occurred independently of other changes over time and outcome was not influenced by other confounding variables/historic events during study period.

2. Appropriate analysis of data

Adequate:

- ARIMA models were used OR

- time series regression models were used to analyze data and serial correlation was adjusted/tested for OR

- reanalysis (See Data Analyses) was performed.

3. Reasons for number of data points given

Adequate:

- data for 12 months (or more) pre- and post-intervention were used and data points were at least monthly OR

- reason for number and spacing of data points was given OR

- sample size calculation was performed.

4. Shape of the intervention effect pre-specified

Adequate:

- point of analysis or re-analysis was point of intervention $\mathrm{OR}$

- rational explanation for shape of intervention effect was given by author(s), including explanation if point of analysis was not point of intervention.

5. Intervention unlikely to affect data collection (protection against detection bias)

Adequate:

- authors report that intervention itself was unlikely to affect data collection (for example, sources and methods of data collection were the same before and after intervention).

6. Completeness of data set

Adequate:

- data set covered $80-100 \%$ of all study participants. This criterion was not applied to studies that assessed outcomes on population cross-sections.

\section{CITS}

Quality for CITS studies was assessed using all criteria for both ITS and CBA studies, with two exceptions:

1. Protection against secular changes

Not adequate:

- authors report that comparison group did not control for other changes over time.

Increased police patrols for preventing alcohol-impaired driving (Review)

Copyright $\Subset 2008$ The Cochrane Collaboration. Published by John Wiley \& Sons, Ltd. 
Not applicable:

- all other CITS studies, because the presence of a comparison group generally addresses sources of invalidity (e.g., history effects) that single-group ITS designs fail to address.

2. Appropriate analysis of data

Adequate:

- autoregressive integrated moving average (ARIMA) models were used OR time series regression models were used to analyze data and serial correlation was adjusted/test

Not applicable:

- all other CITS studies (because they could also be analyzed like CBAs).

\section{All Designs}

For all types of designs, the following additional criteria were assessed:

1. Blinded assessment of primary outcome(s) (protection against detection bias)

Adequate:

- authors stated explicitly that primary outcome variables were assessed blindly OR

- outcome variables were objective, e.g. alcohol levels as assessed by blood test.

2. Reliable primary outcome measure(s)

Adequate:

- two or more raters with at least $90 \%$ agreement or kappa greater than or equal to $0.8 \mathrm{OR}$

- outcome was obtained from automated system, e.g. length of hospital stay from administrative records, alcohol levels as assessed by a blood test.

\section{WHAT'S NEW}

Last assessed as up-to-date: 31 May 2006.

Date Event Description

1 June 2008 Amended Converted to new review format.

\section{H IS T O R Y}

Protocol first published: Issue 2, 2005

Review first published: Issue 4, 2008 


\section{CONTRIBUTIONSOFAUTHORS}

Drs. Van Bramer, DiGuiseppi, Lowenstein, and Roberts, and Ms Goss participated in study conception and design. Drs. Van Bramer and DiGuiseppi and Ms Goss performed data collection. Drs. Porter and DiGuiseppi and Ms Goss extracted data and assessed study quality. Drs. Gliner, Porter and DiGuiseppi and Ms Goss performed data analysis and interpreted results. Ms. Goss drafted the manuscript and all review authors revised the manuscript critically for intellectual content and approved the final version.

\section{DECLARATIONSOF INTEREST}

None known.

\section{SOURCES OF SUPPORT}

\section{Internal sources}

- No sources of support supplied

\section{External sources}

- Centers for Disease Control and Prevention (CDC), US Department of Health and Human Services (DHHS), USA.

- Colorado Injury Control Research Center, Colorado State University, USA.

- Health Resources and Services Administration (HRSA), US Department of Health and Human Services (DHHS), USA.

\section{NOT E S}

This research was supported by Grant Number R49/CCR811509 from the Centers for Disease Control and Prevention (CDC), U.S. Department of Health and Human Services. Its contents are solely the responsibility of the authors and do not necessarily represent the official views of the CDC.

Eligible studies identified prior to 1 June 2006 are included in this review. Studies identified after 1 June 2006 are listed under Studies Awaiting Assessment.

\section{INDEX TERMS}

\section{Medical Subject Headings (MeSH)}

*Automobile Driving; *Police; Accident Prevention [methods]; Accidents, Traffic [mortality; * prevention \& control]; Alcohol Drinking [ ${ }^{*}$ adverse effects]; Controlled Clinical Trials as Topic; Law Enforcement; Randomized Controlled Trials as Topic

\section{MeSH check words}

Humans 